SUPPLEMENTARY INFORMATION

\title{
Extended Aromatic and Heteroaromatic Ring Systems in the Chalcone-Flavanone Molecular Switch Scaffold
}

Brian M. Muller, Theodore J. Litberg, Reid A. Yocum, Chanté A. Pniewski, and Marc J. Adler*

Department of Chemistry \& Biochemistry, Northern Illinois University, 1425 W Lincoln Hwy, DeKalb, IL, 60115, USA, mjadler@niu.edu

\section{TABLE OF CONTENTS}

1H NMR and 13C NMR Spectra for Compounds $\mathbf{1 b - 1 n , ~} \mathbf{2 b - 2 n}$...............................S2

Sigmoidal Curves Derived from UV/VIS Equilibration Assay ...............................S28 
${ }^{1} \mathrm{H}$ NMR Spectrum of (E)-1-(2-hydroxyphenyl)-3-(naphthalen-2-yl)prop-2-en-1-one (1b)
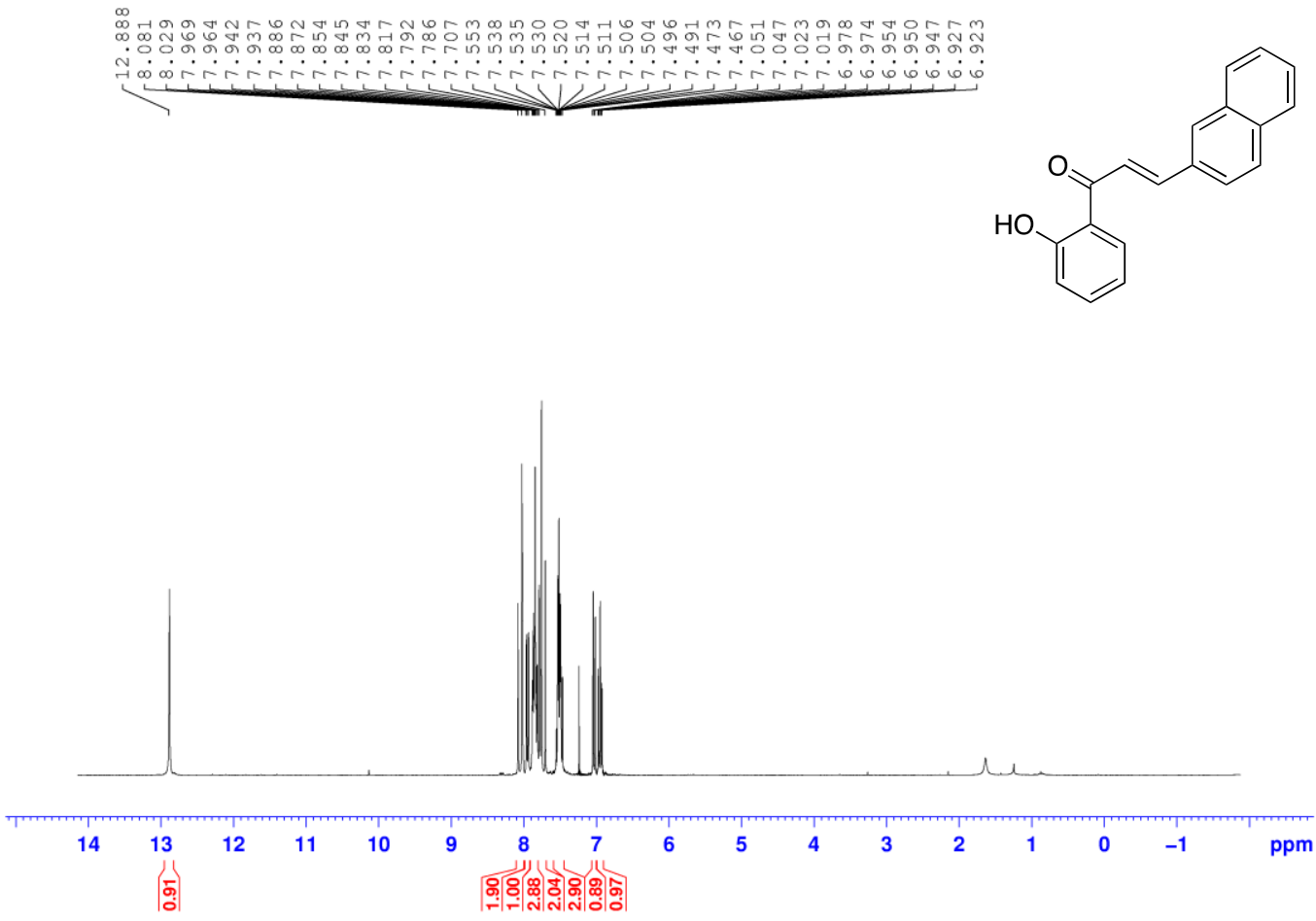

${ }^{13}$ C NMR Spectrum of (E)-1-(2-hydroxyphenyl)-3-(naphthalen-2-yl)prop-2-en-1-one (1b)

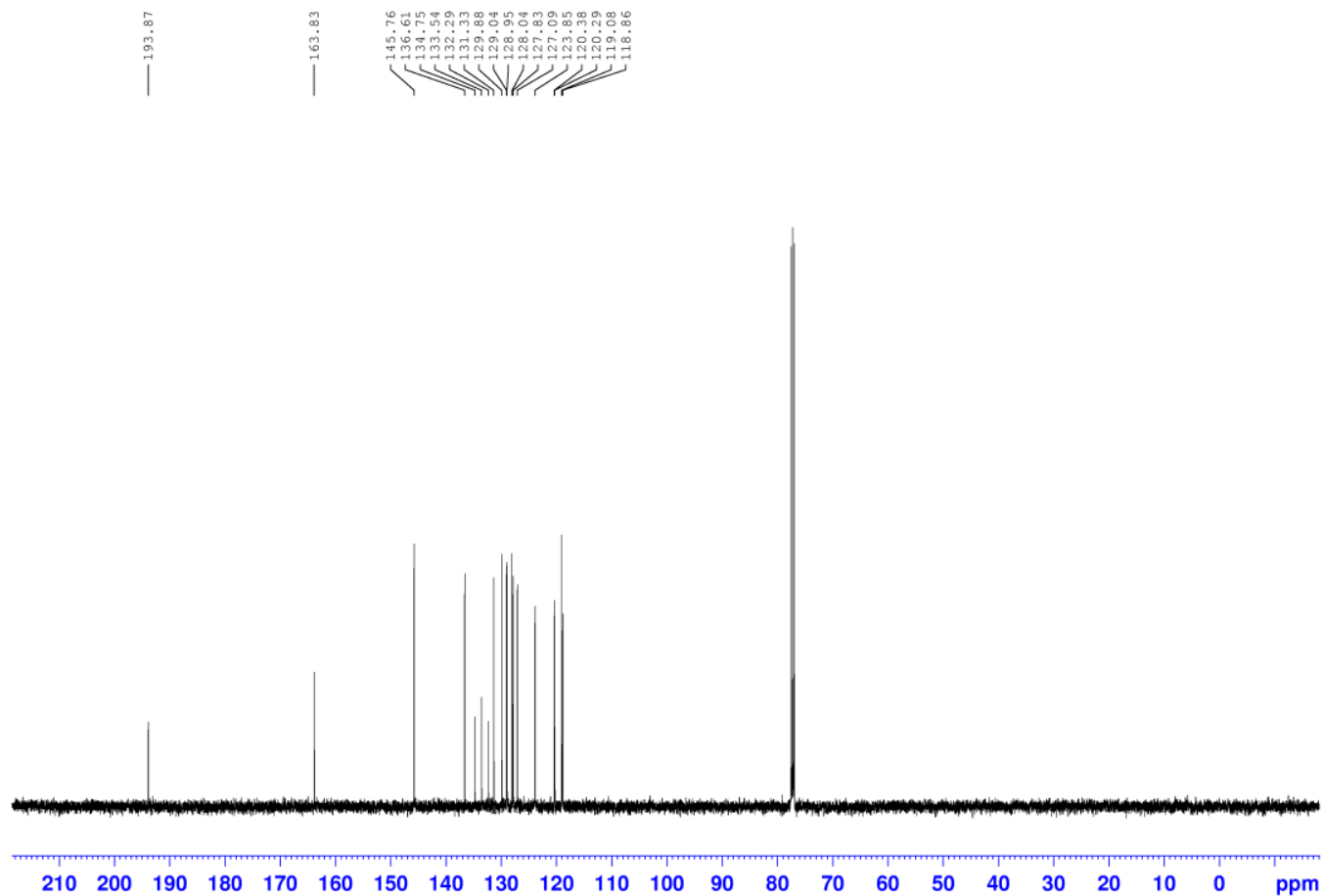


${ }^{1} \mathrm{H}$ NMR Spectrum of (E)-1-(2-hydroxyphenyl)-3-(naphthalen-1-yl)prop-2-en-1-one (1c)
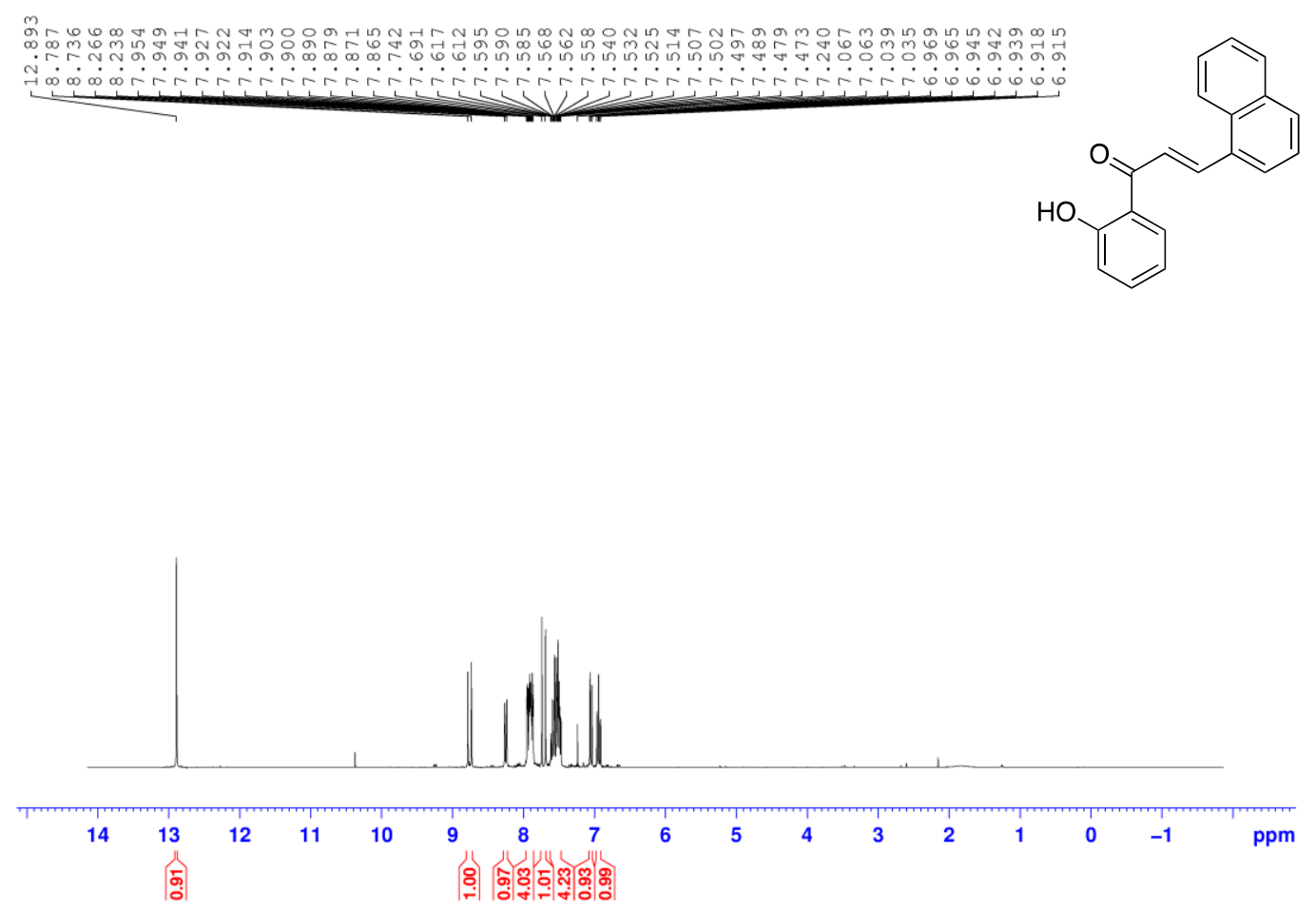

${ }^{13}$ C NMR Spectrum of (E)-1-(2-hydroxyphenyl)-3-(naphthalen-1-yl)prop-2-en-1-one (1c)

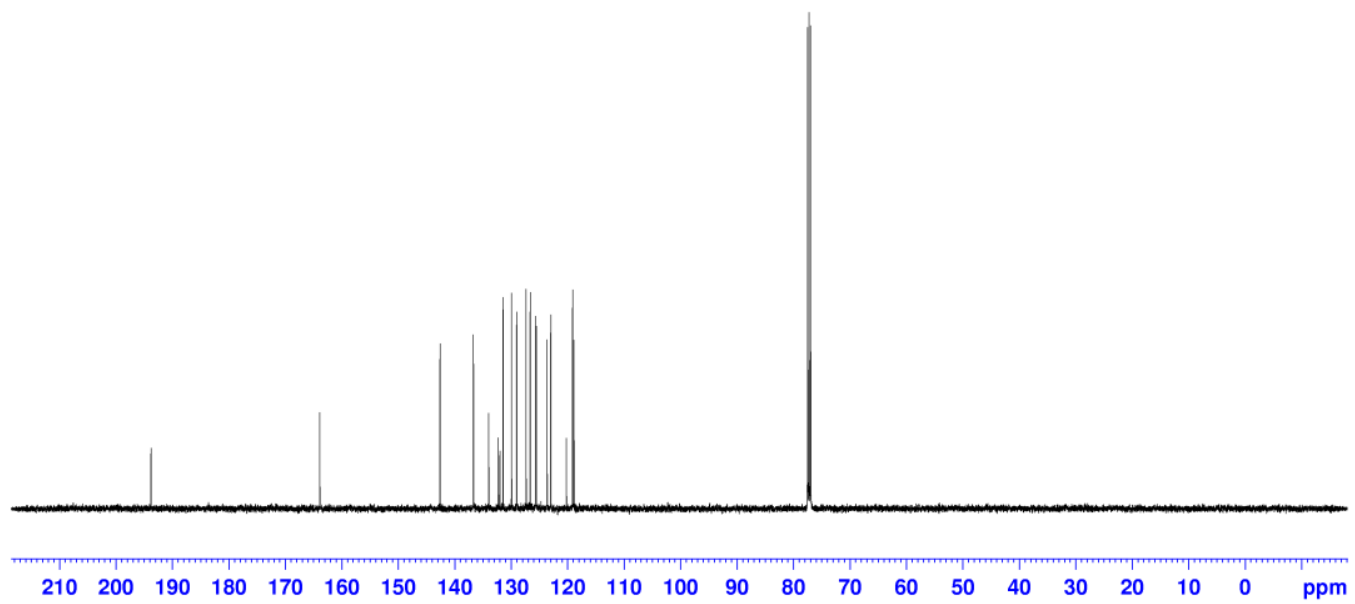


${ }^{1}$ H NMR Spectrum of (E)-3-([1,1'-biphenyl]-4-yl)-1-(2-hydroxyphenyl)prop-2-en-1-one (1d)

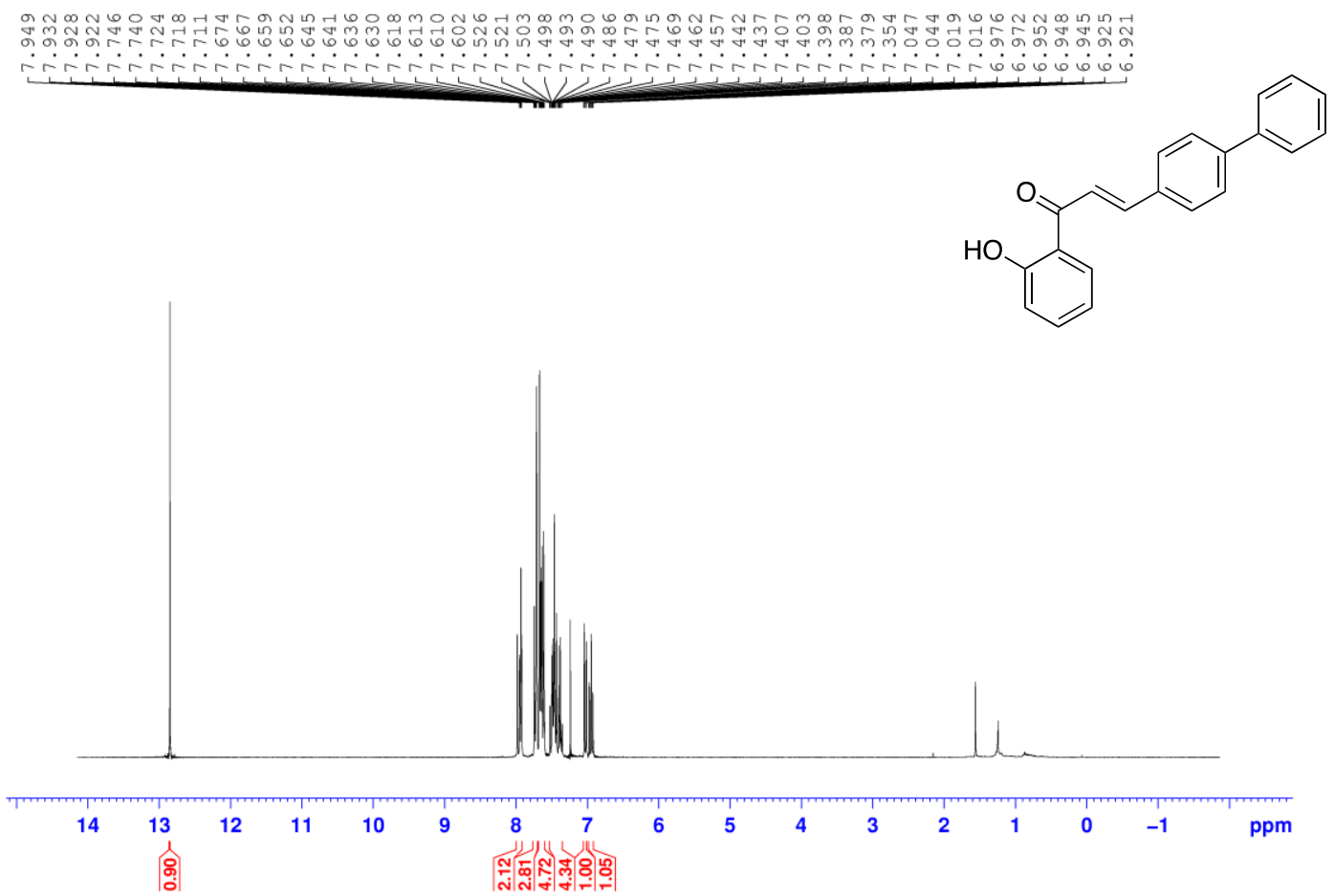

${ }^{13}$ C NMR Spectrum of (E)-3-([1,1'-biphenyl]-4-yl)-1-(2-hydroxyphenyl)prop-2-en-1-one (1d)

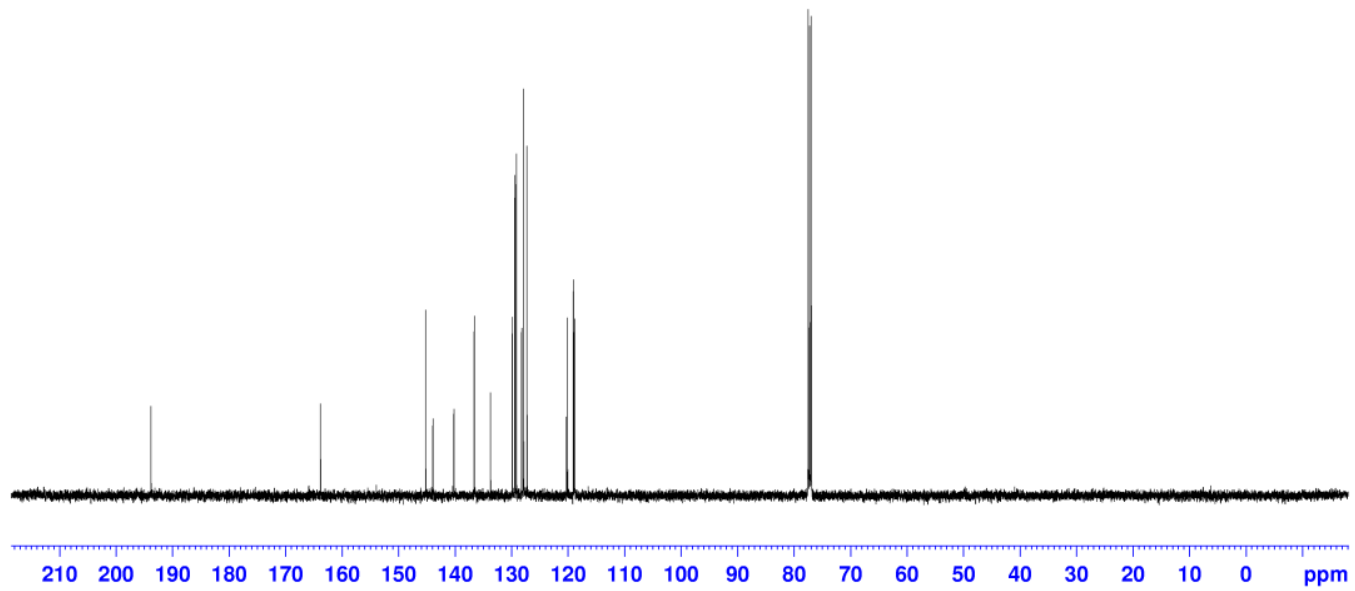


${ }^{1} \mathrm{H}$ NMR Spectrum of (E)-3-(furan-2-yl)-1-(2-hydroxyphenyl)prop-2-en-1-one (1e)
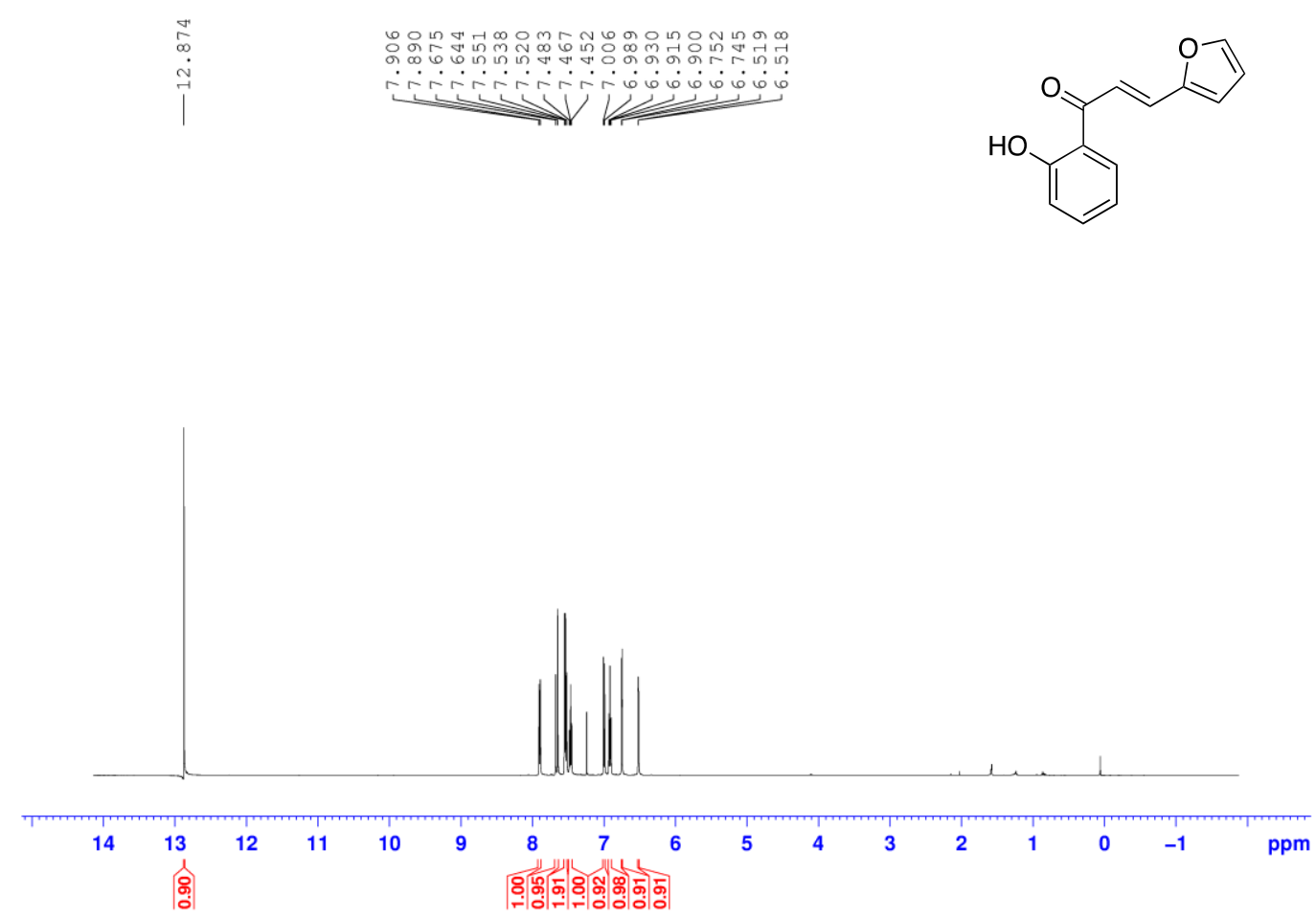

${ }^{13}$ C NMR Spectrum of (E)-3-(furan-2-yl)-1-(2-hydroxyphenyl)prop-2-en-1-one (1e)
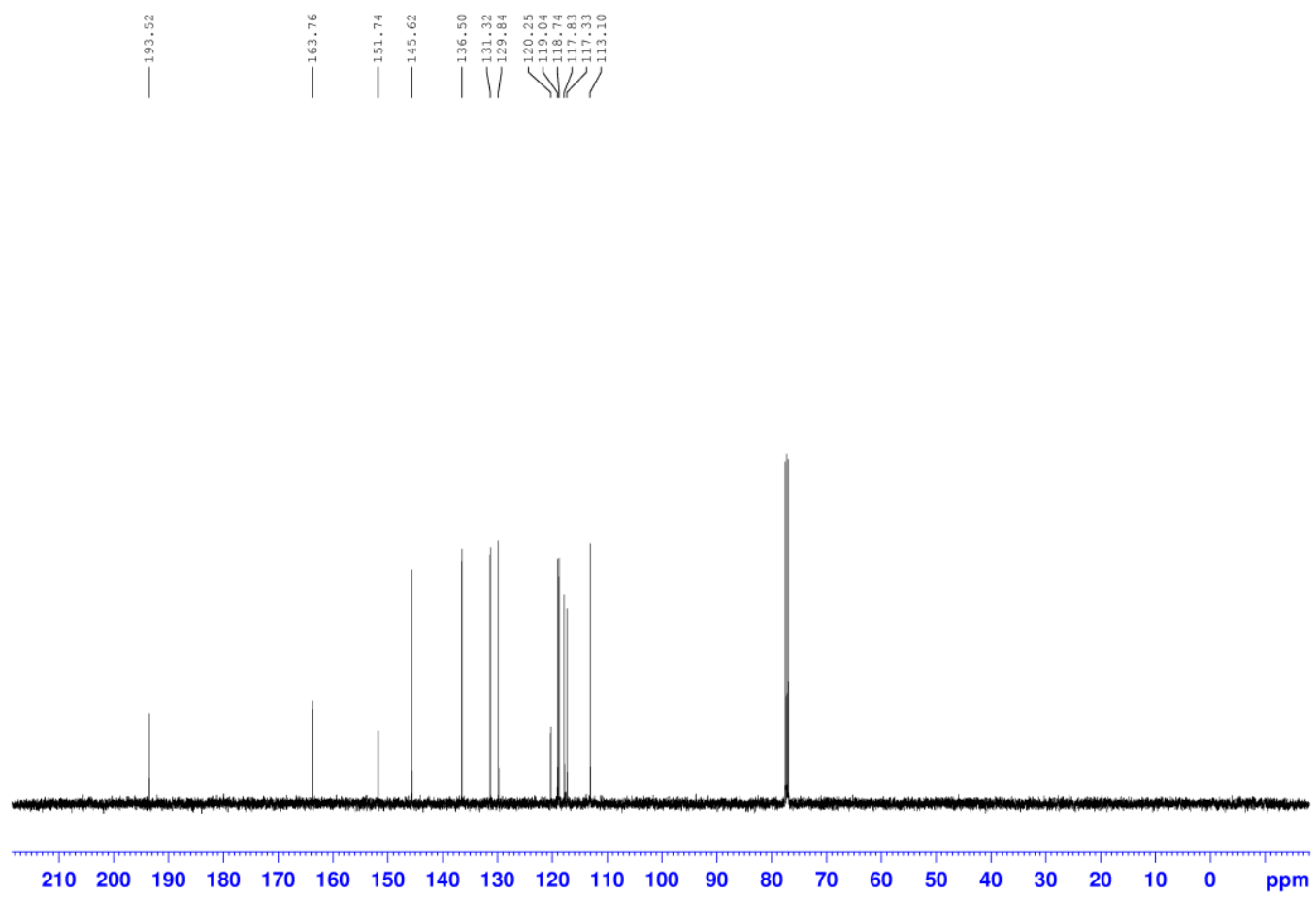
${ }^{1} \mathrm{H}$ NMR Spectrum of (E)-1-(2-hydroxyphenyl)-3-(thiophen-2-yl)prop-2-en-1-one (1f)
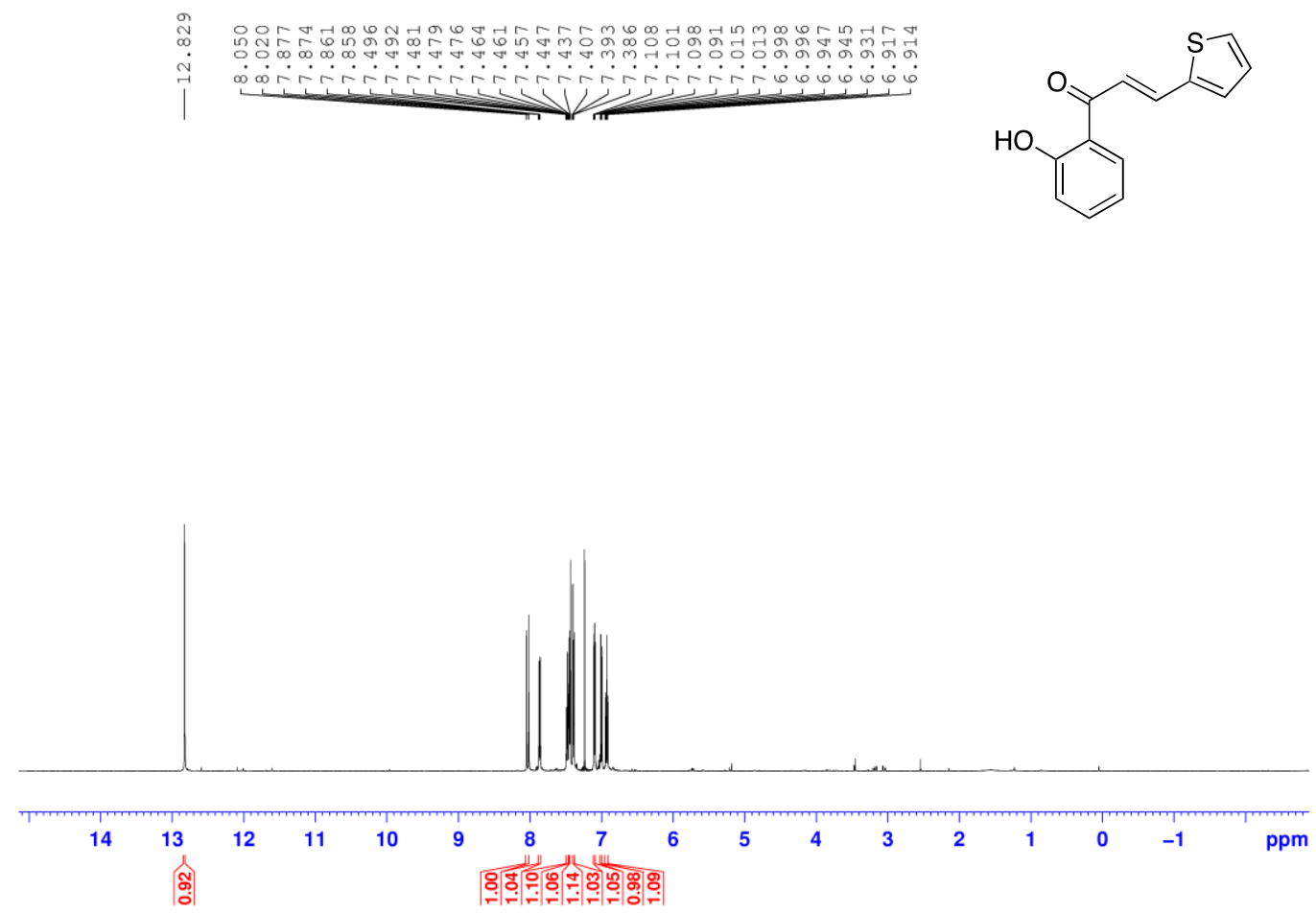

${ }^{13}$ C NMR Spectrum of (E)-1-(2-hydroxyphenyl)-3-(thiophen-2-yl)prop-2-en-1-one (1f)

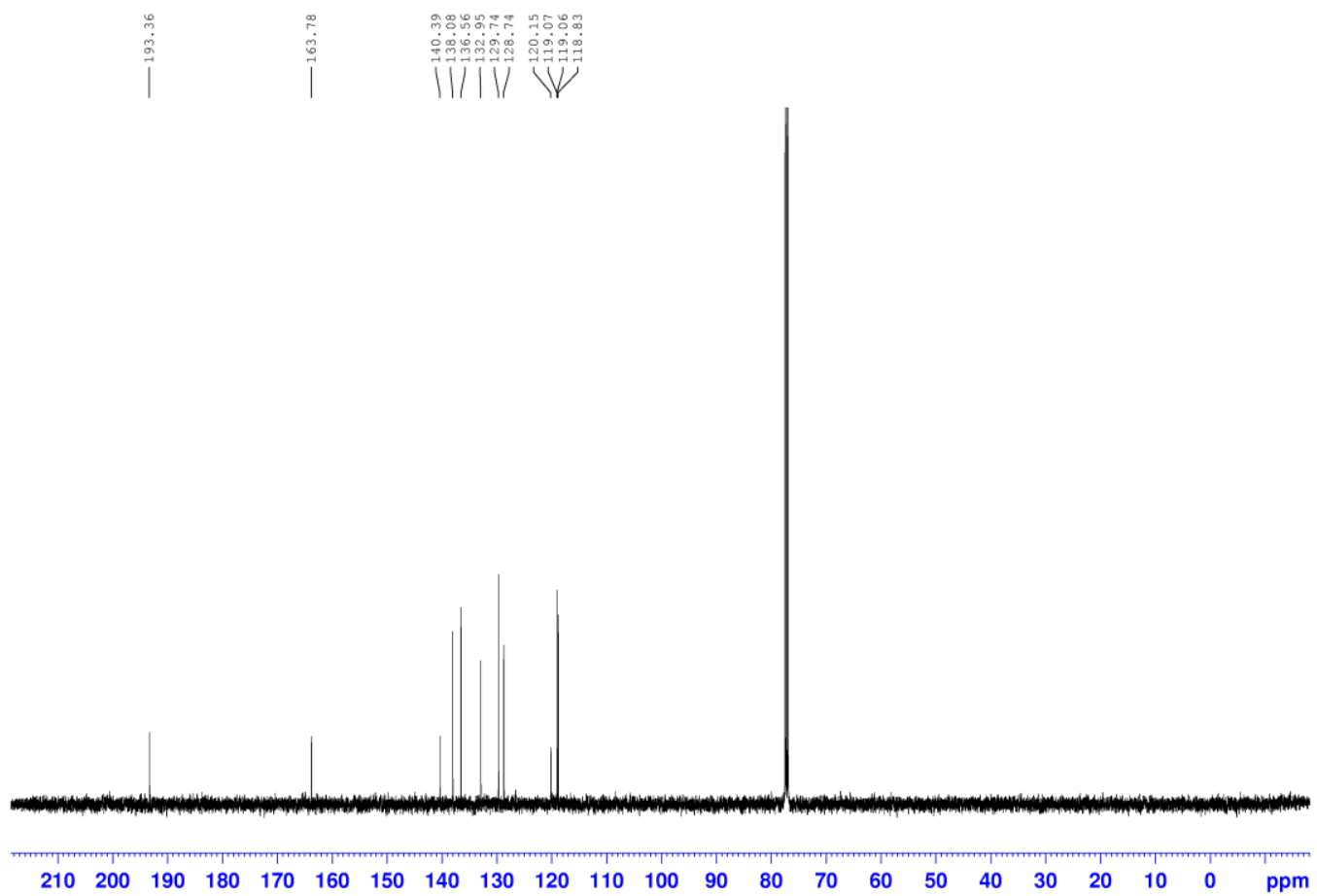


${ }^{1} \mathrm{H}$ NMR Spectrum of (E)-1-(2-hydroxyphenyl)-3-(thiophen-3-yl)prop-2-en-1-one (1g)
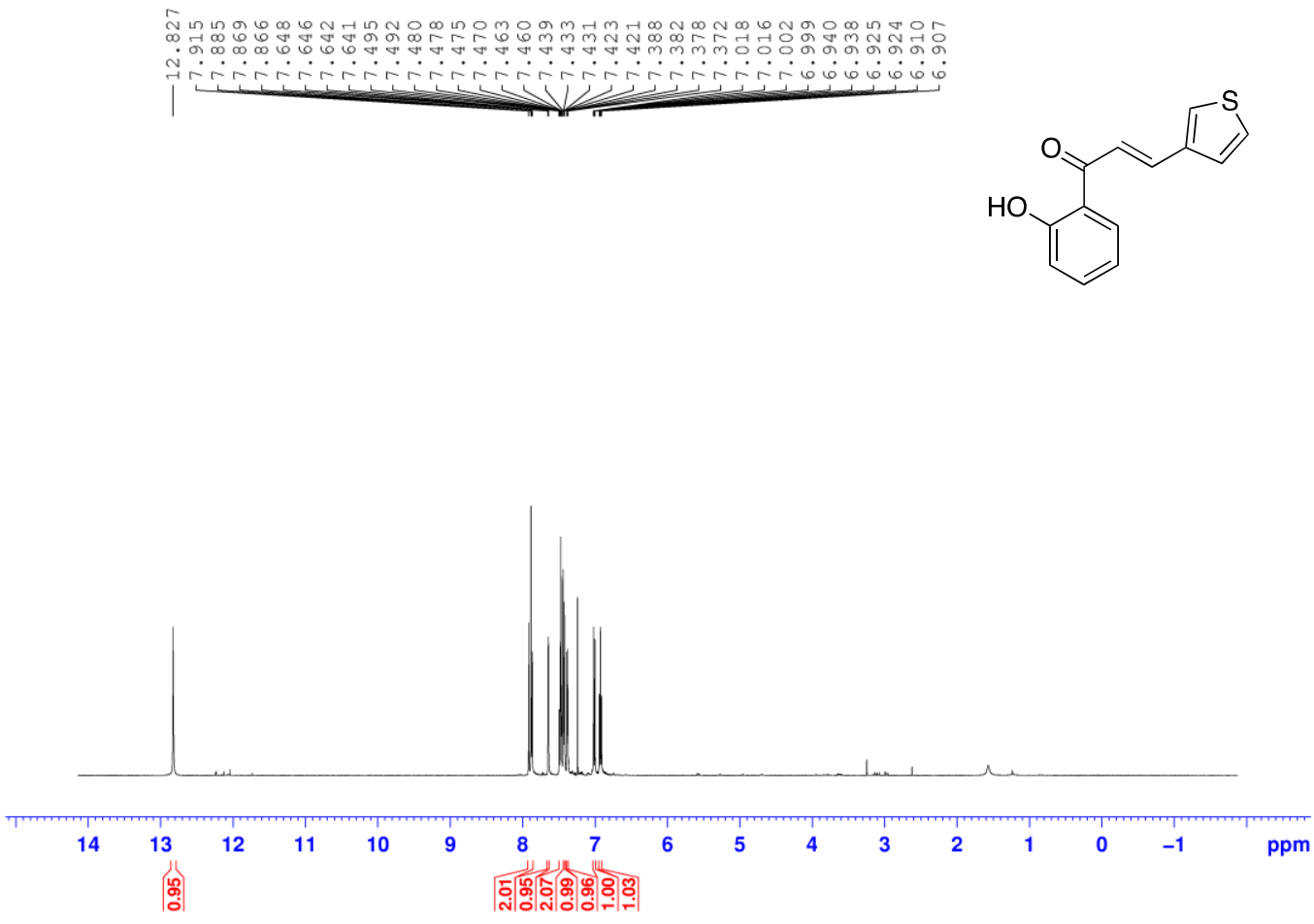

${ }^{13}$ C NMR Spectrum of (E)-1-(2-hydroxyphenyl)-3-(thiophen-3-yl)prop-2-en-1-one (1g)

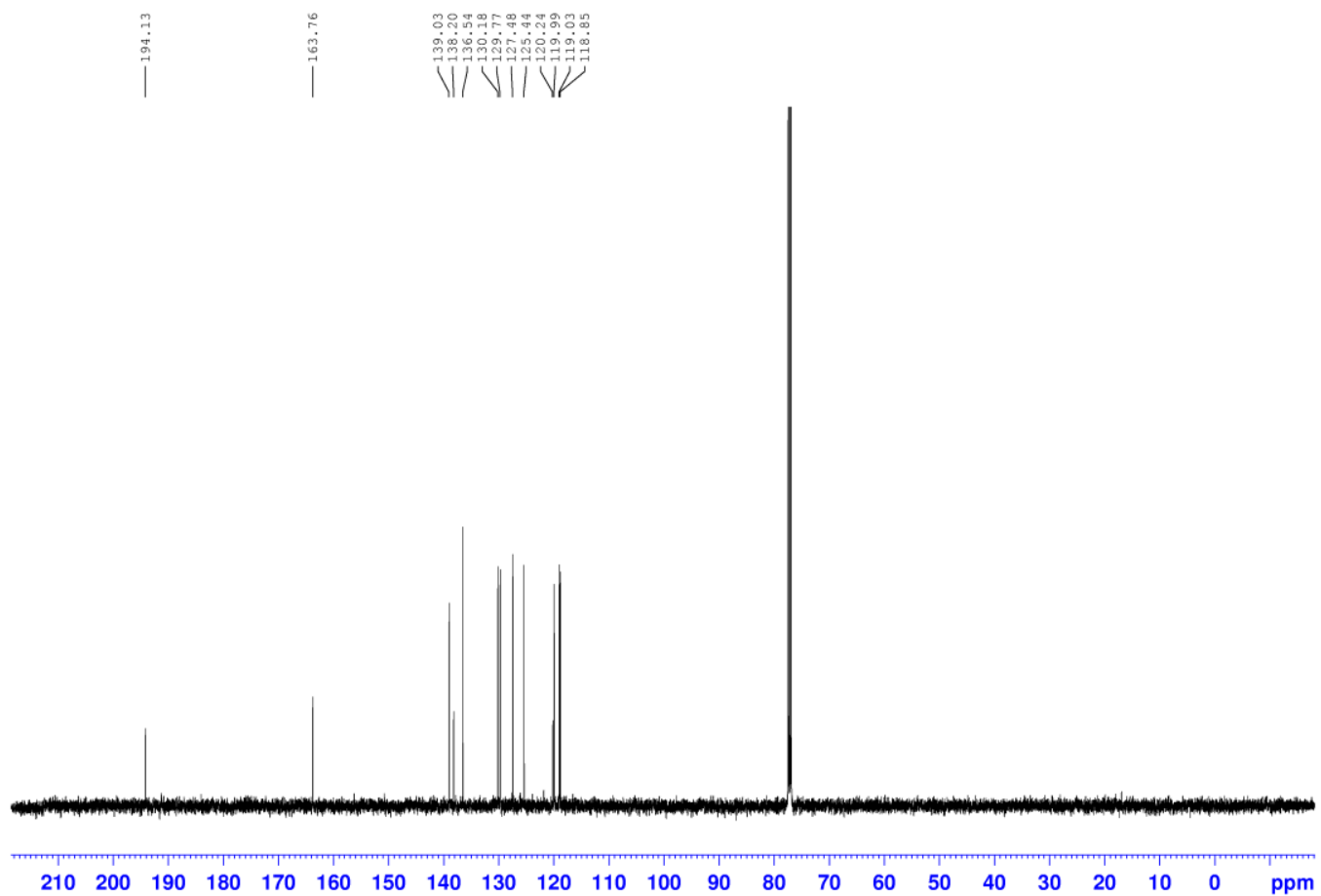


${ }^{1}$ H NMR Spectrum of (E)-1-(2-hydroxynaphthalen-1-yl)-3-phenylprop-2-en-1-one (1h)

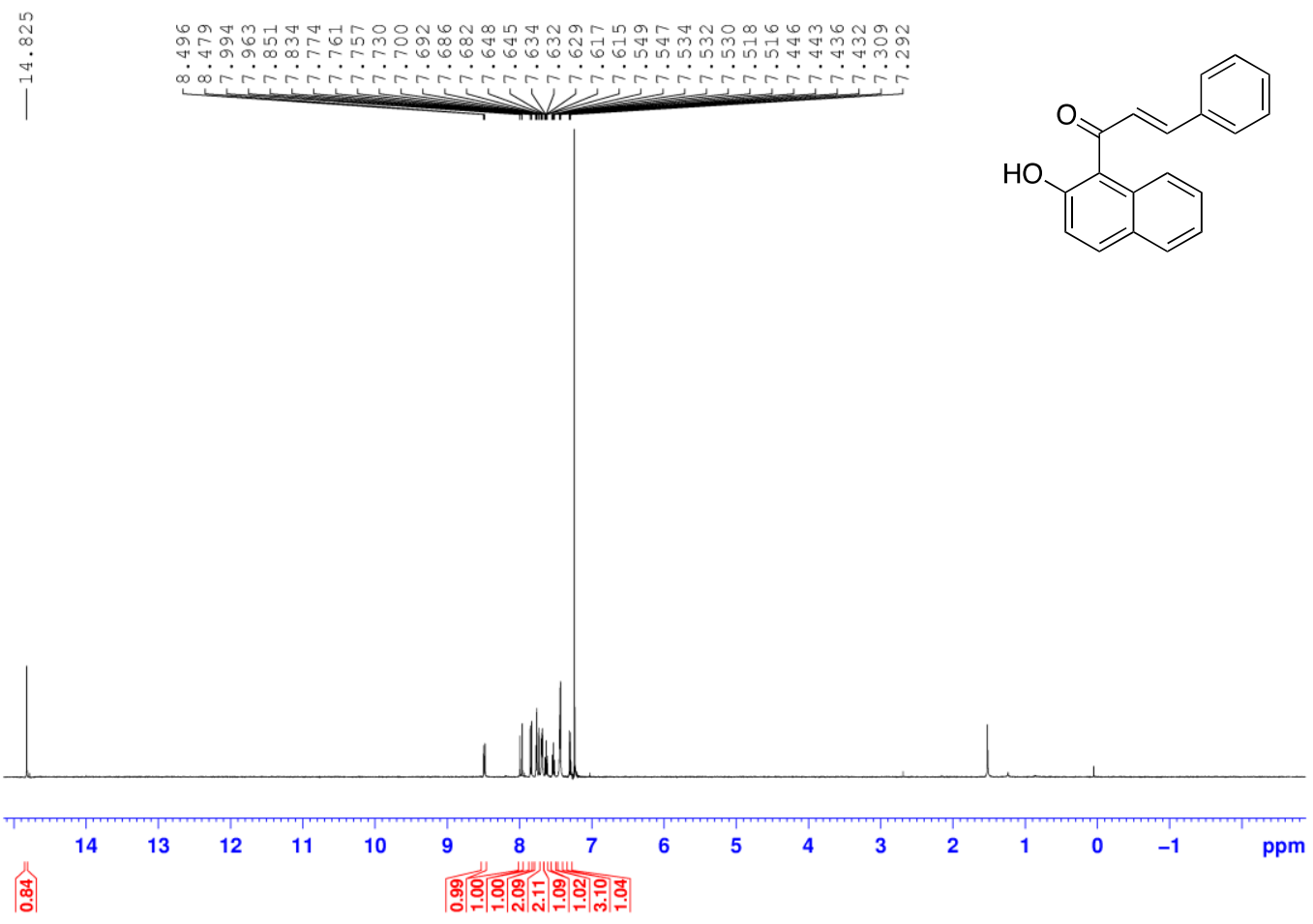

${ }^{13}$ C NMR Spectrum of (E)-1-(2-hydroxynaphthalen-1-yl)-3-phenylprop-2-en-1-one (1h)

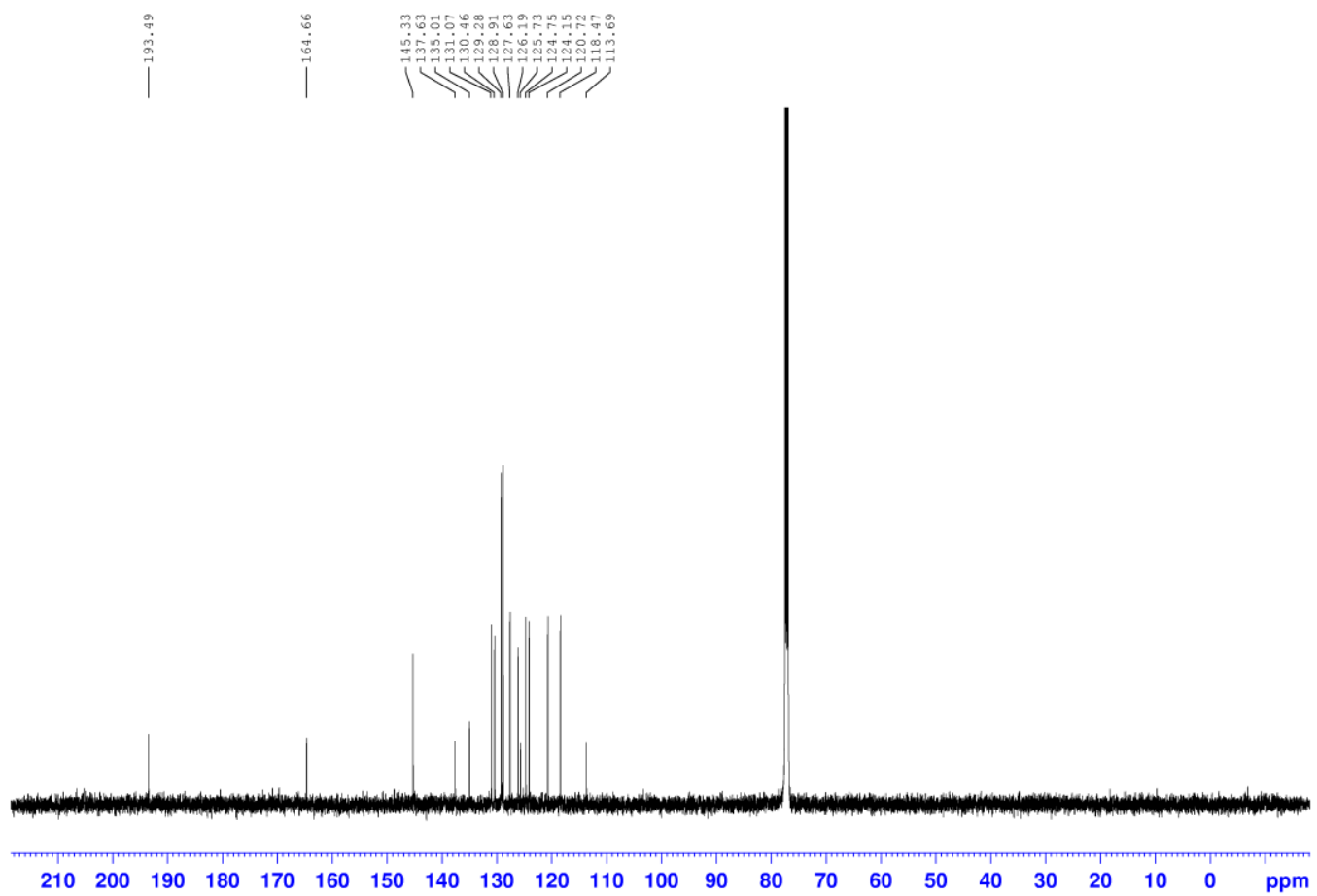




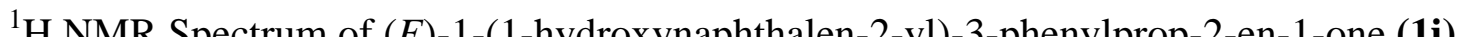

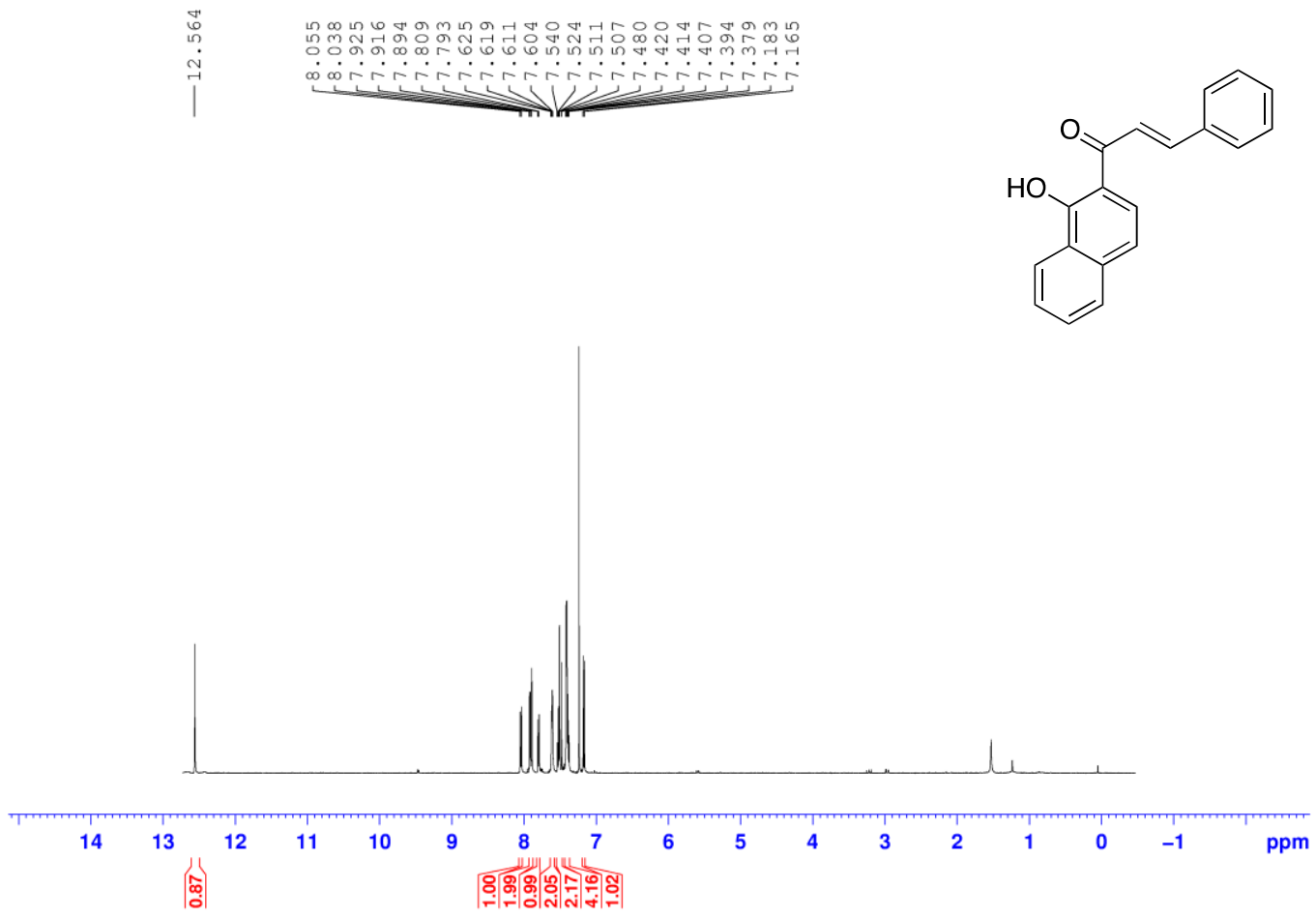

${ }^{13} \mathrm{C}$ NMR Spectrum of (E)-1-(1-hydroxynaphthalen-2-yl)-3-phenylprop-2-en-1-one (1i)

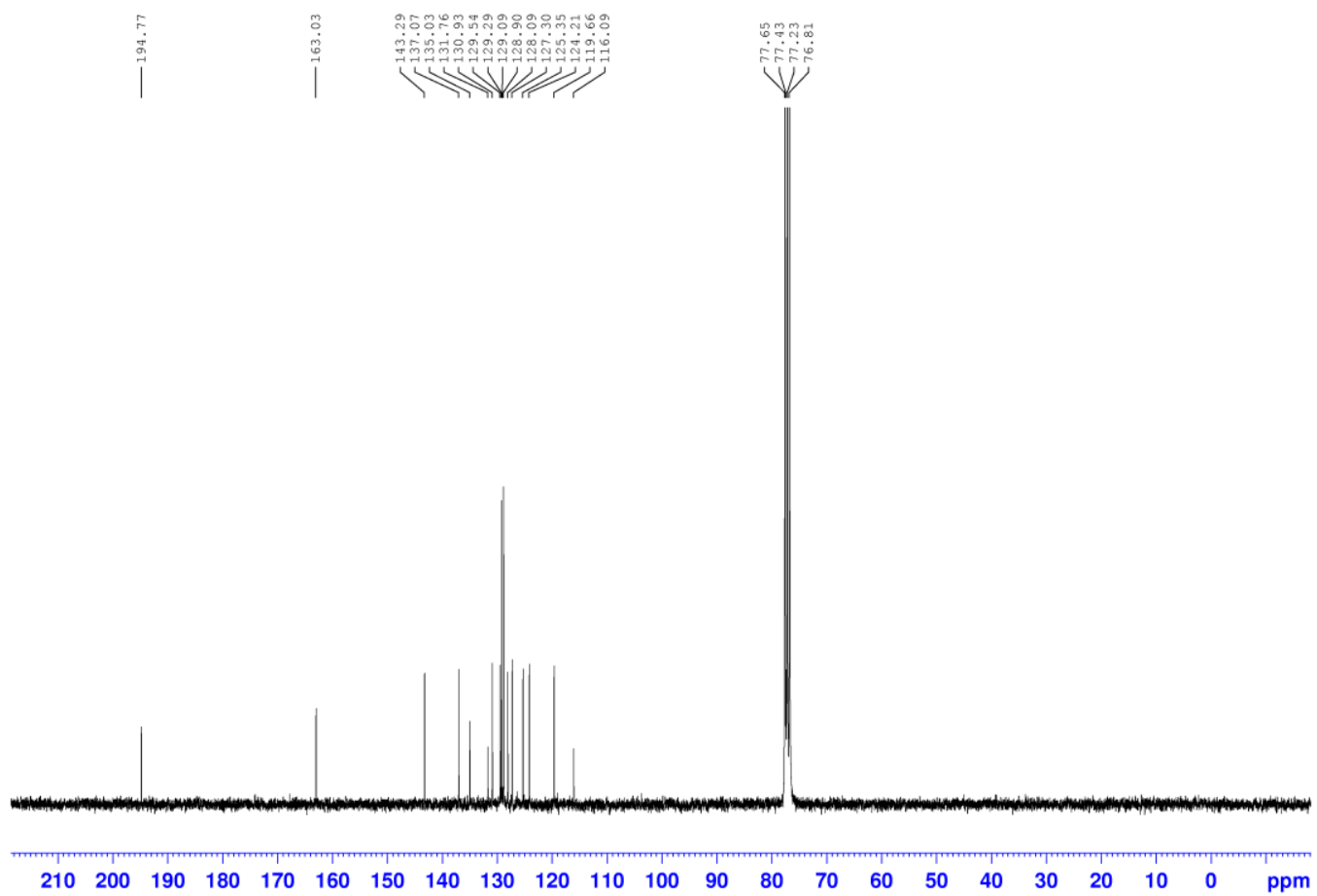


${ }^{1} \mathrm{H}$ NMR Spectrum of (E)-1-(4-fluoro-2-hydroxyphenyl)-3-(furan-2-yl)prop-2-en-1-one (1j)

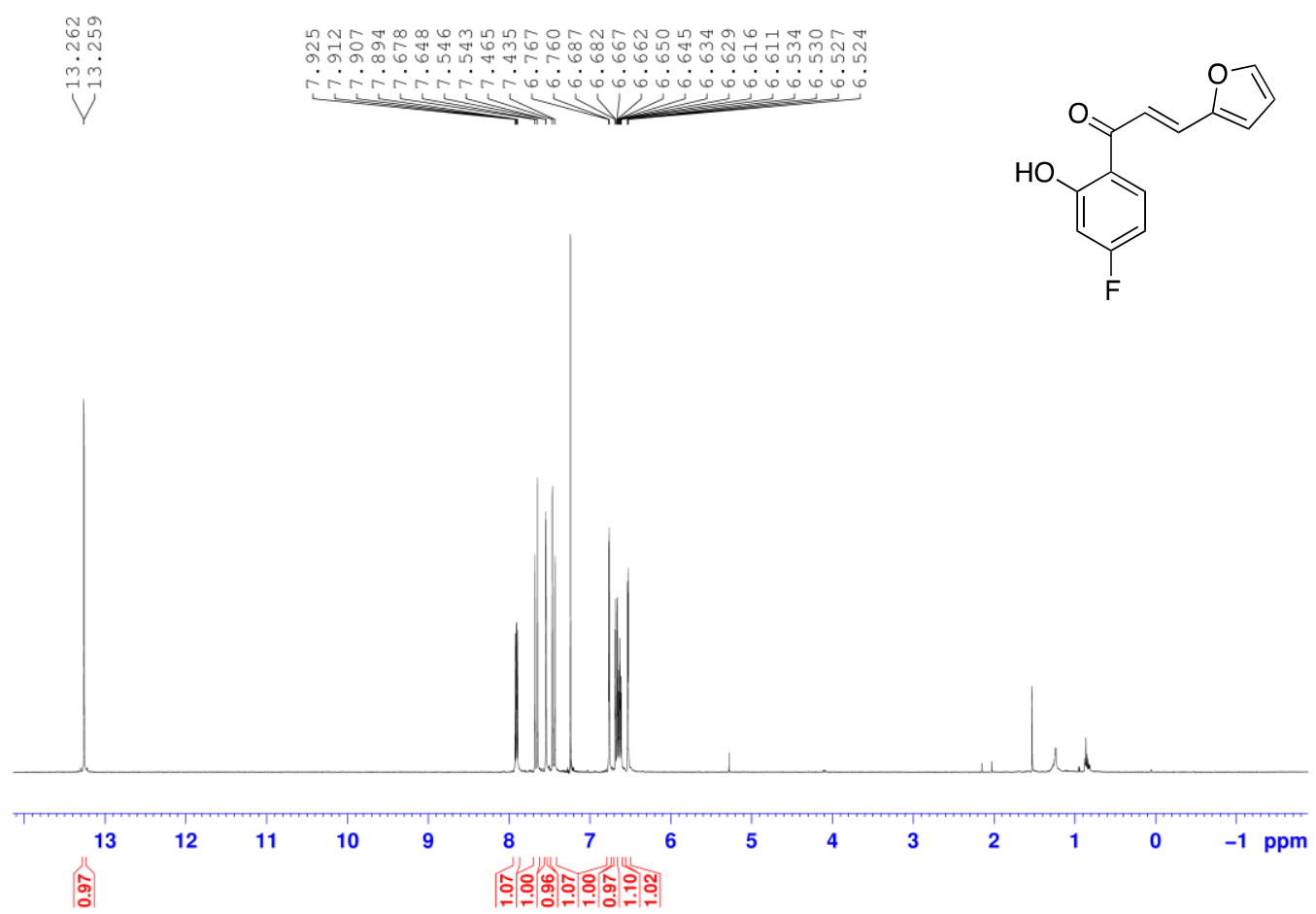

${ }^{13}$ C NMR Spectrum of (E)-1-(4-fluoro-2-hydroxyphenyl)-3-(furan-2-yl)prop-2-en-1-one (1j)

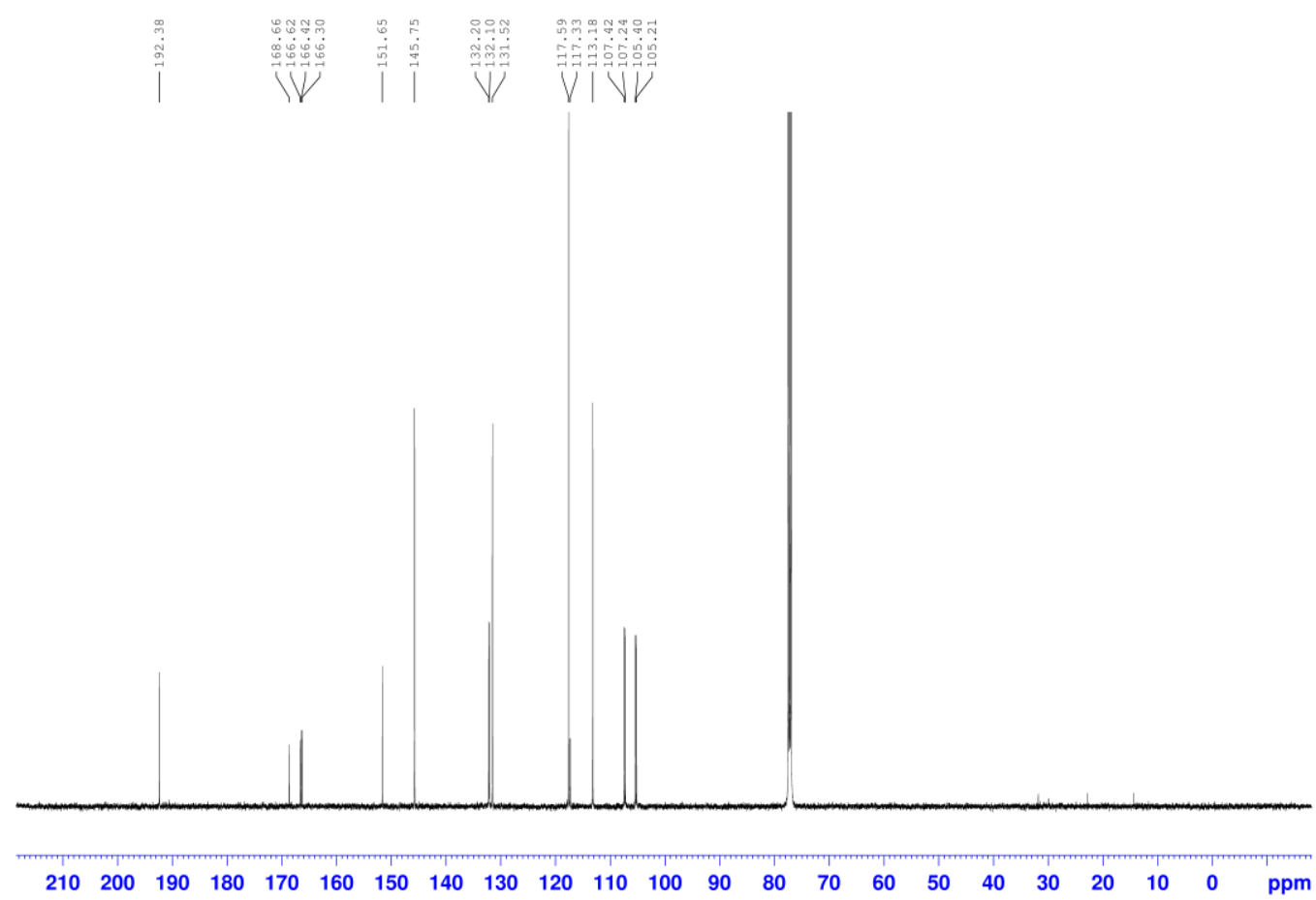


${ }^{1} \mathrm{H}$ NMR Spectrum of (E)-1-(2-hydroxy-4-methoxyphenyl)-3-(thiophen-2-yl)prop-2-en1-one (1k)

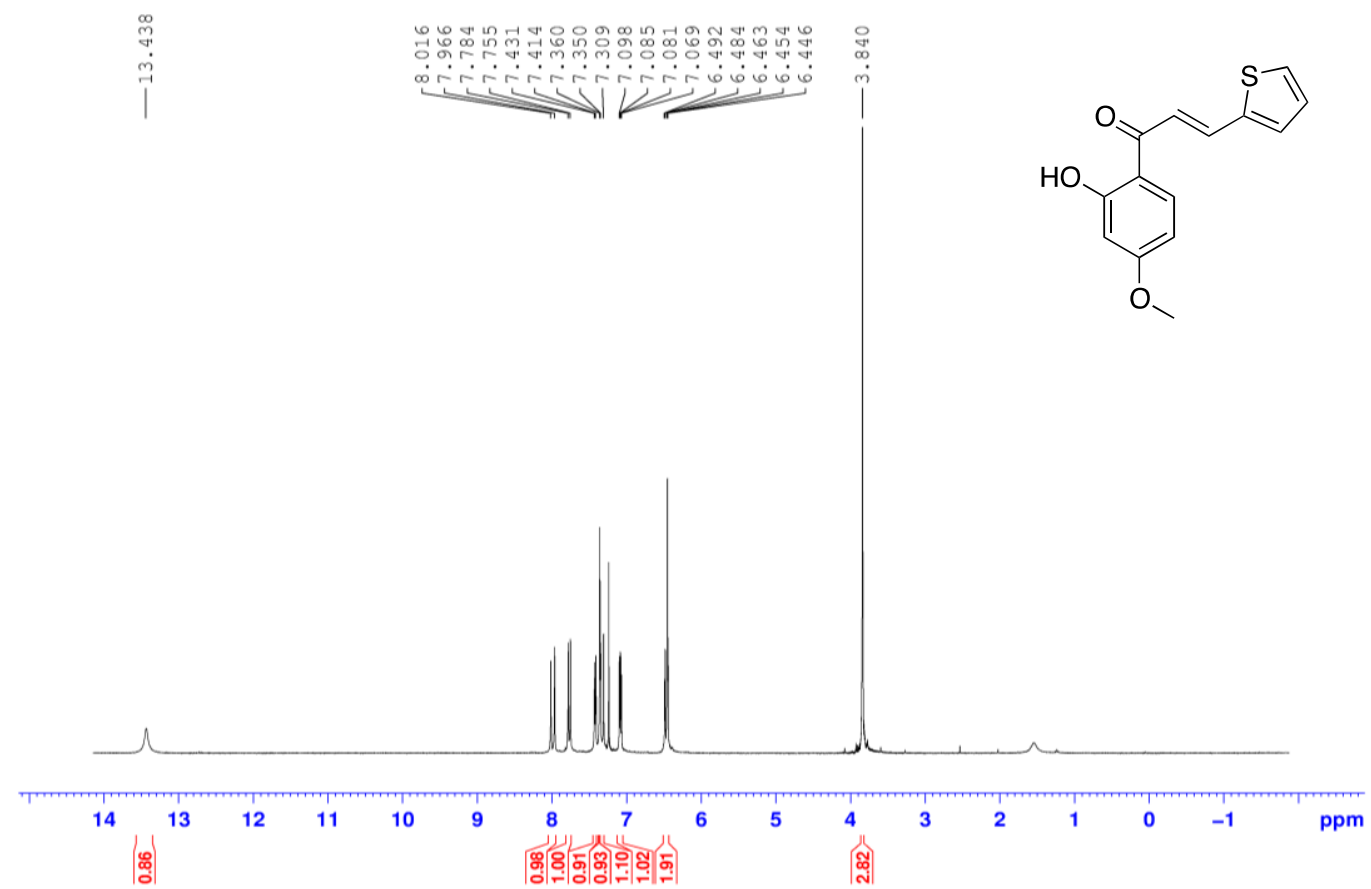

${ }^{13} \mathrm{C}$ NMR Spectrum of (E)-1-(2-hydroxy-4-methoxyphenyl)-3-(thiophen-2-yl)prop-2-en1-one (1k)

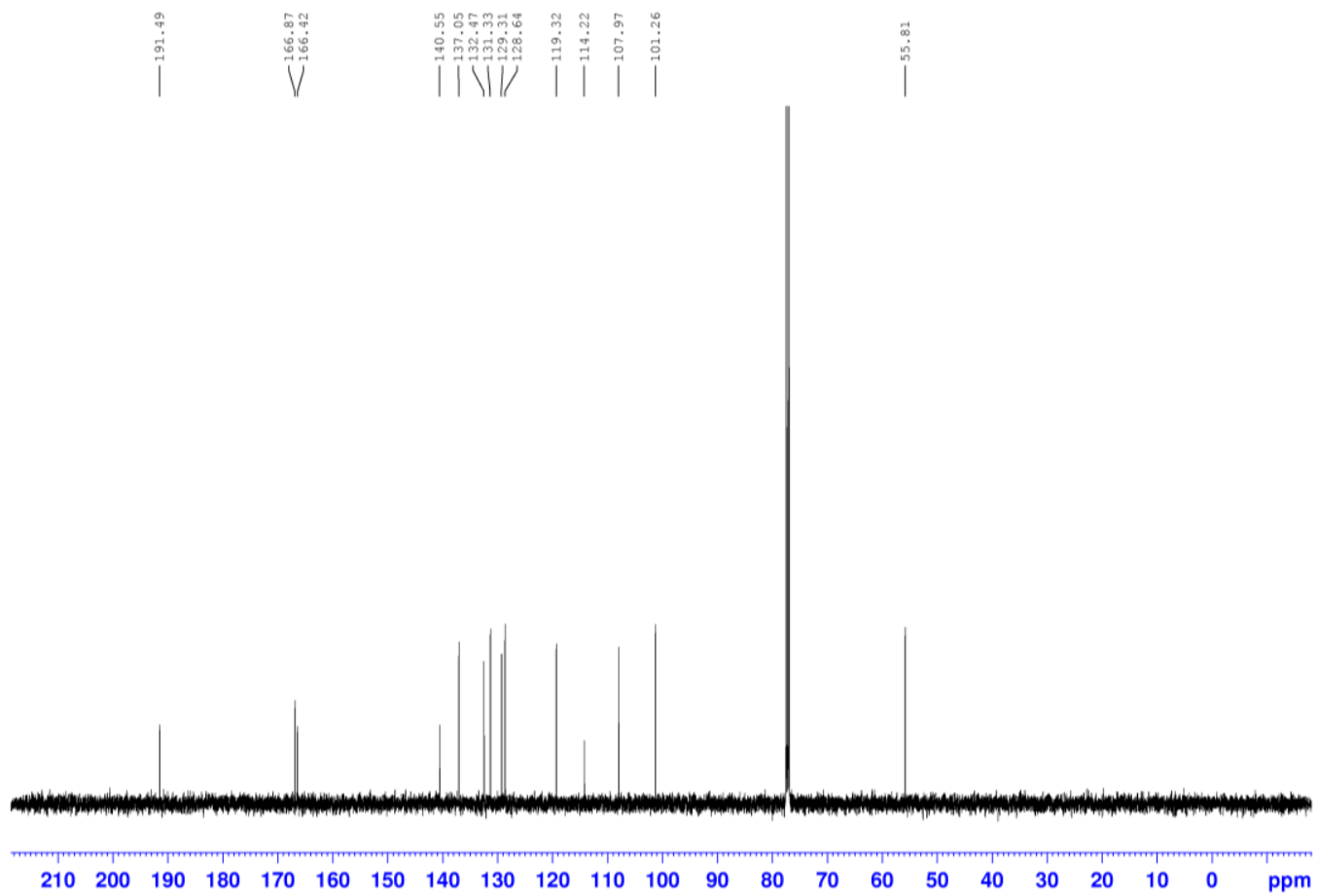


${ }^{1} \mathrm{H}$ NMR Spectrum of (E)-1-(2-hydroxy-4-methoxyphenyl)-3-(thiophen-3-yl)prop-2-en1-one (11)

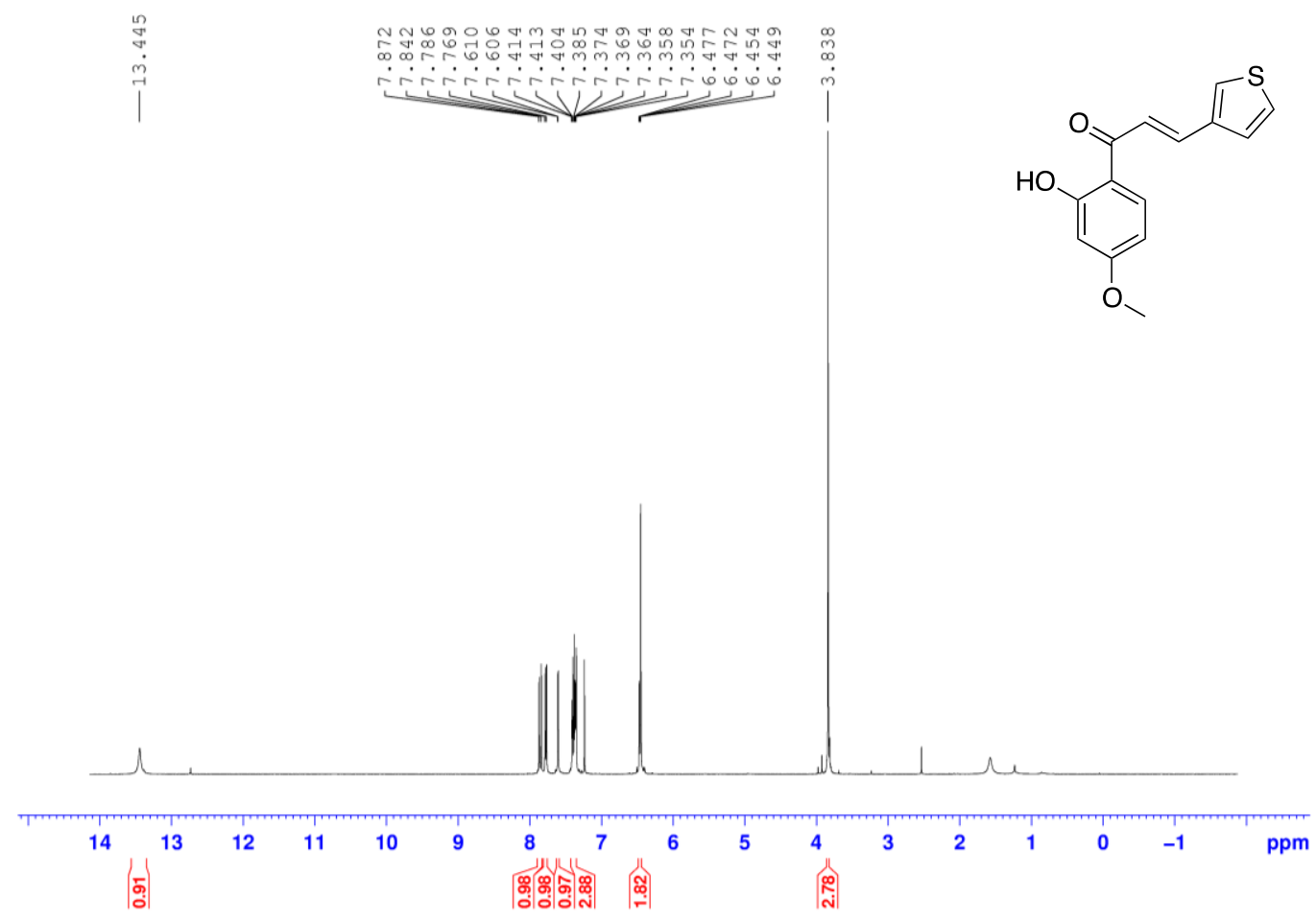

${ }^{13}$ C NMR Spectrum of (E)-1-(2-hydroxy-4-methoxyphenyl)-3-(thiophen-3-yl)prop-2-en1 _nno (11)

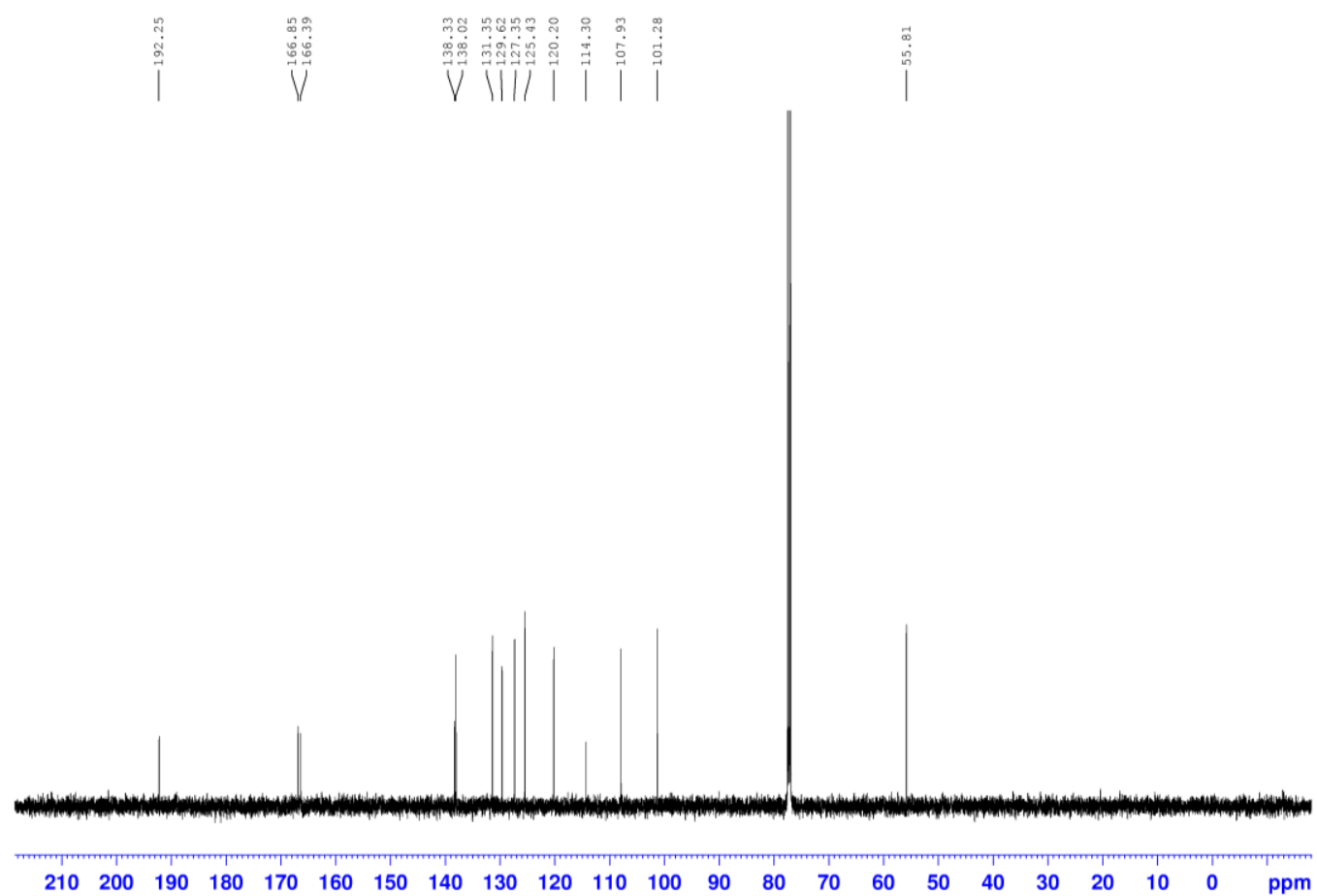


${ }^{1} \mathrm{H}$ NMR Spectrum of (2E,2'E)-3,3'-(1,3-phenylene)bis(1-(2-hydroxyphenyl)prop-2-en-1one) (1m)

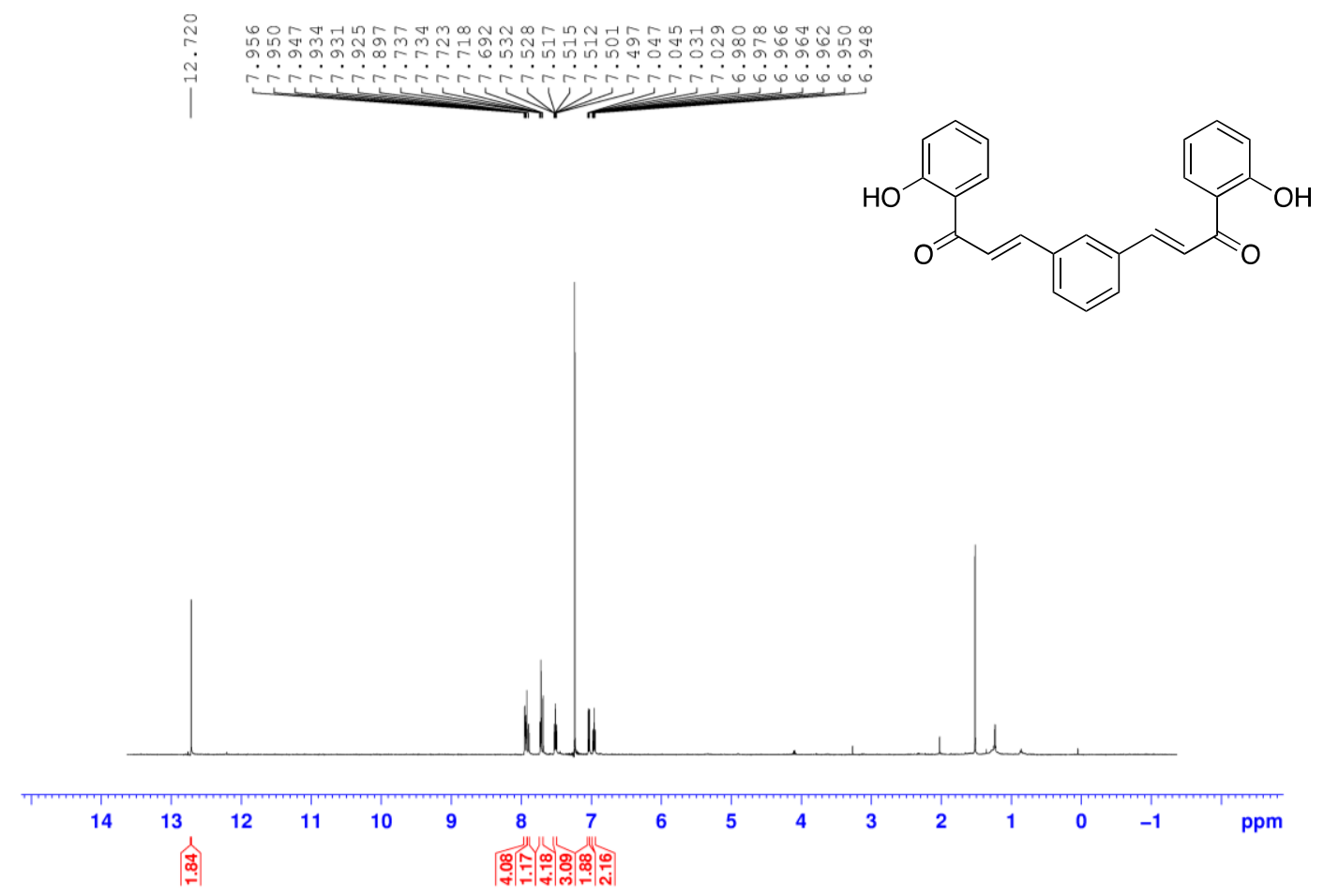

${ }^{13} \mathrm{C}$ NMR Spectrum of (2E,2'E)-3,3'-(1,3-phenylene)bis(1-(2-hydroxyphenyl)prop-2-en1-one) (1m)

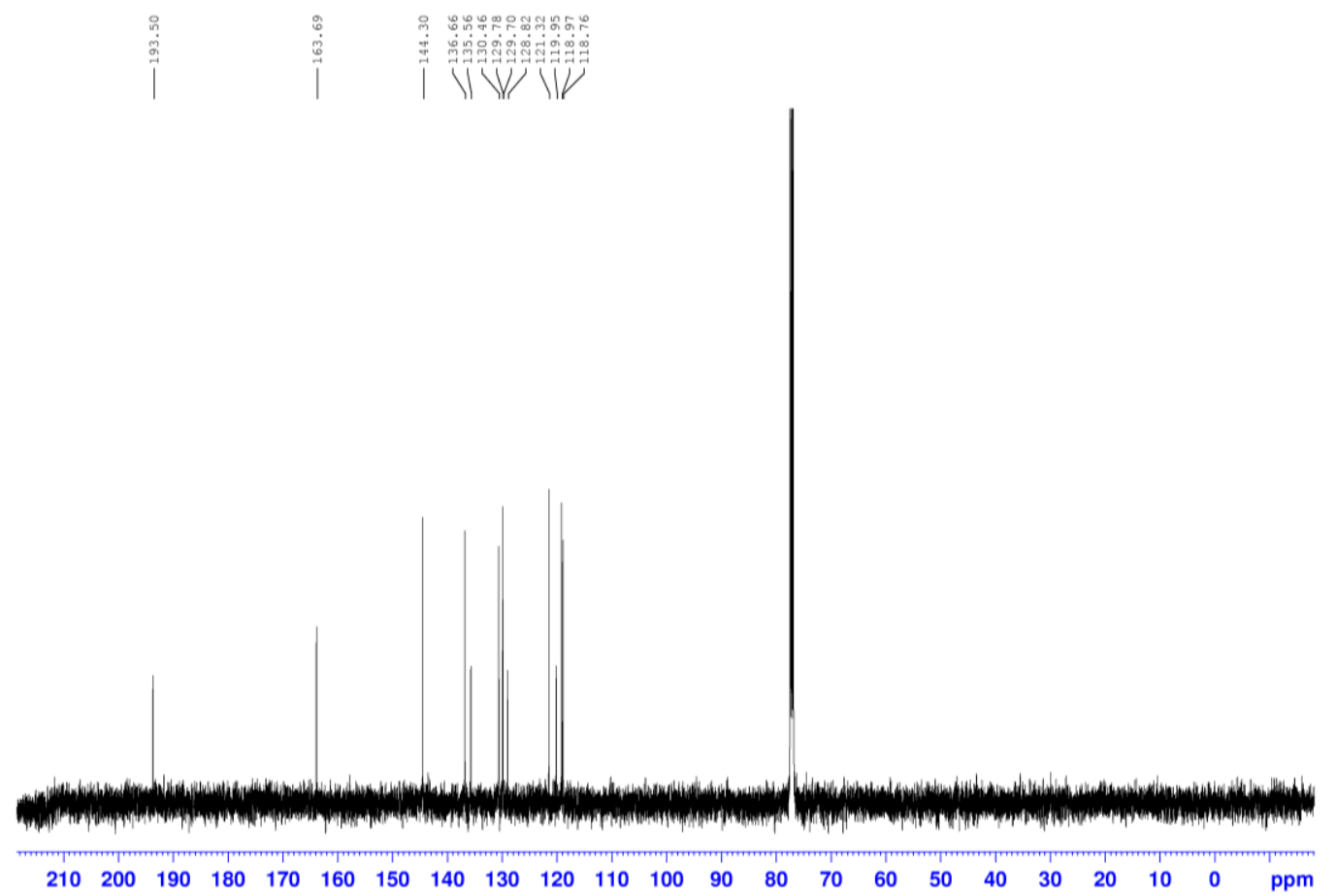


${ }^{1} \mathrm{H}$ NMR Spectrum of (2E,2' E)-3,3'-(1,4-phenylene)bis(1-(2-hydroxyphenyl)prop-2-en-1one) (1n)

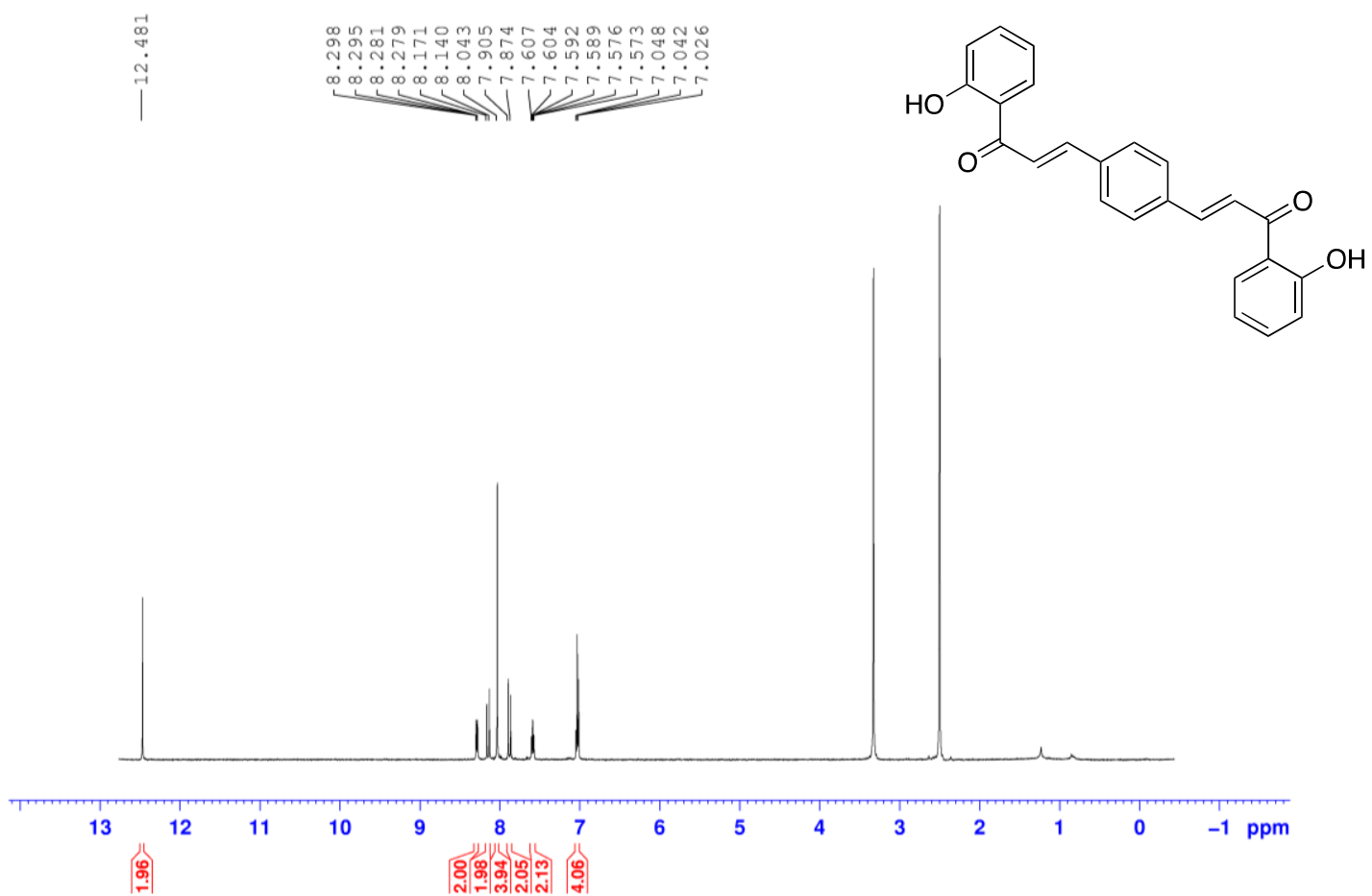

${ }^{13} \mathrm{C}$ NMR Spectrum of (2E,2'E)-3,3'-(1,4-phenylene)bis(1-(2-hydroxyphenyl)prop-2-en1-one) (1n)

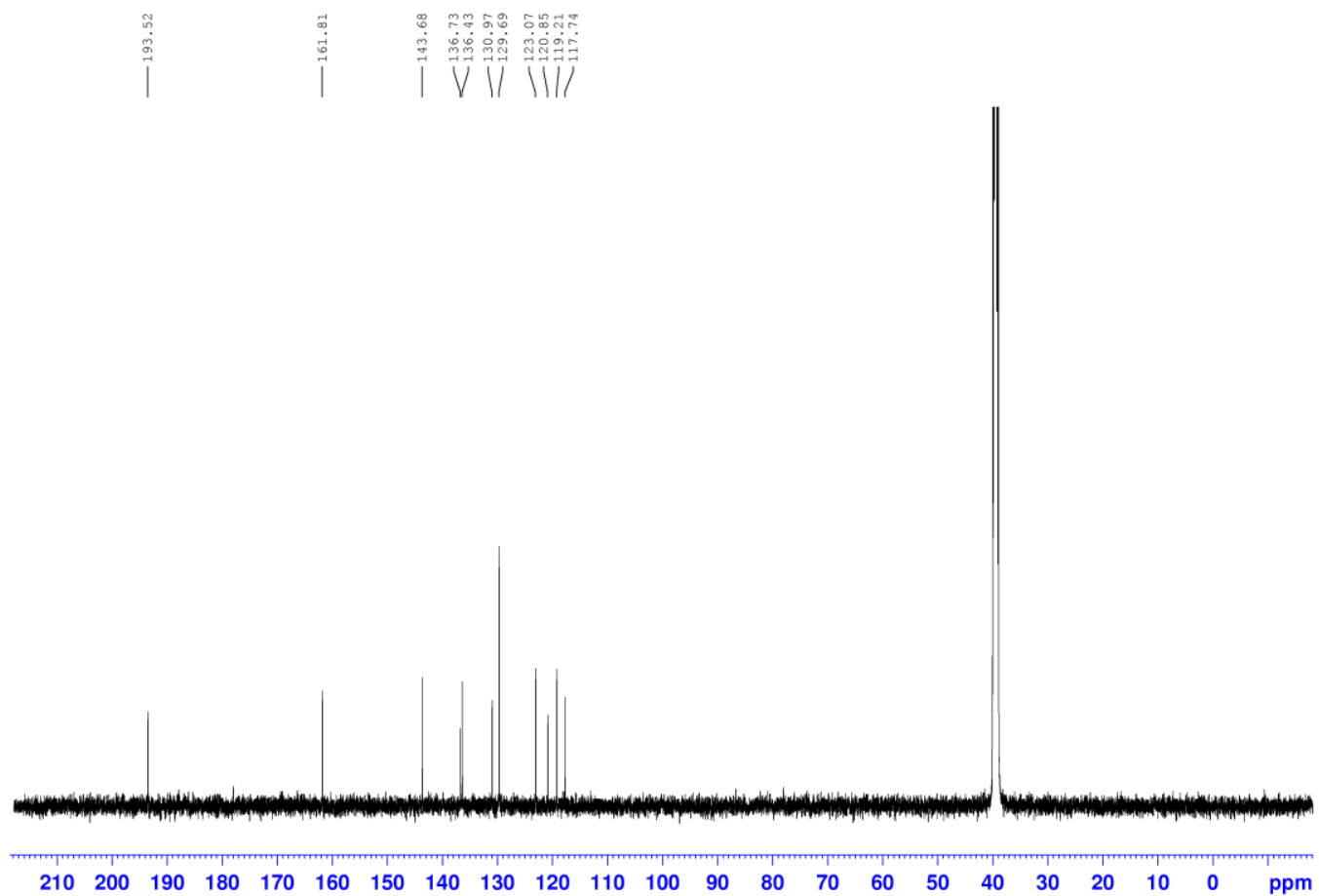


${ }^{1} \mathrm{H}$ NMR Spectrum of 2-(naphthalen-2-yl)chroman-4-one (2b)
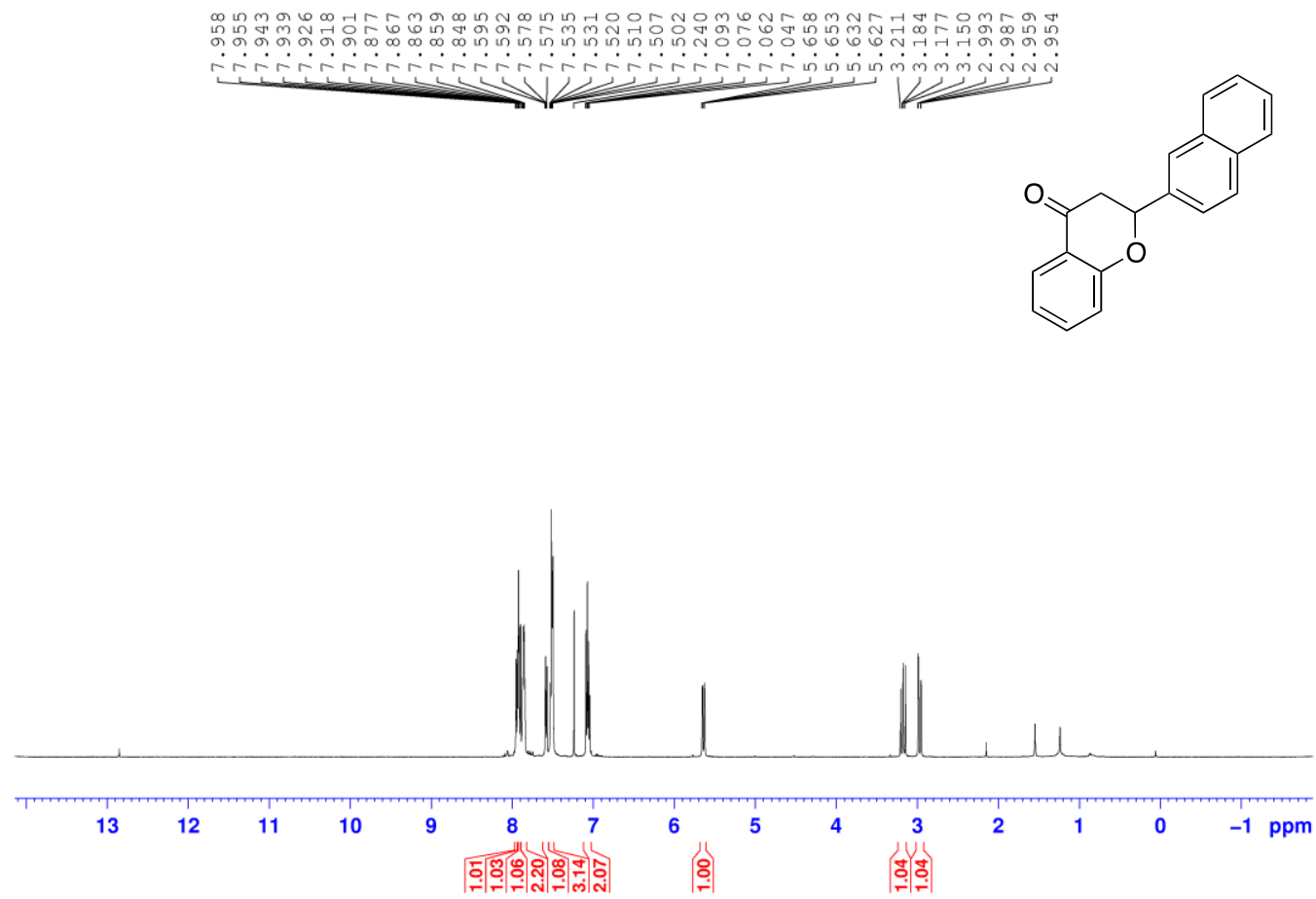

${ }^{13}$ C NMR Spectrum of 2-(naphthalen-2-yl)chroman-4-one (2b)

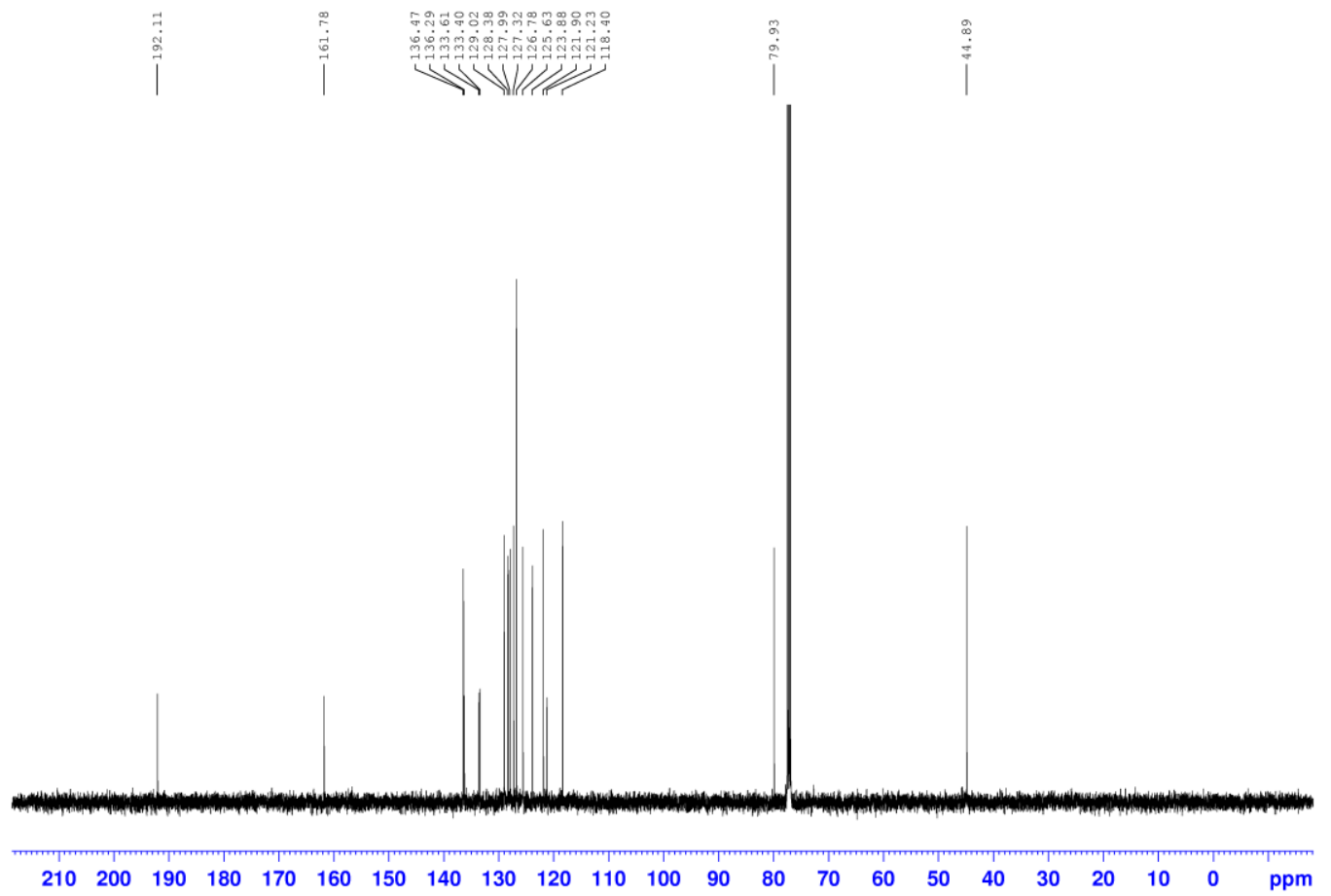


${ }^{1}$ H NMR Spectrum of 2-(naphthalen-1-yl)chroman-4-one (2c)
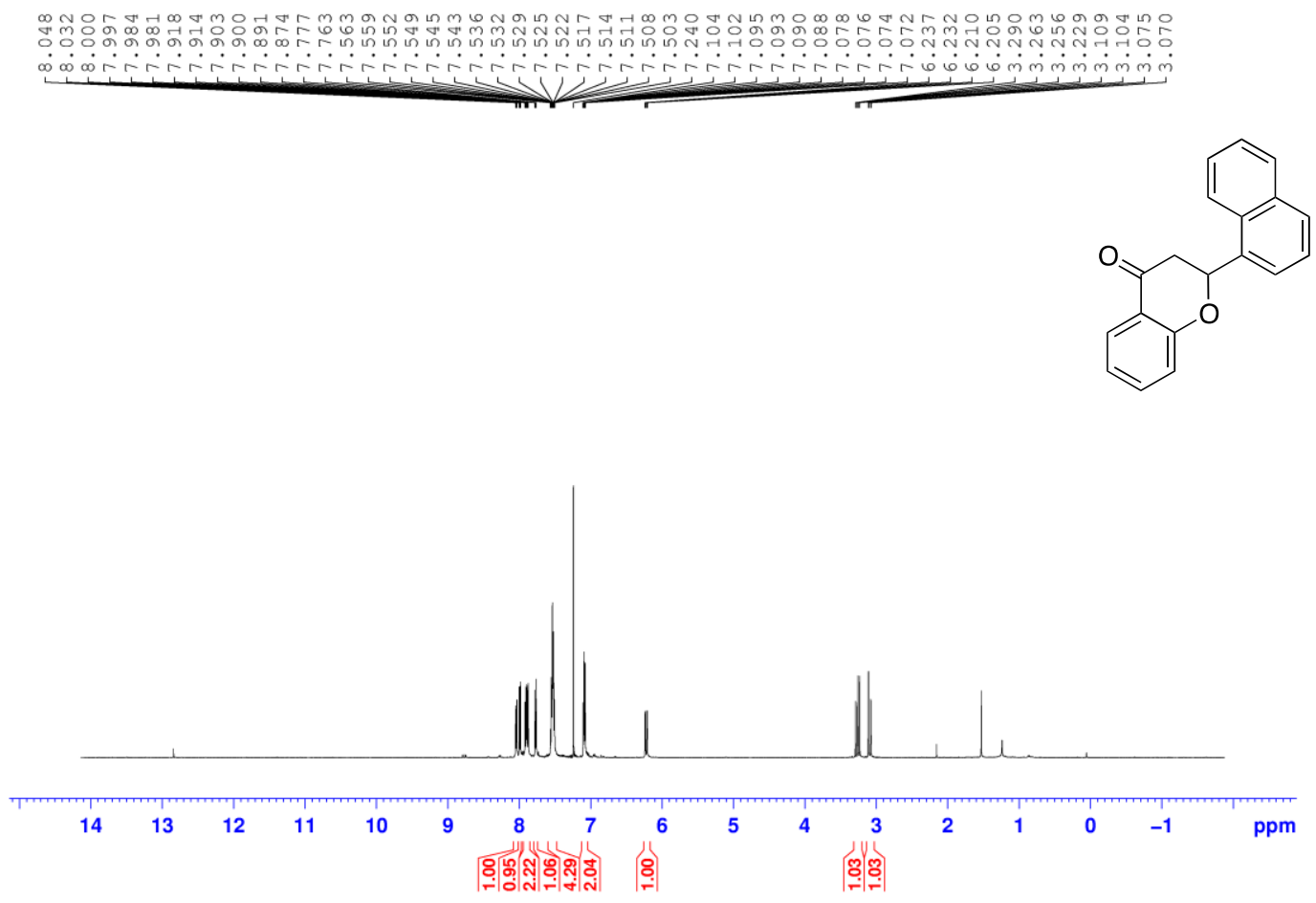

${ }^{13}$ C NMR Spectrum of 2-(naphthalen-1-yl)chroman-4-one (2c)

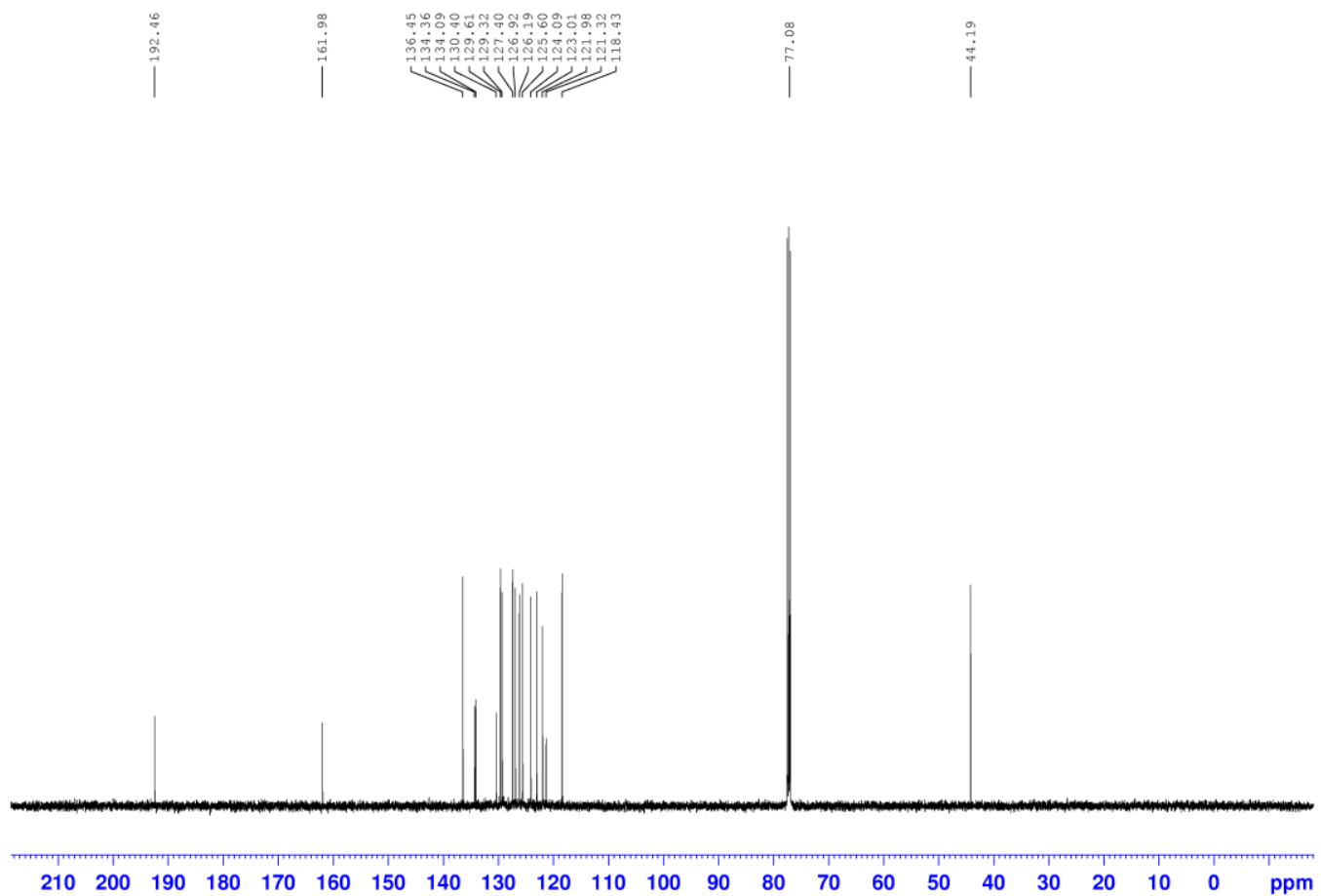


${ }^{1}$ H NMR Spectrum of 2-([1,1'-biphenyl]-4-yl)chroman-4-one (2d)
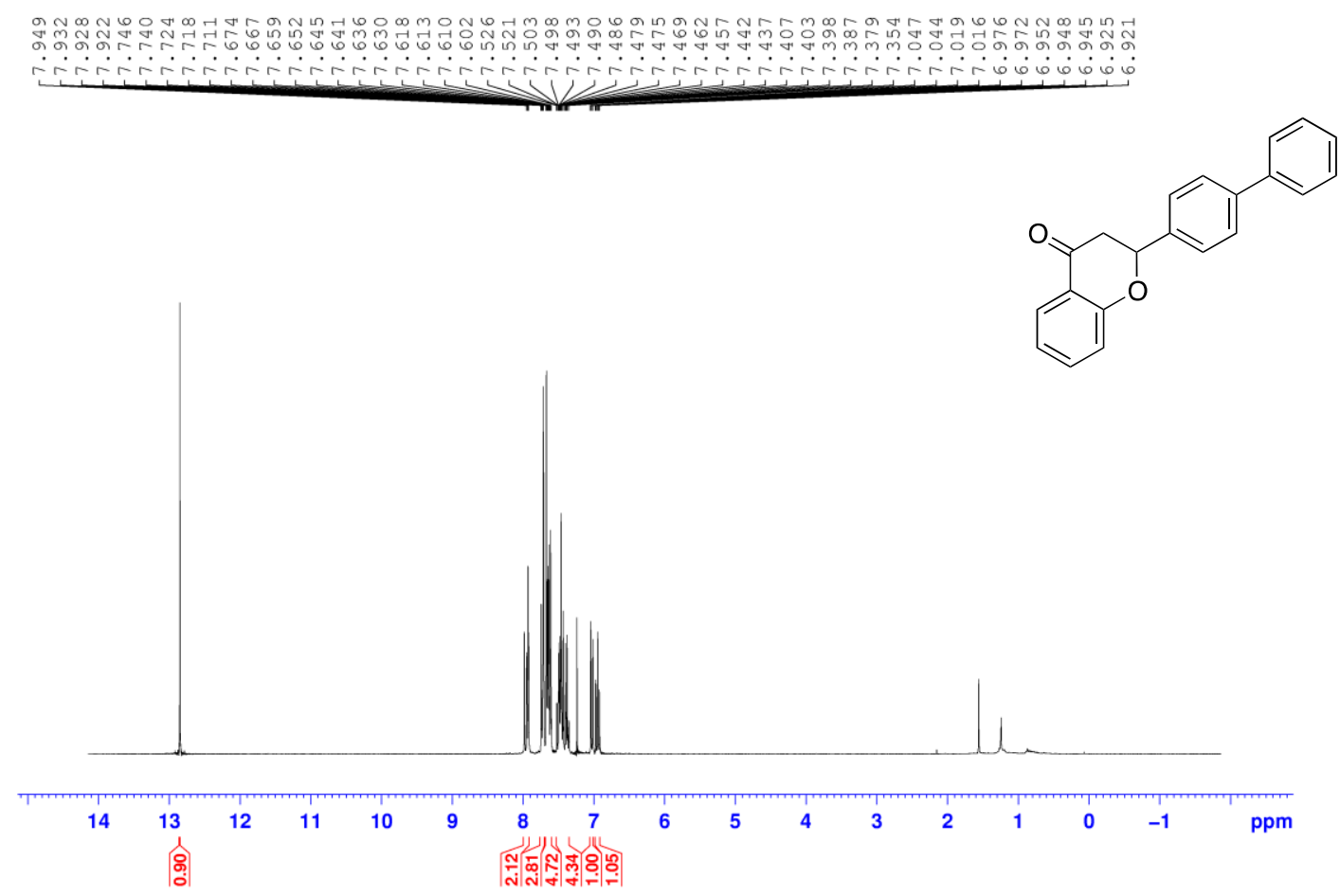

${ }^{13}$ C NMR Spectrum of 2-([1,1'-biphenyl]-4-yl)chroman-4-one (2d)

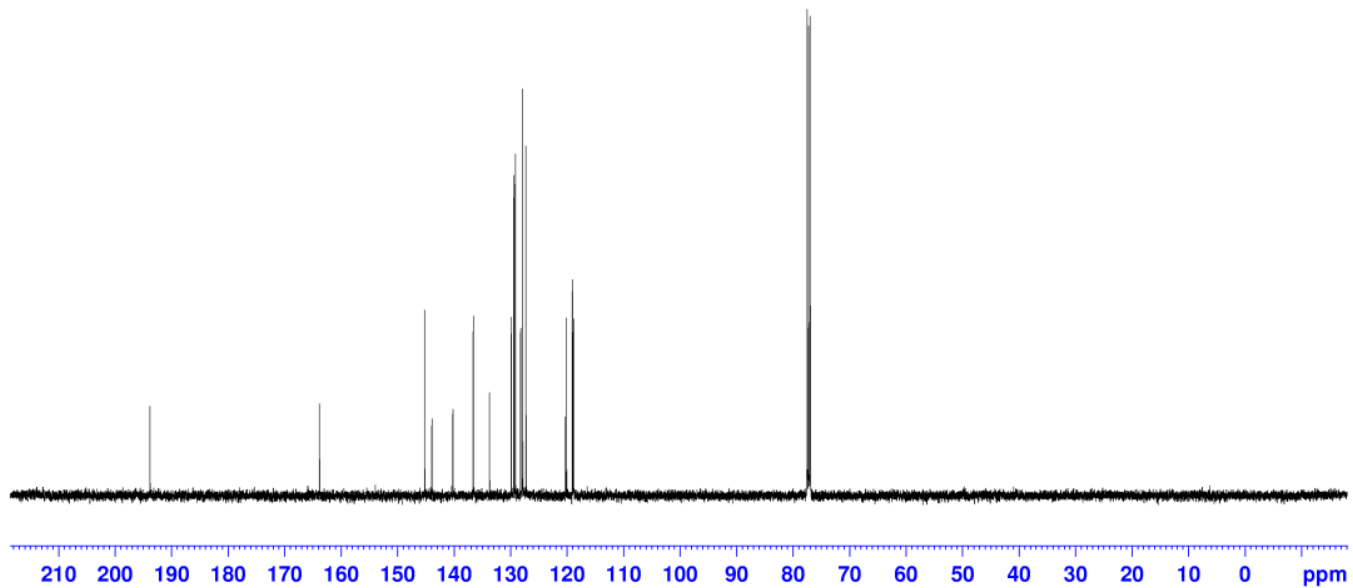


${ }^{1}$ H NMR Spectrum of 2-(furan-2-yl)chroman-4-one (2e)

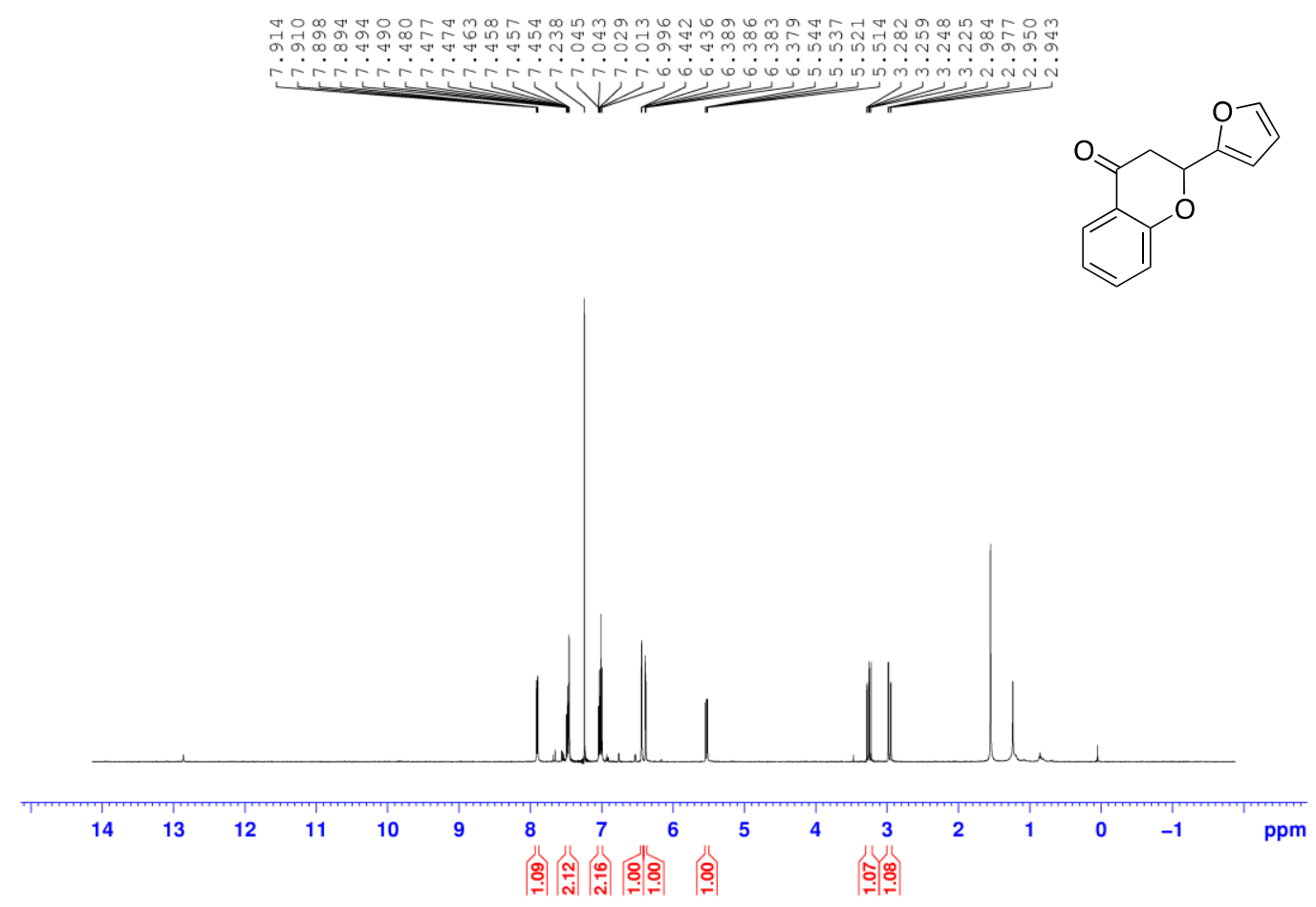

${ }^{13}$ C NMR Spectrum of 2-(furan-2-yl)chroman-4-one (2e)

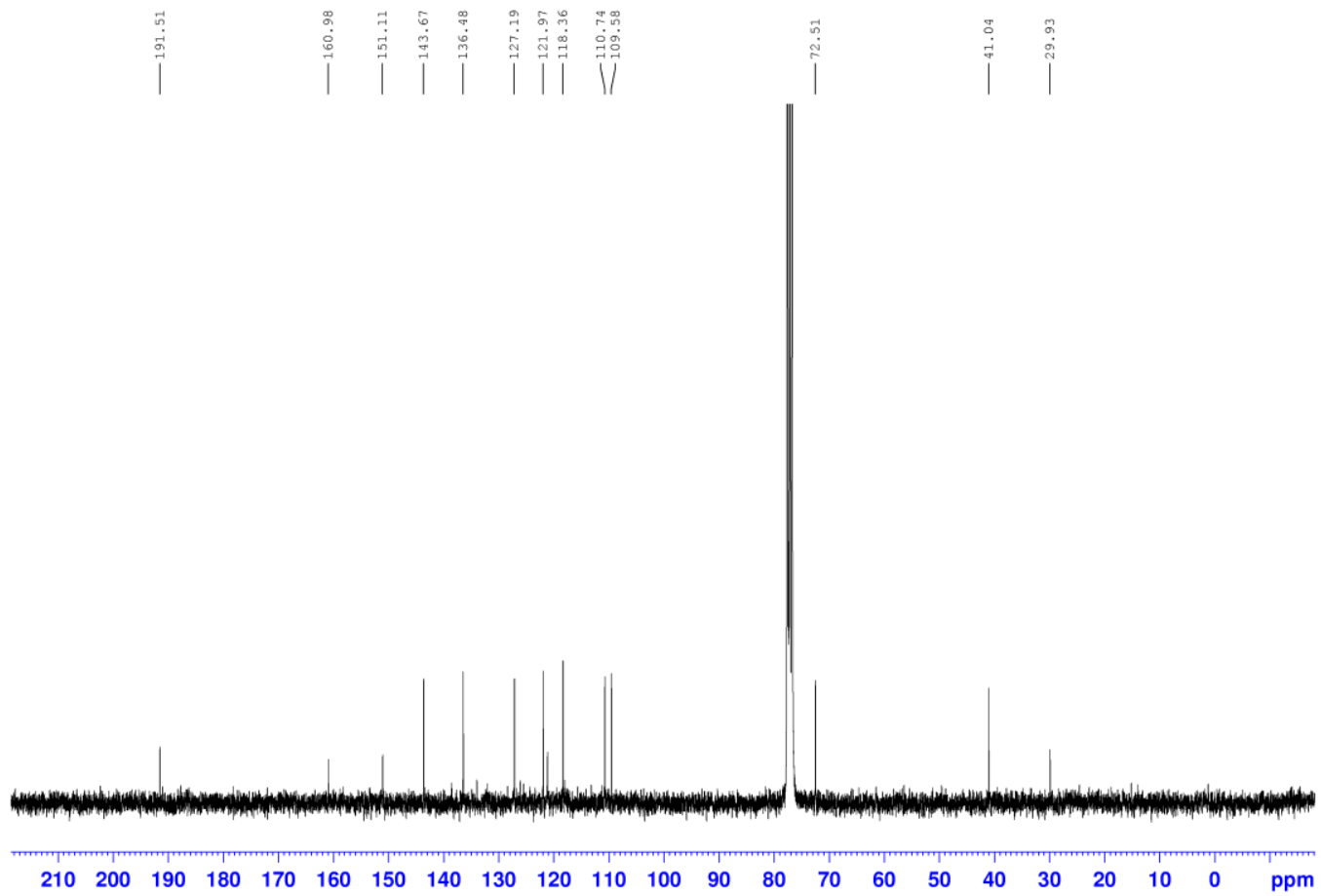


${ }^{1} \mathrm{H}$ NMR Spectrum of 2-(thiophen-2-yl)chroman-4-one (2f)

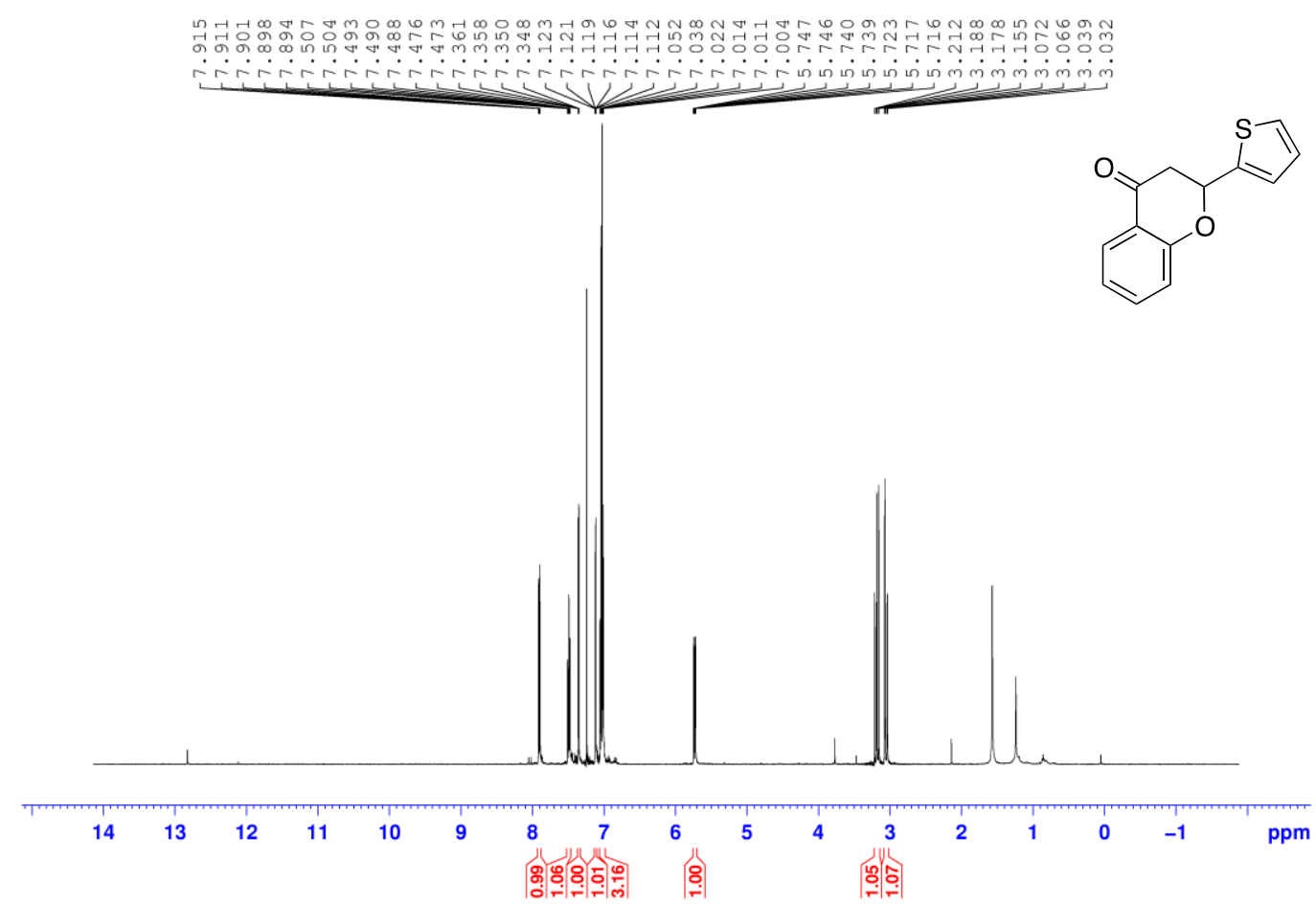

${ }^{13} \mathrm{C}$ NMR Spectrum of 2-(thiophen-2-yl)chroman-4-one (2f)

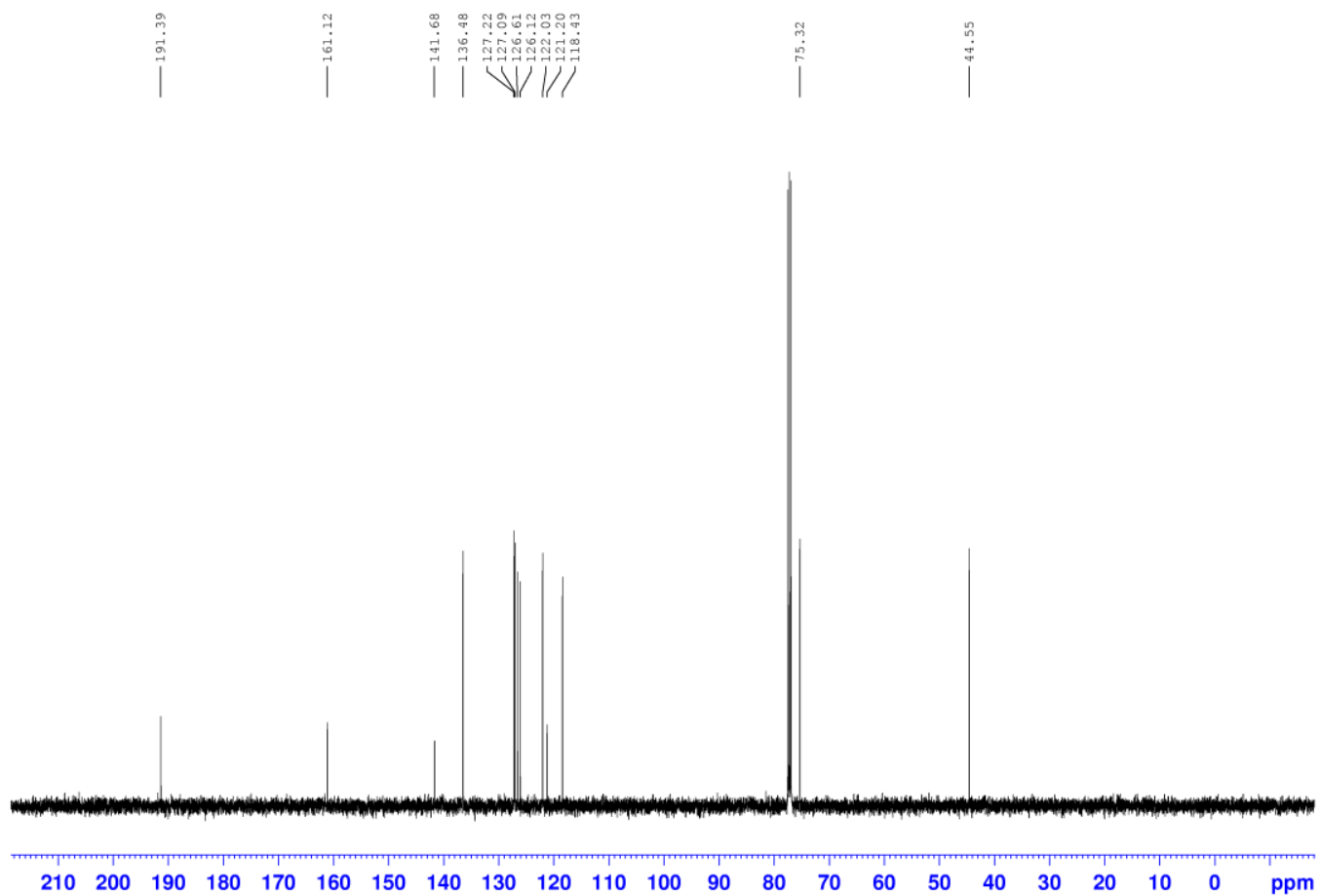


${ }^{1}$ H NMR Spectrum of 2-(thiophen-3-yl)chroman-4-one (2g)

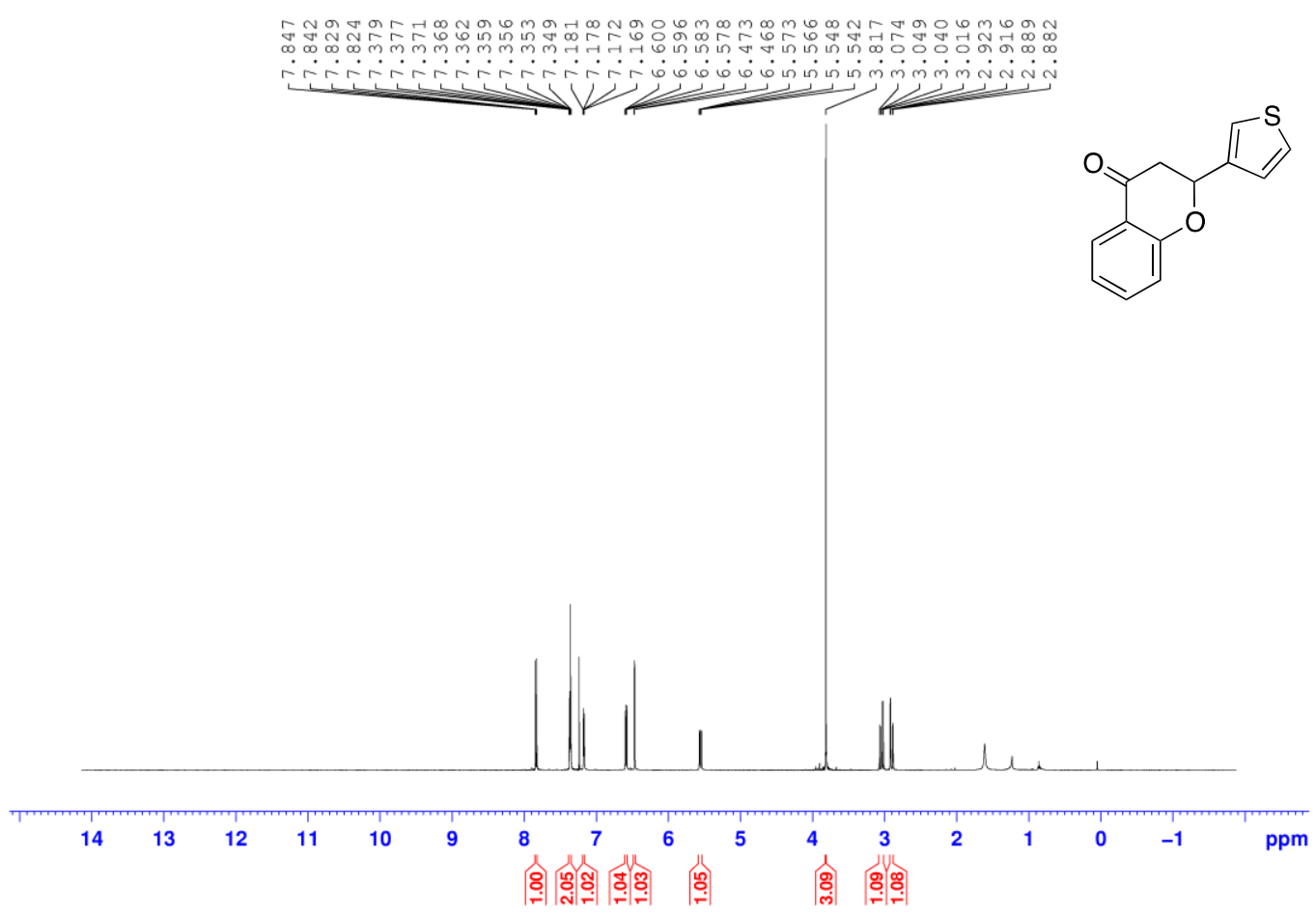

${ }^{13}$ C NMR Spectrum of 2-(thiophen-3-yl)chroman-4-one (2g)

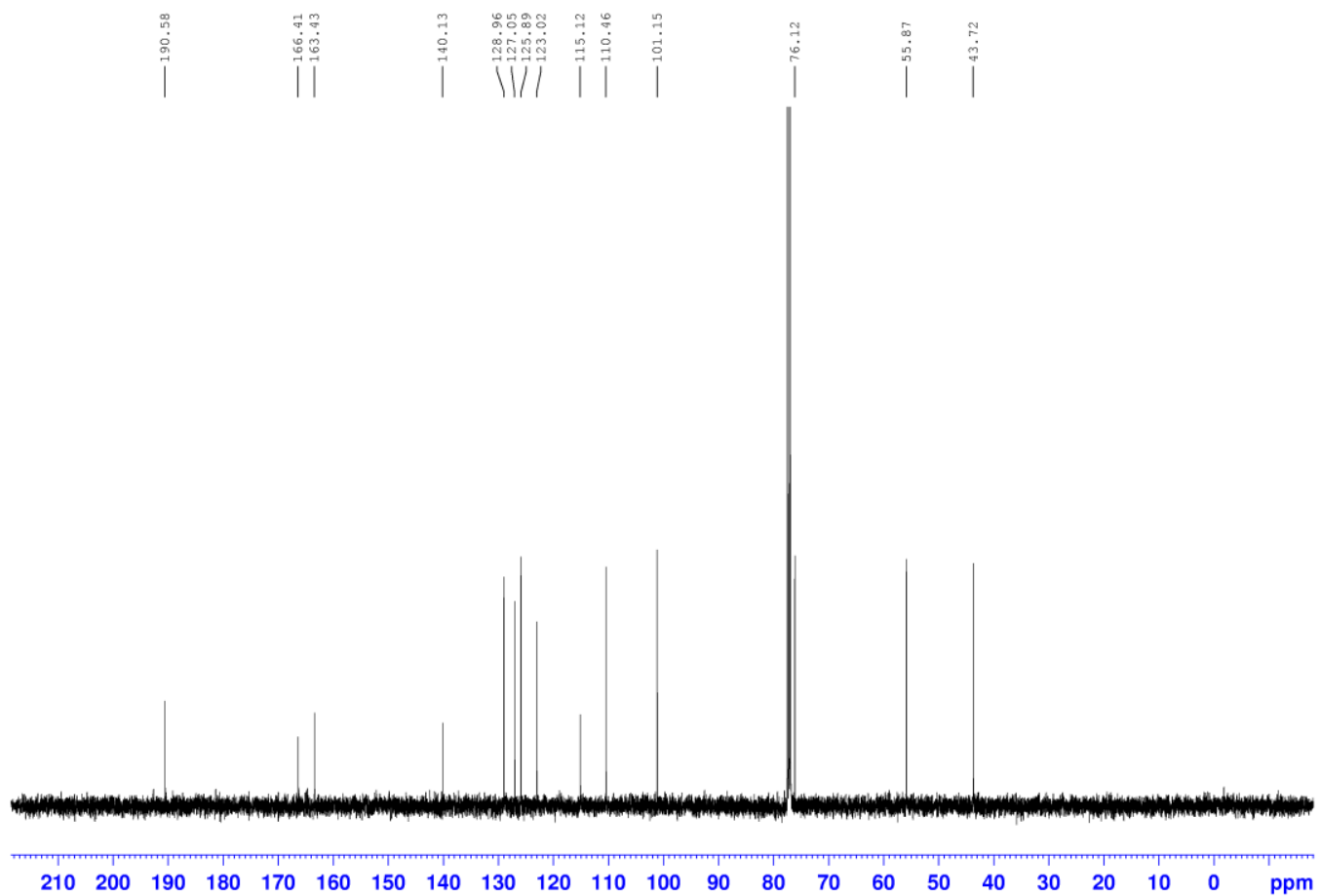


${ }^{1}$ H NMR Spectrum of 3-phenyl-2,3-dihydro-1 $H$-benzo[f]chromen-1-one (2h)

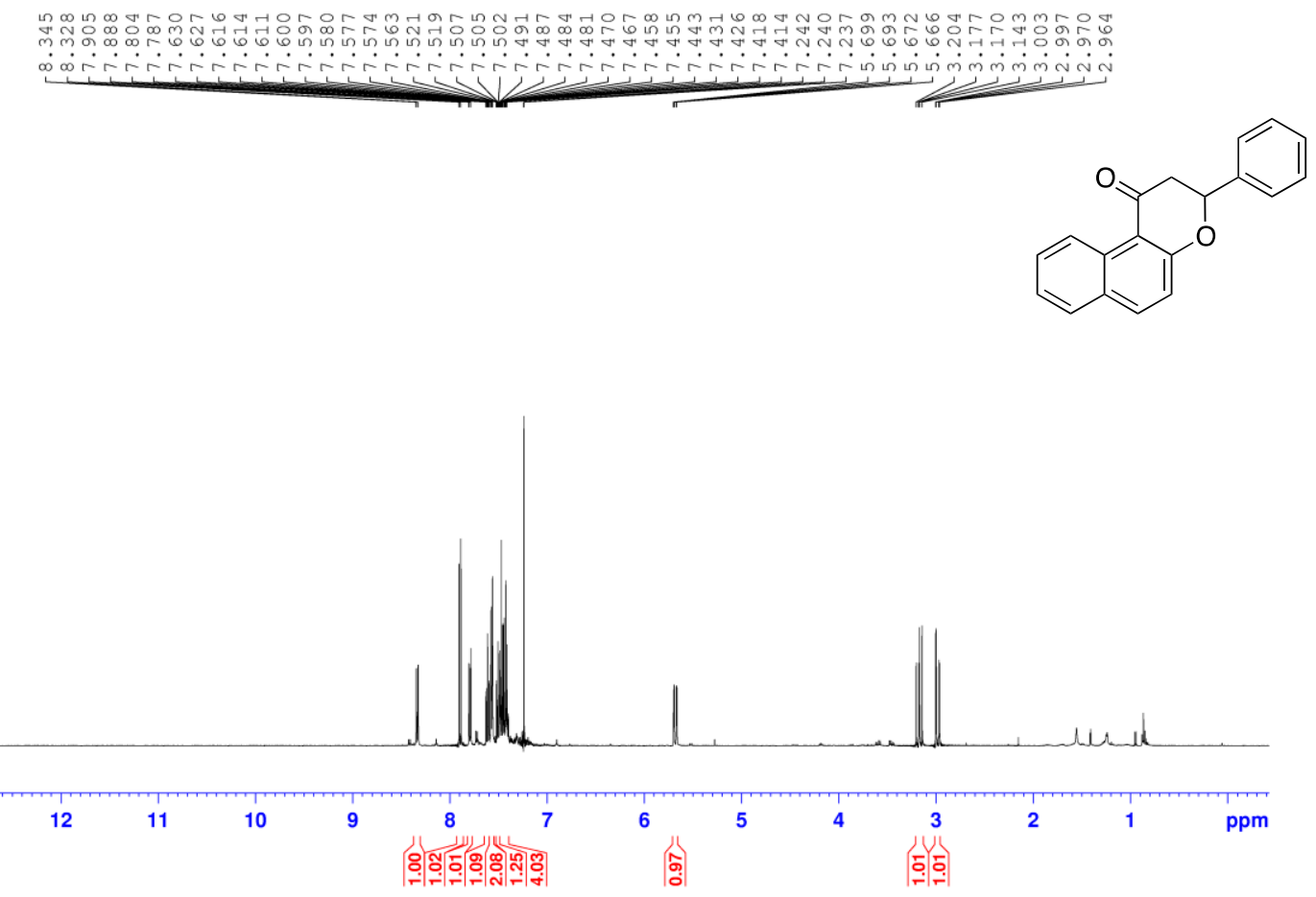

${ }^{13} \mathrm{C}$ NMR Spectrum of 3-phenyl-2,3-dihydro-1H-benzo[f]chromen-1-one (2h)

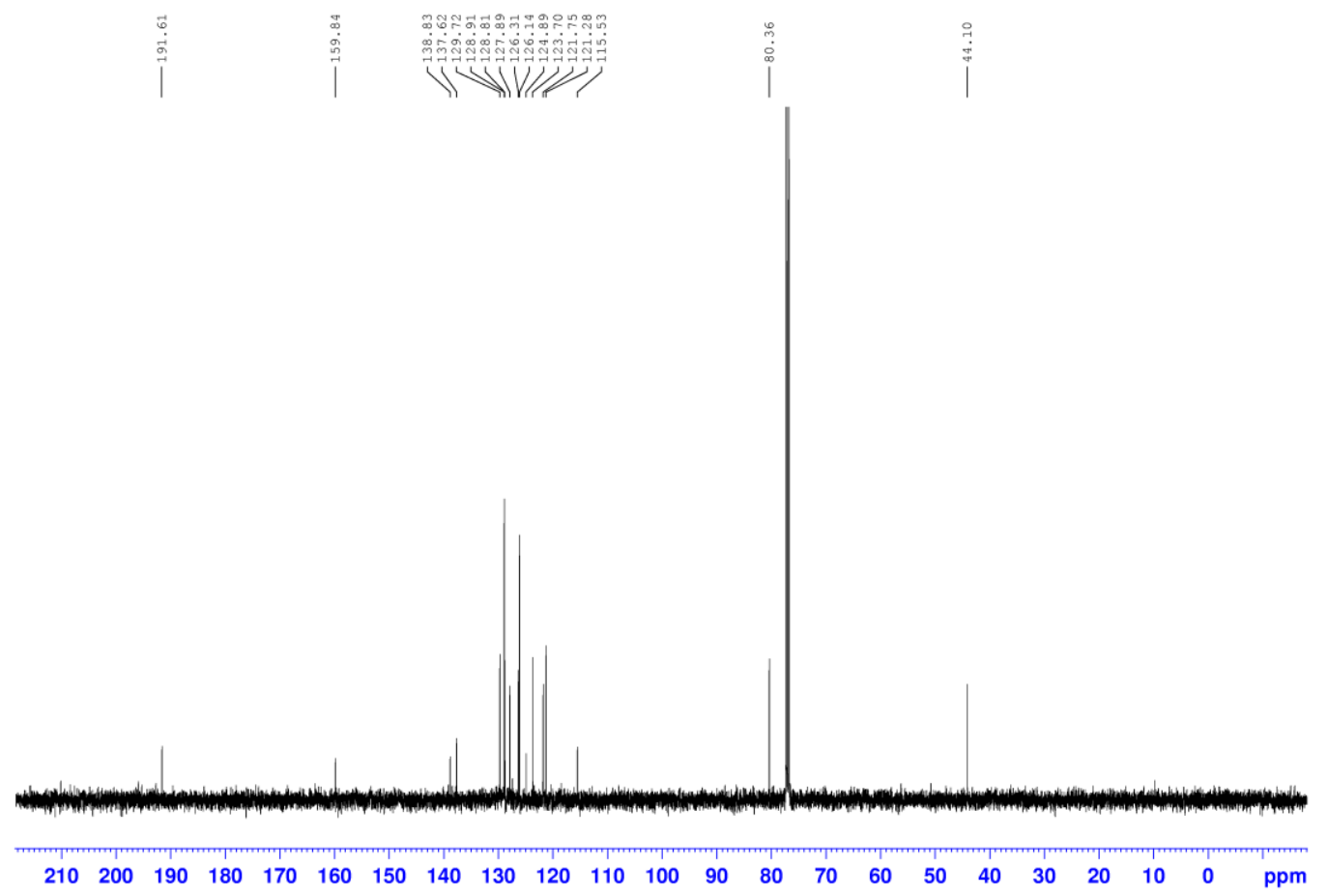


${ }^{1}$ H NMR Spectrum of 2-phenyl-2H-benzo[ $\left.h\right]$ chromen-4(3H)-one (2i)

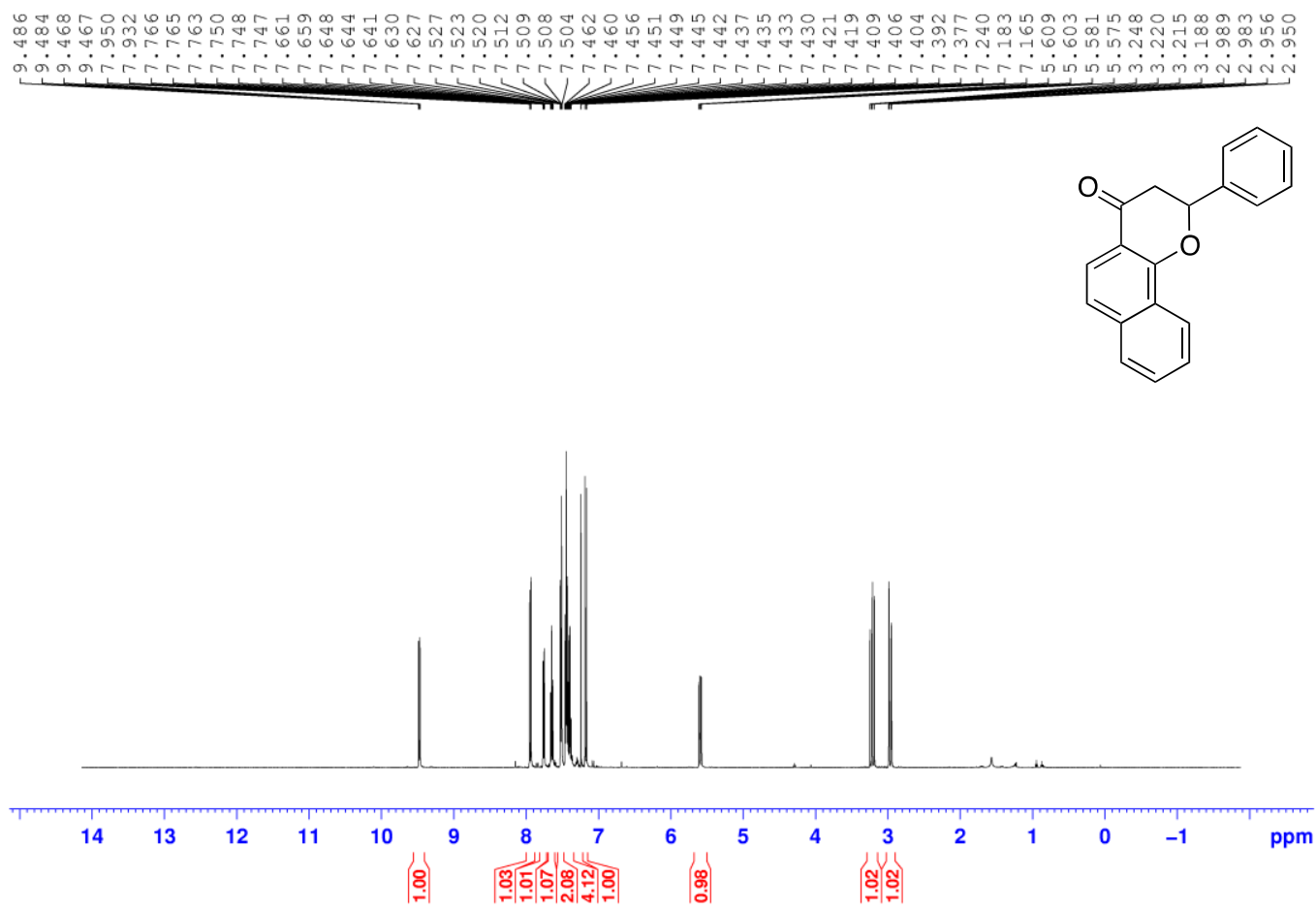

${ }^{13} \mathrm{C}$ NMR Spectrum of 2-phenyl-2H-benzo $[h]$ chromen-4(3H)-one (2i)

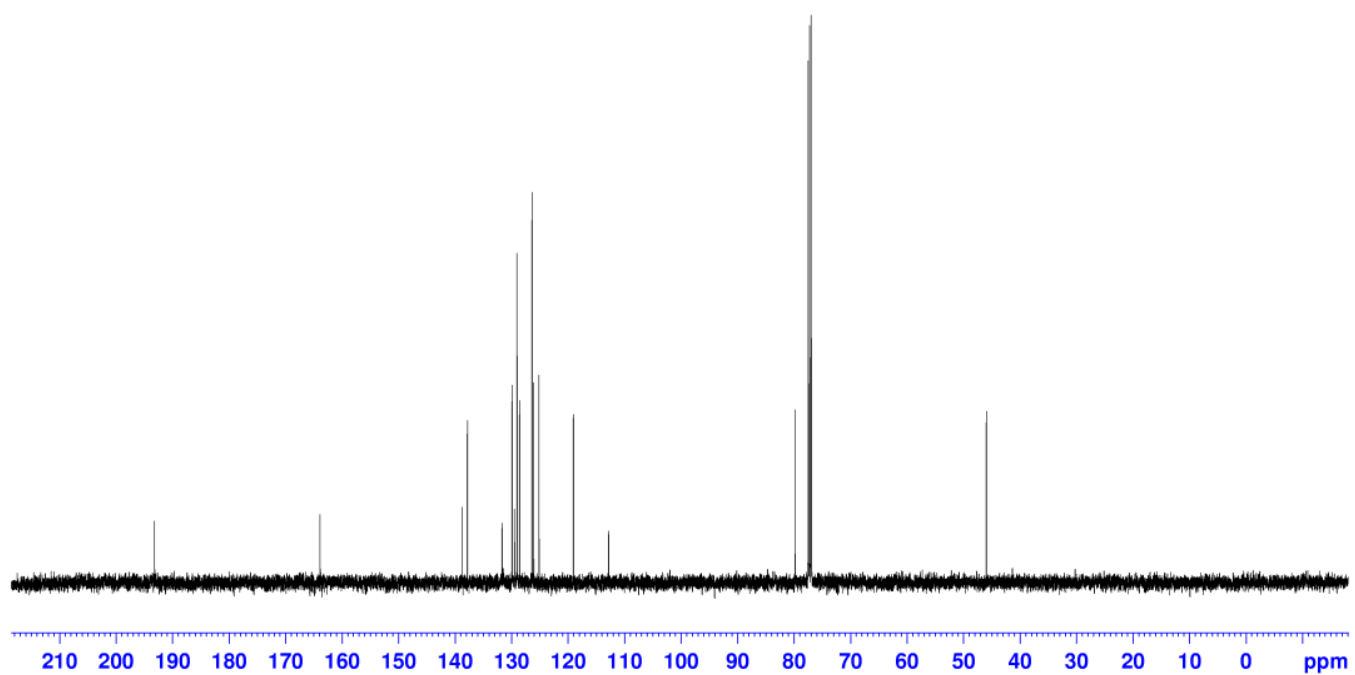


${ }^{1}$ H NMR Spectrum of 7-fluoro-2-(furan-2-yl)chroman-4-one (2j)

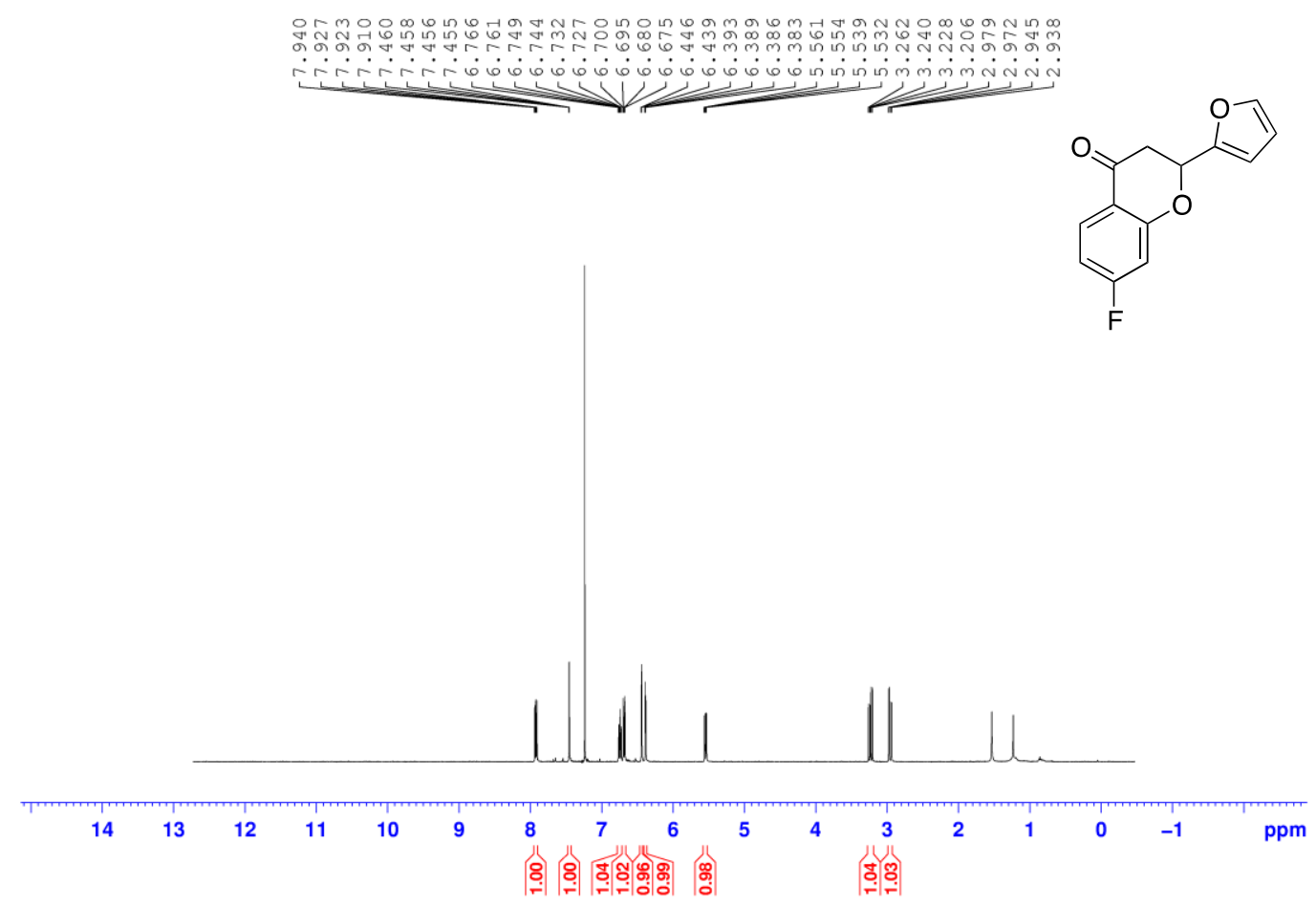

${ }^{13}$ C NMR Spectrum of 7-fluoro-2-(furan-2-yl)chroman-4-one (2j)

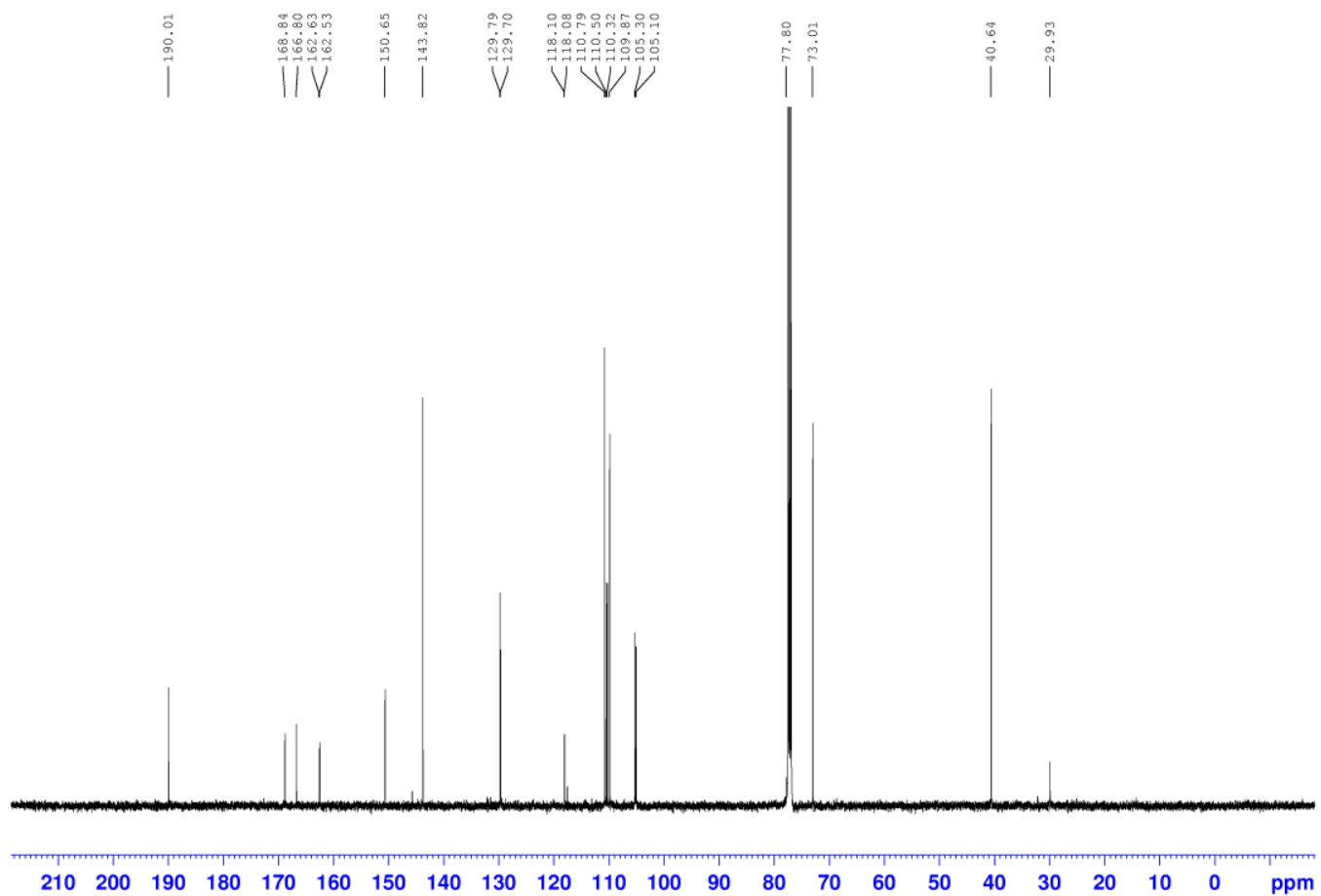


${ }^{1} \mathrm{H}$ NMR Spectrum of 7-methoxy-2-(thiophen-2-yl)chroman-4-one (2k)

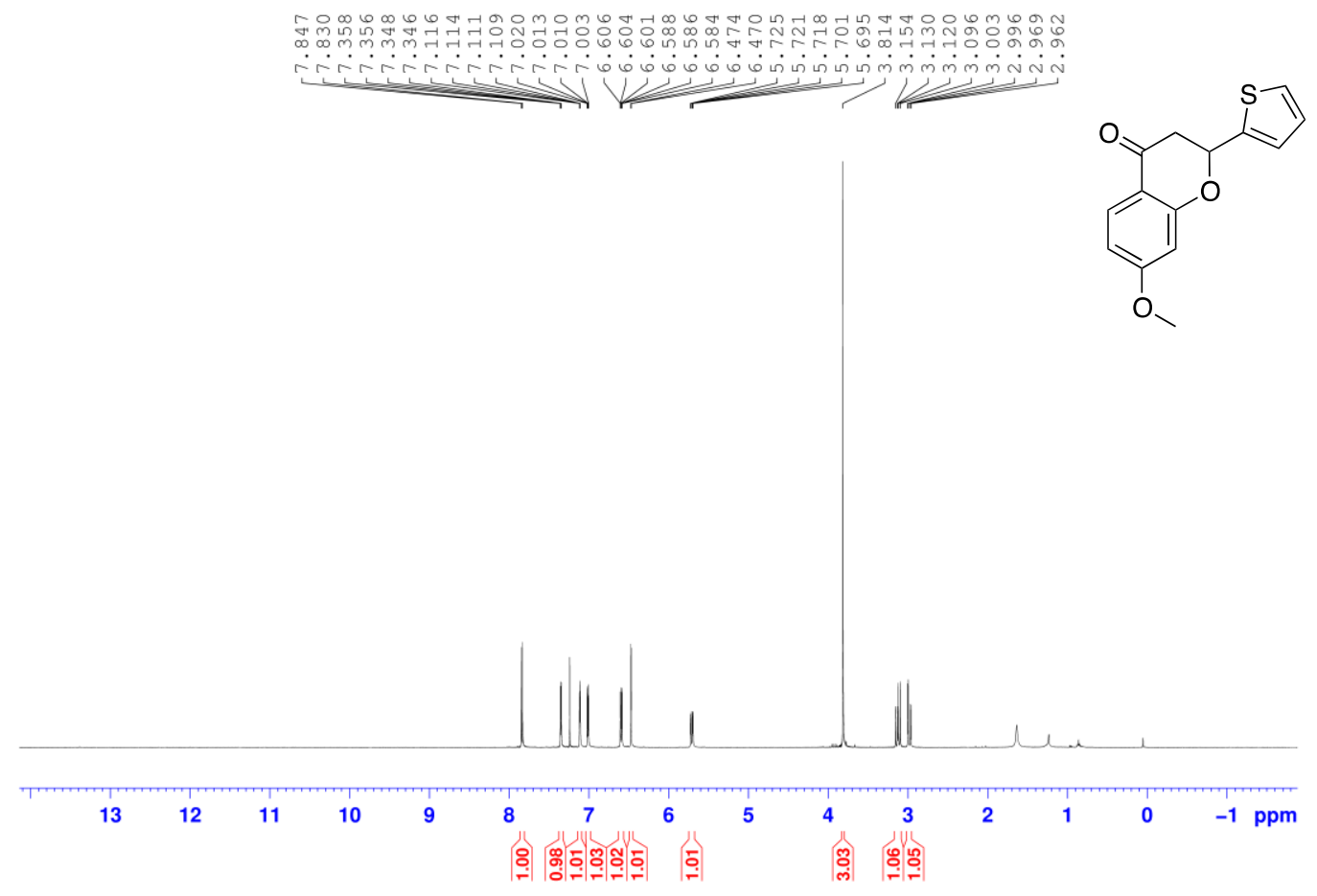

${ }^{13}$ C NMR Spectrum of 7-methoxy-2-(thiophen-2-yl)chroman-4-one (2k)

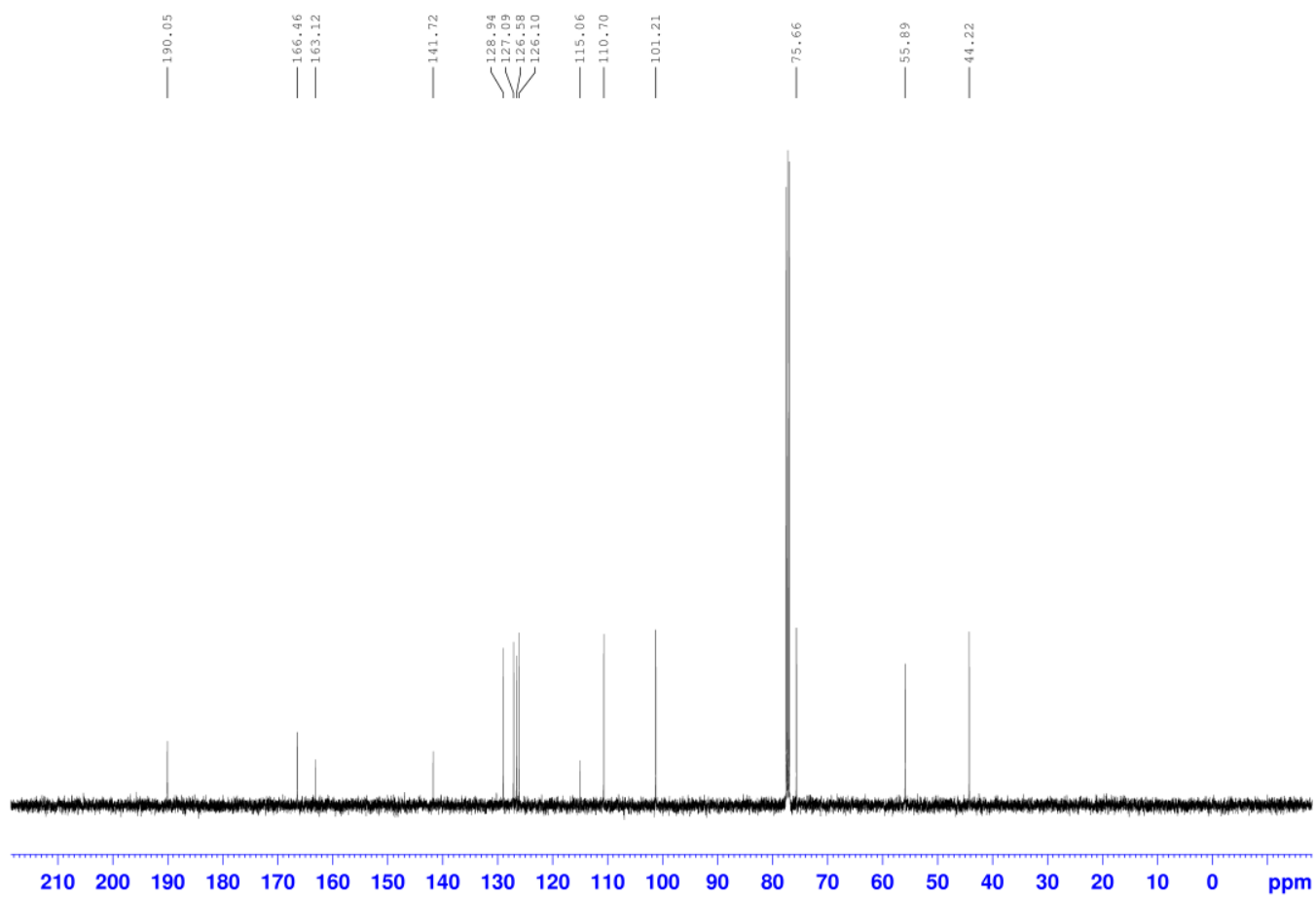


${ }^{1}$ H NMR Spectrum of 7-methoxy-2-(thiophen-3-yl)chroman-4-one (2l)

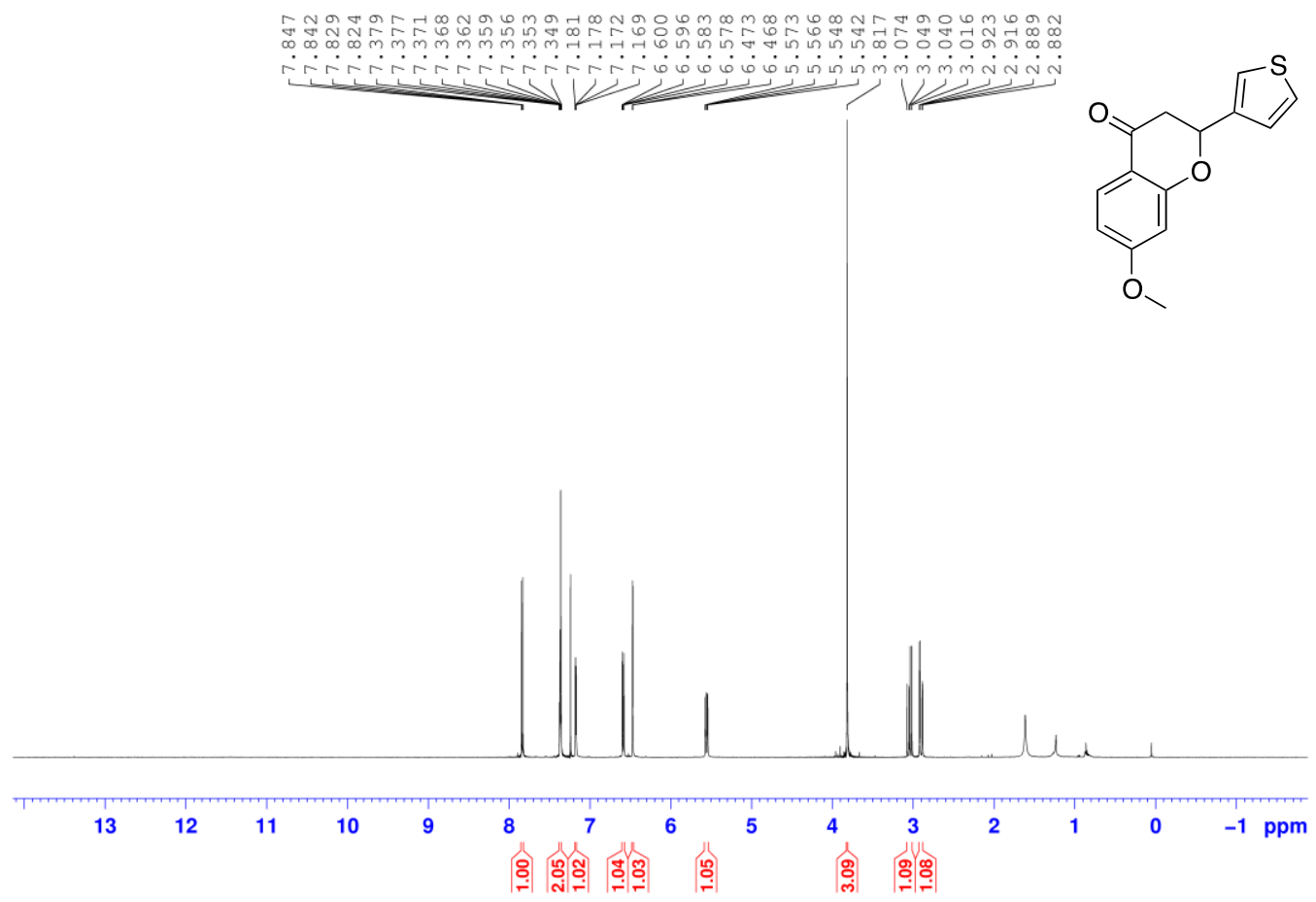

${ }^{13}$ C NMR Spectrum of 7-methoxy-2-(thiophen-3-yl)chroman-4-one (2I)

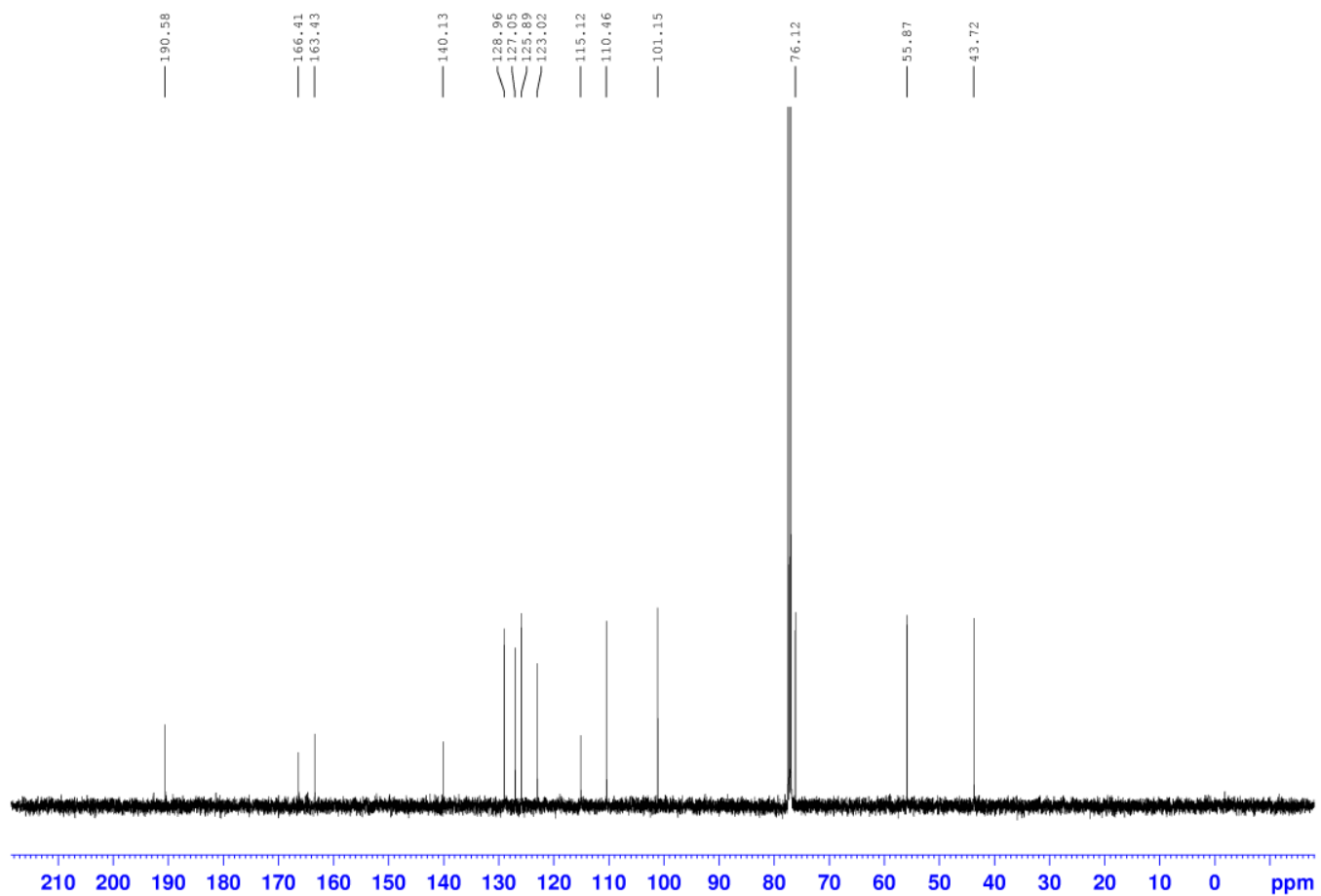


${ }^{1}$ H NMR Spectrum of 2,2'-(1,3-phenylene)bis(chroman-4-one) (2m)
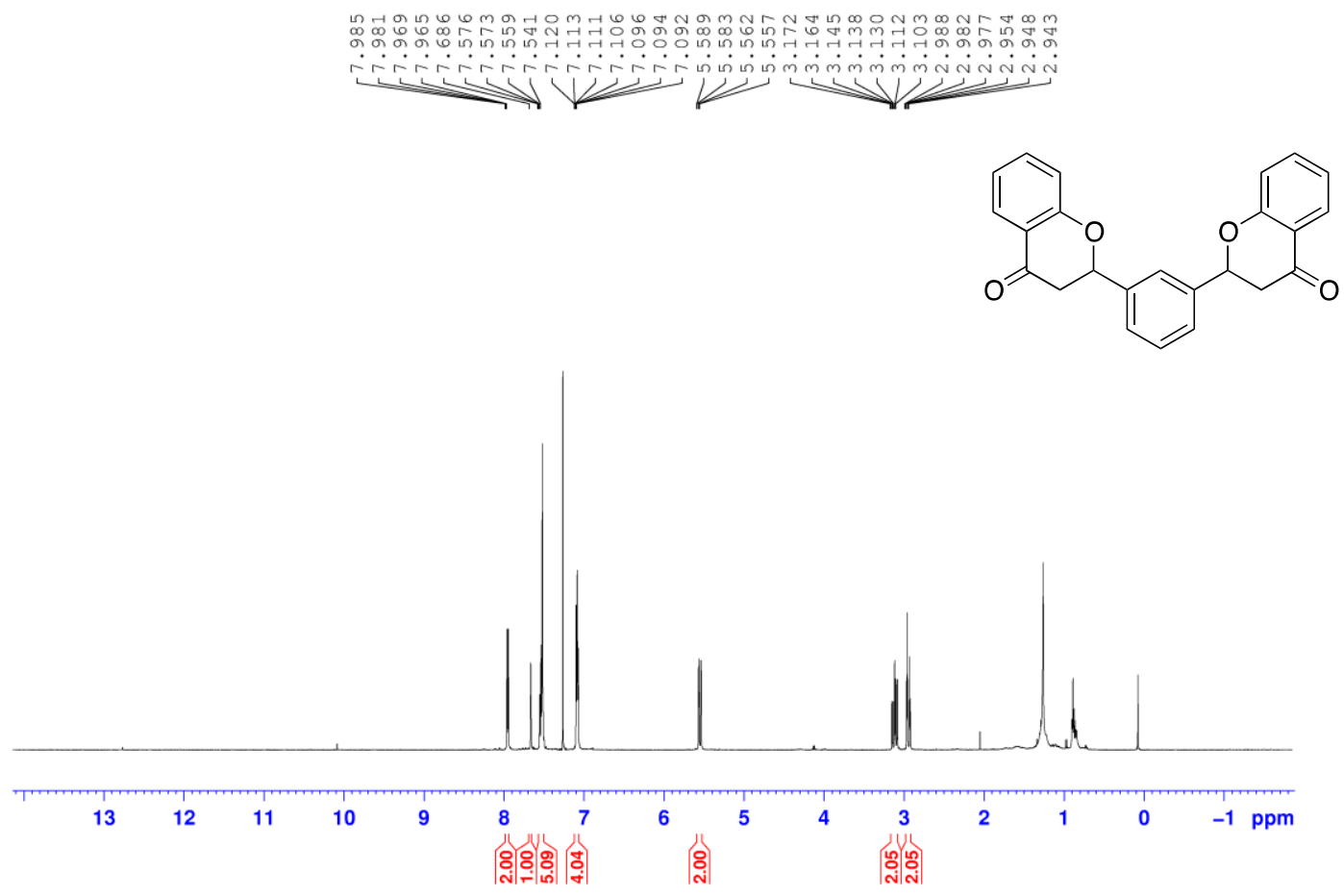

${ }^{13} \mathrm{C}$ NMR Spectrum of 2,2'-(1,3-phenylene)bis(chroman-4-one) (2m)

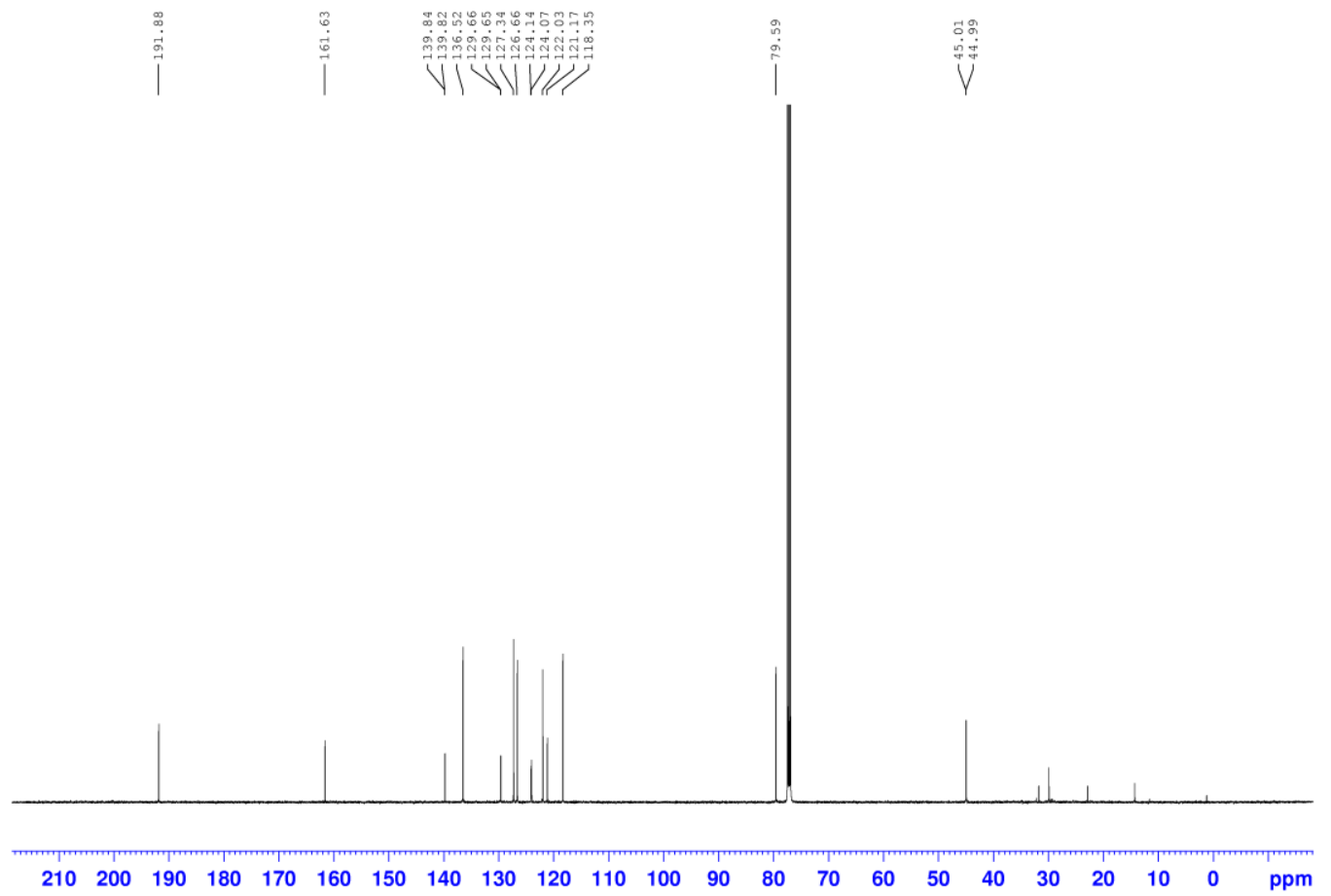


${ }^{1}$ H NMR Spectrum of 2,2'-(1,4-phenylene)bis(chroman-4-one) (2n)
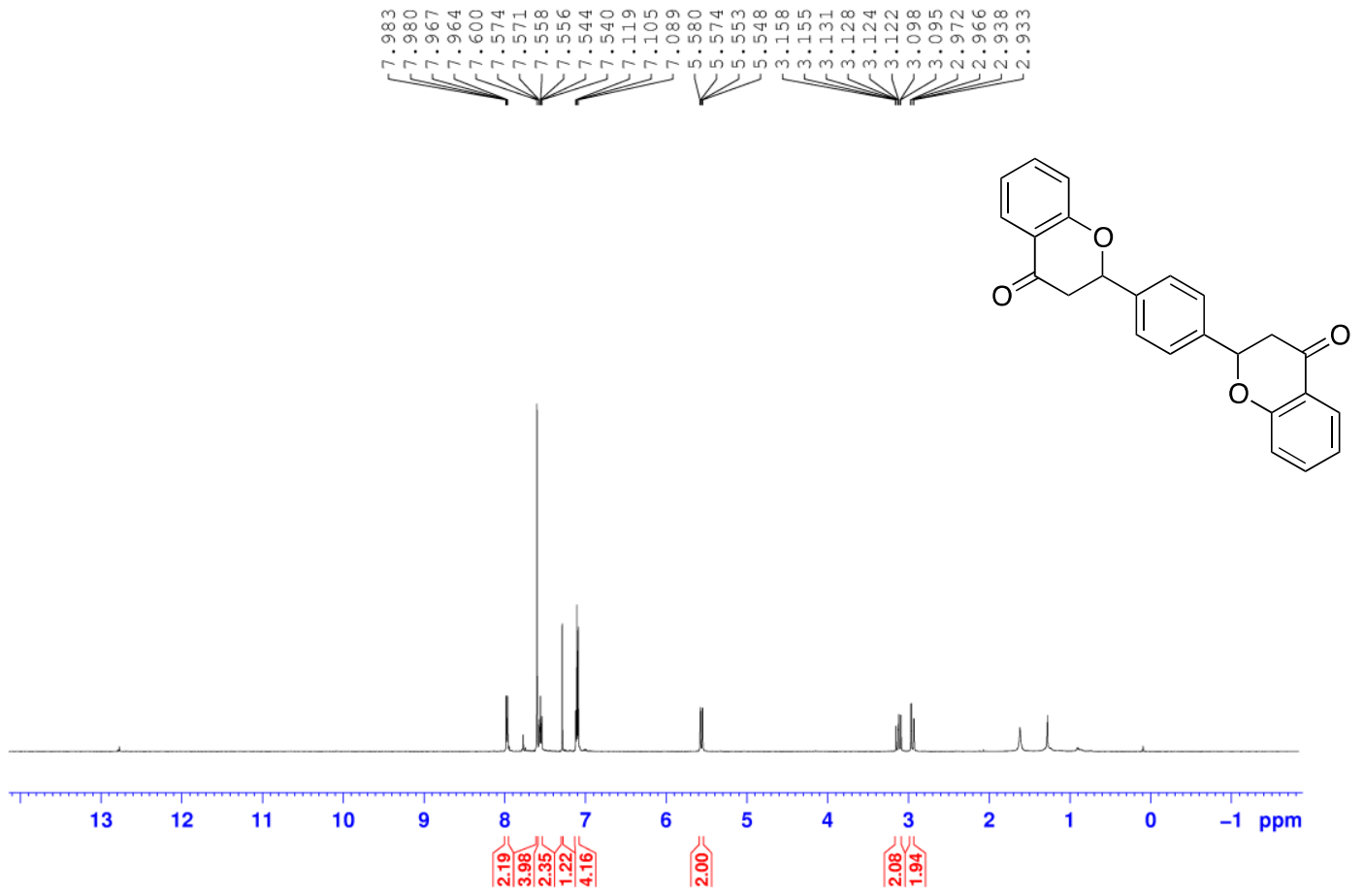

${ }^{13}$ C NMR Spectrum of 2,2'-(1,4-phenylene)bis(chroman-4-one) (2n)

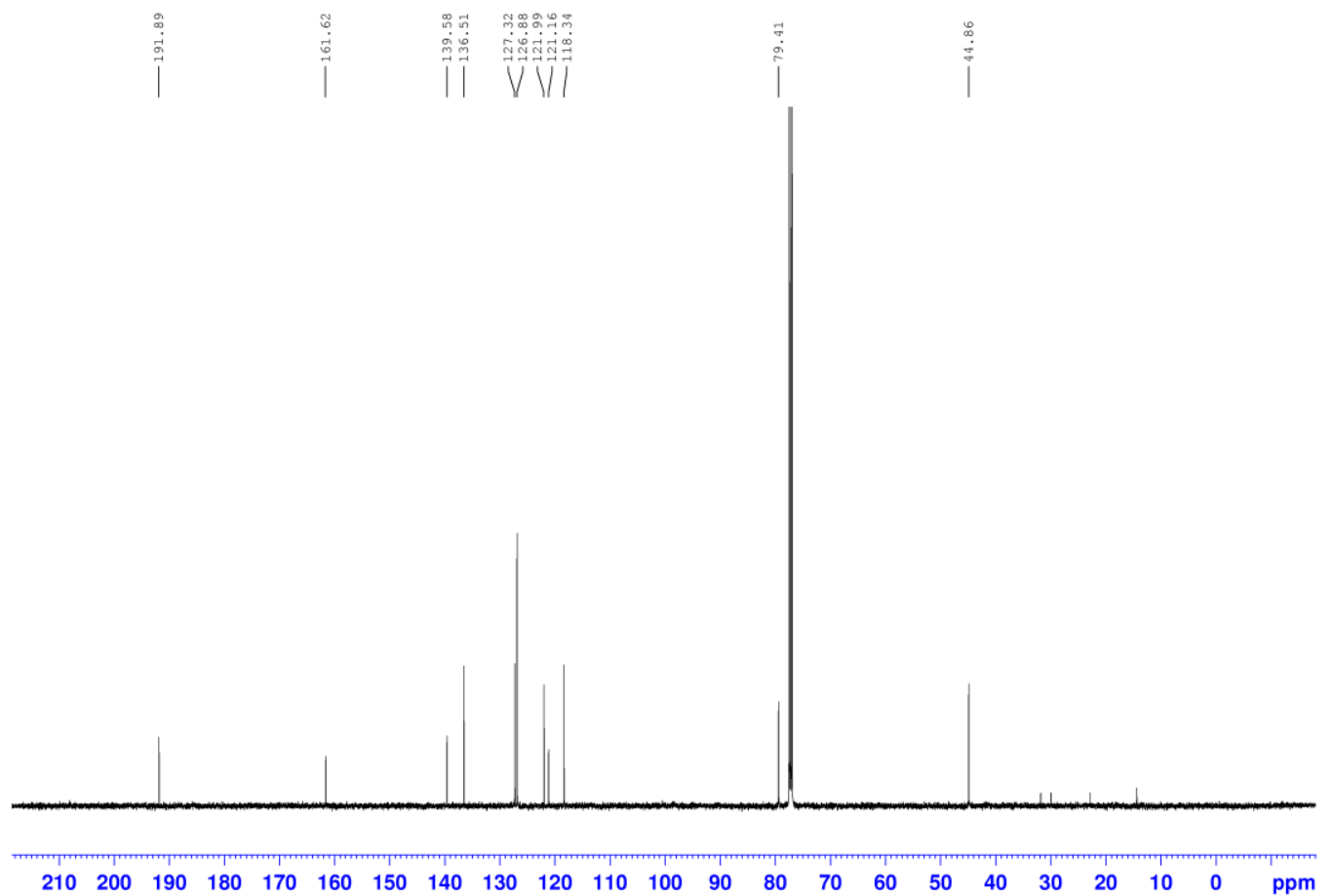




\section{Sigmoid Graphs for Determination of Midpoint pH}

pH vs. Absorbance Plot for $\mathbf{1 b} / \mathbf{2 b}$

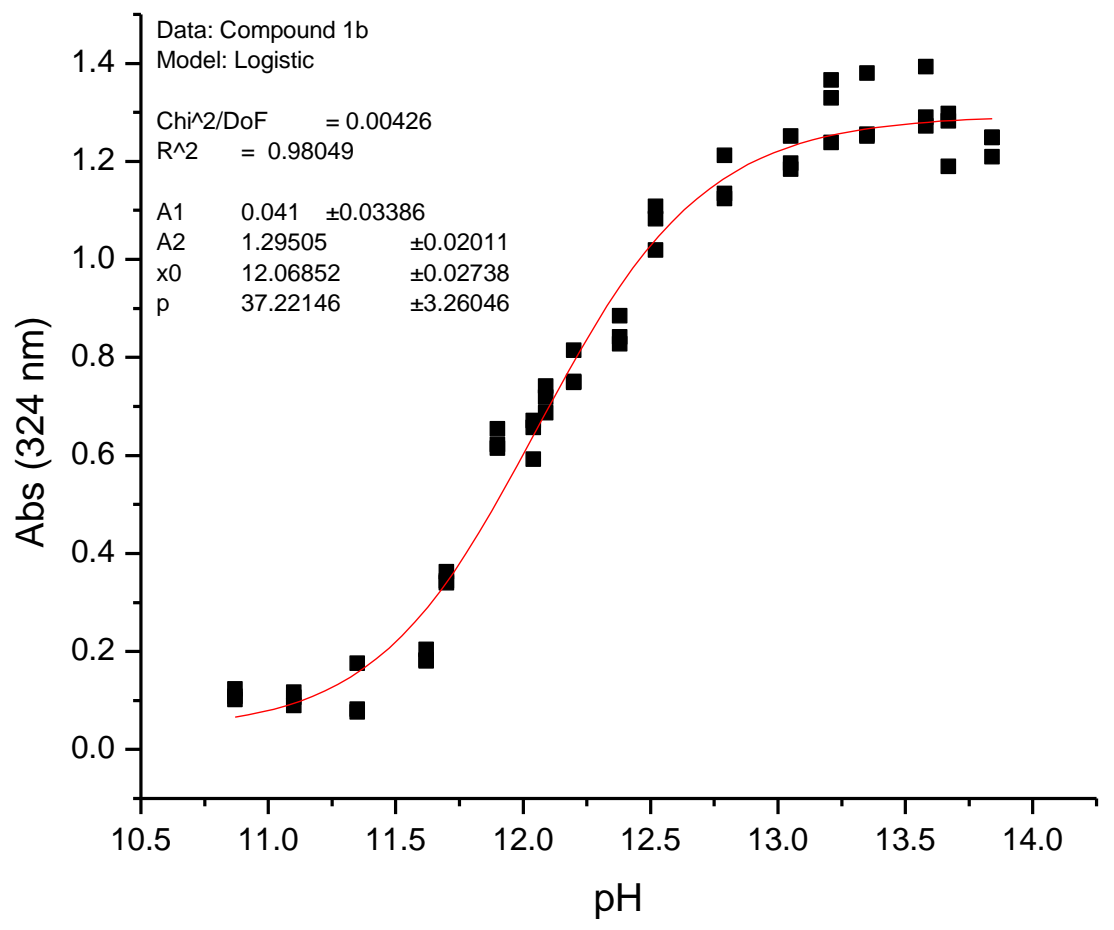




\section{pH vs absorbance plot for $1 \mathrm{c} / 2 \mathrm{c}$}

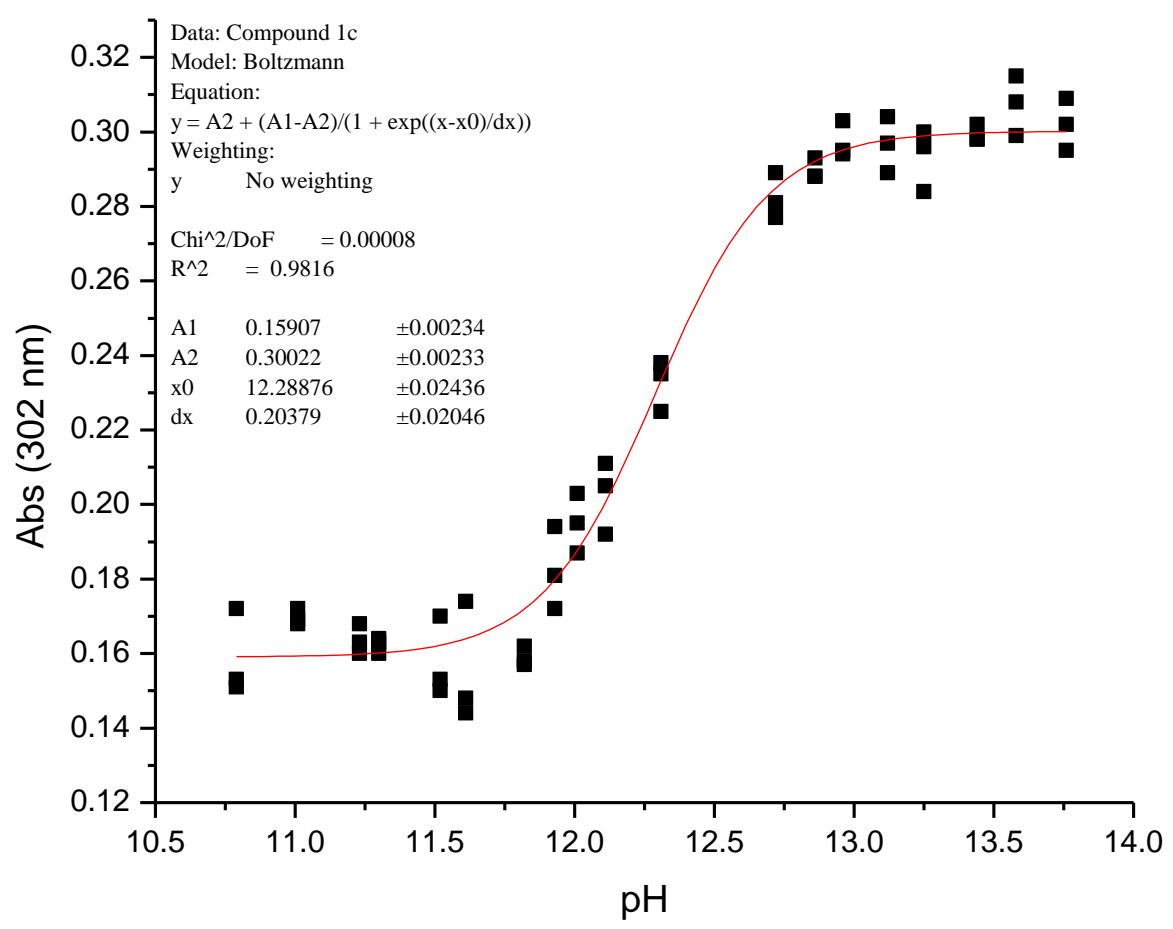

pH vs. absorbance plot for $1 \mathrm{~d} / \mathbf{2 d}$

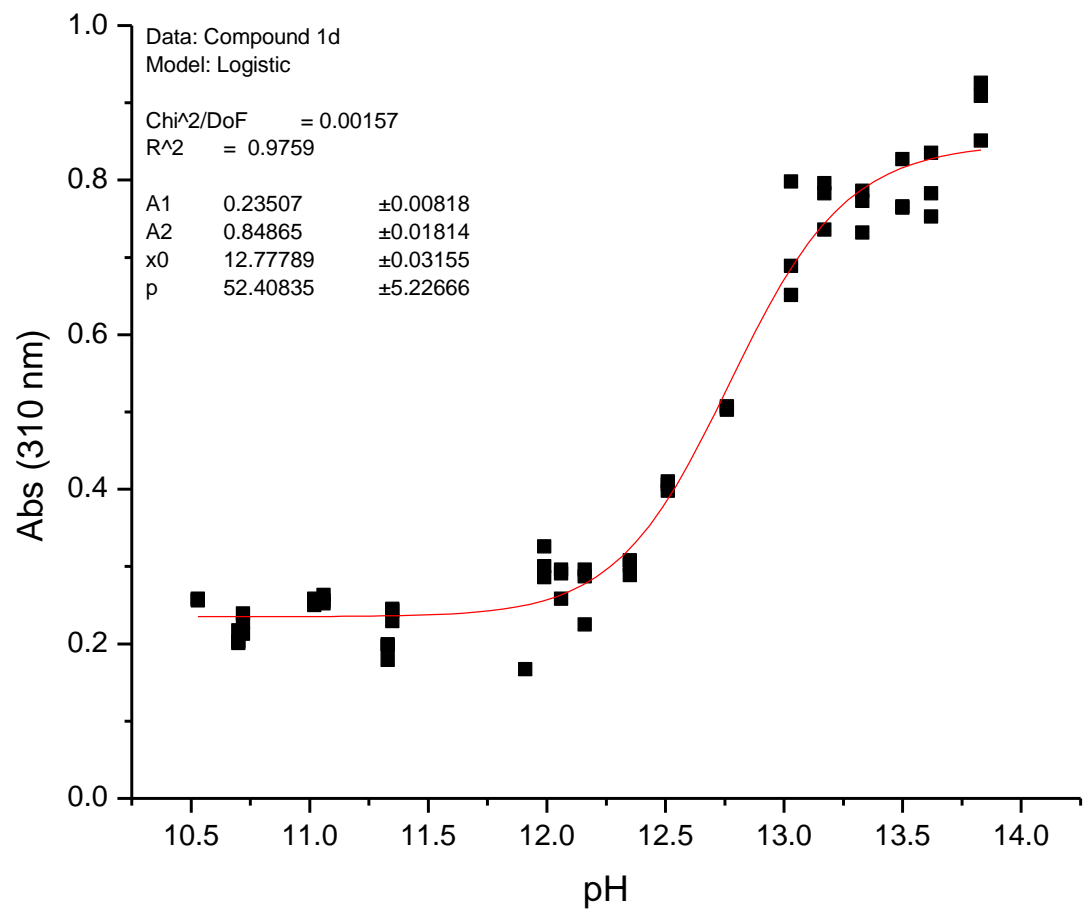




\section{pH vs. absorbance plot for $1 \mathrm{e} / 2 \mathrm{e}$}

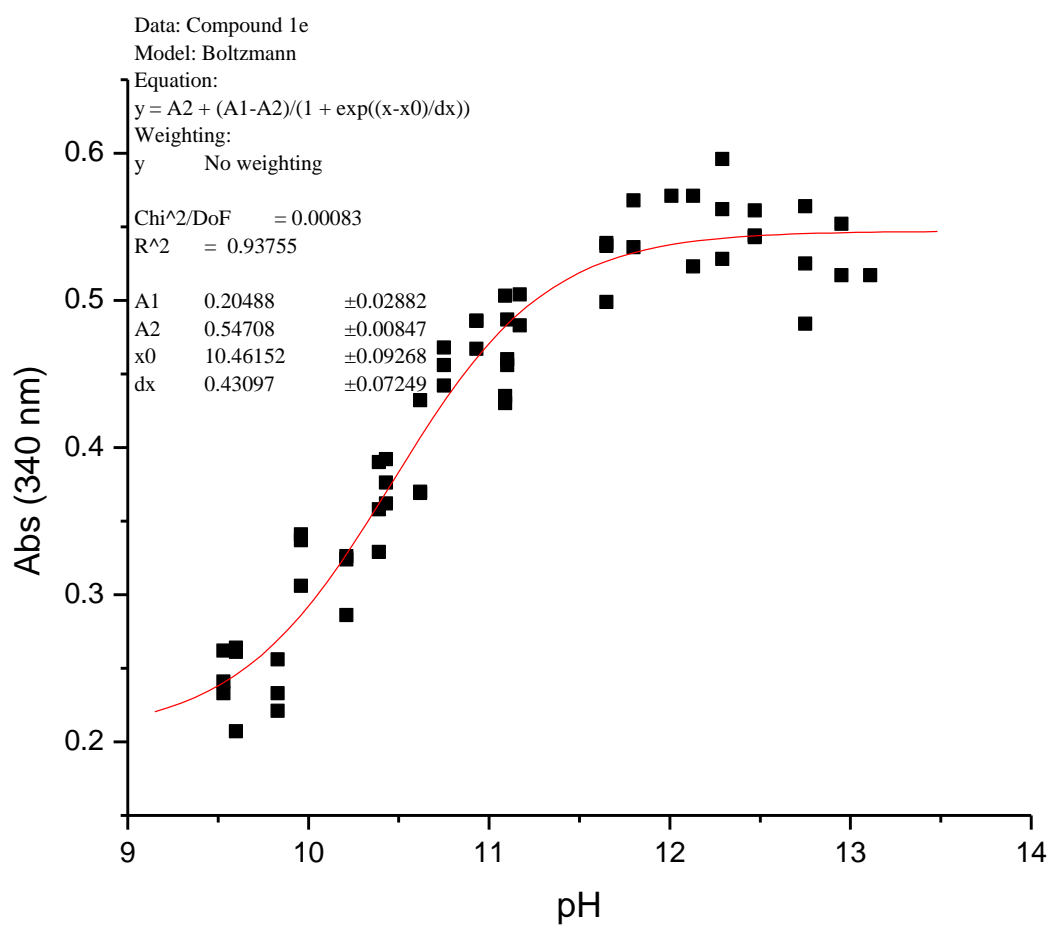

pH vs. absorbance plot for $1 \mathrm{f} / \mathbf{2 f}$

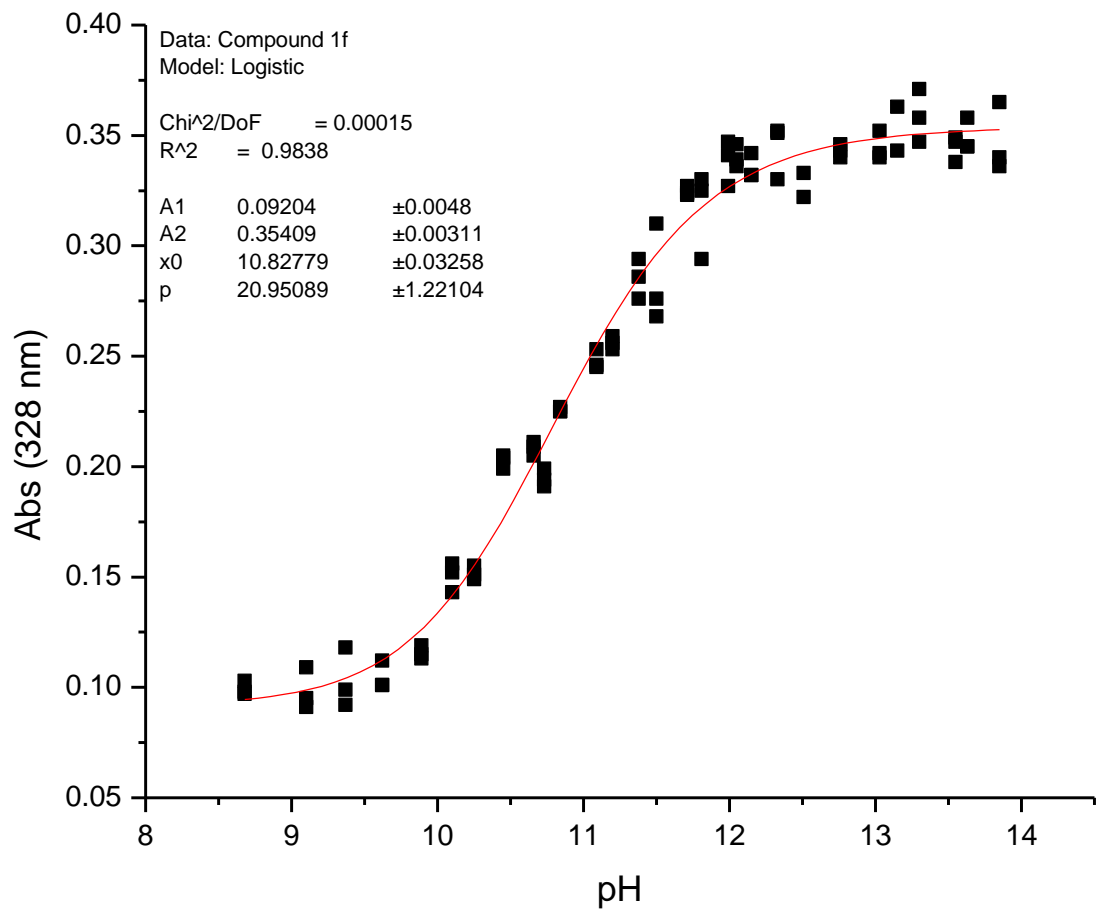


pH vs. absorbance plot for $1 \mathrm{~g} / 2 \mathrm{~g}$

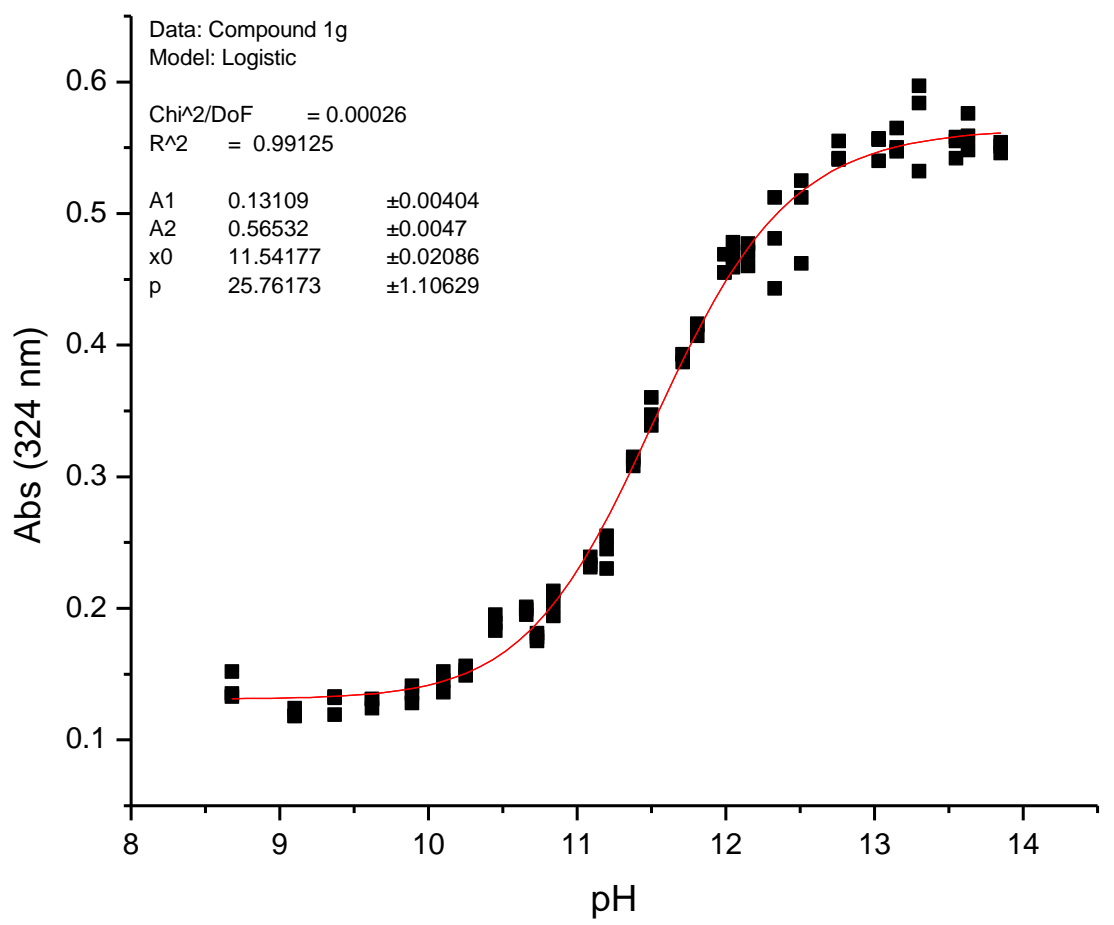

pH vs. absorbance plot for $1 \mathrm{~h} / 2 \mathrm{~h}$

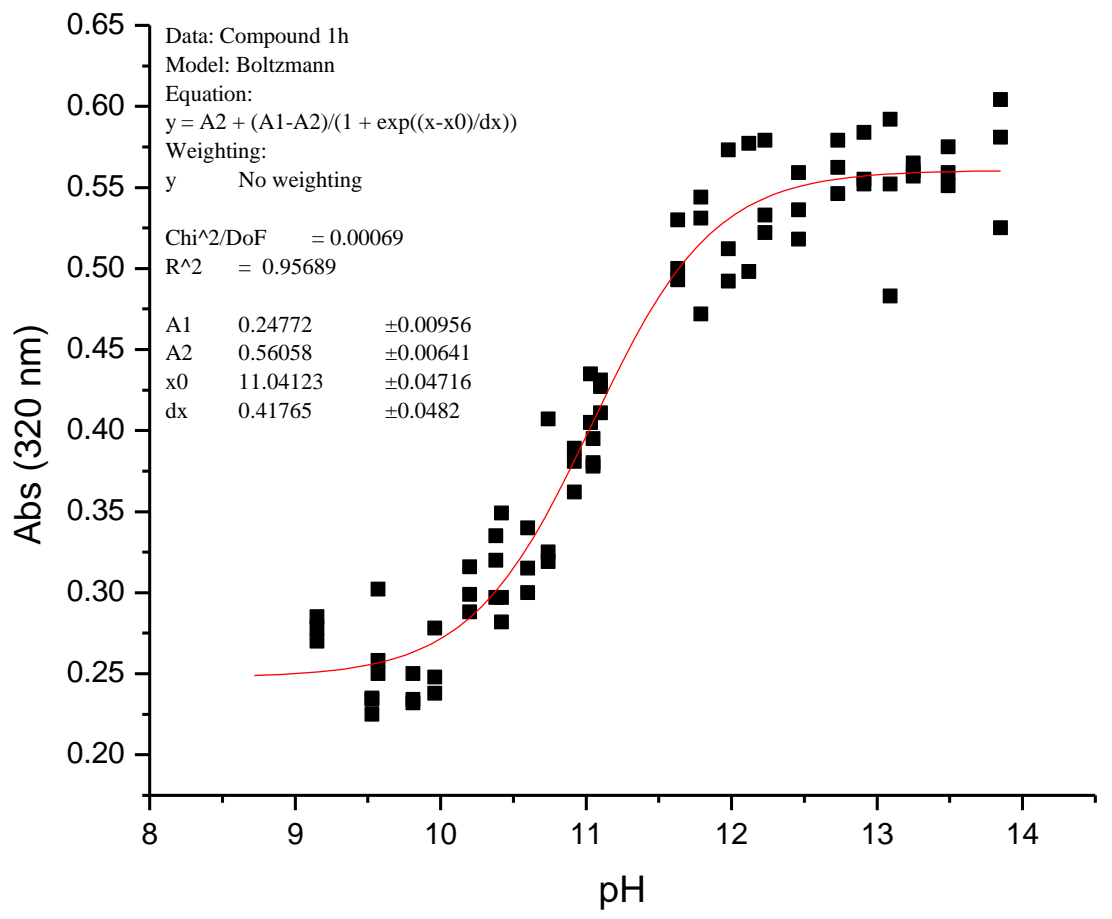


pH vs. absorbance plot for $1 \mathrm{i} / 2 \mathrm{i}$

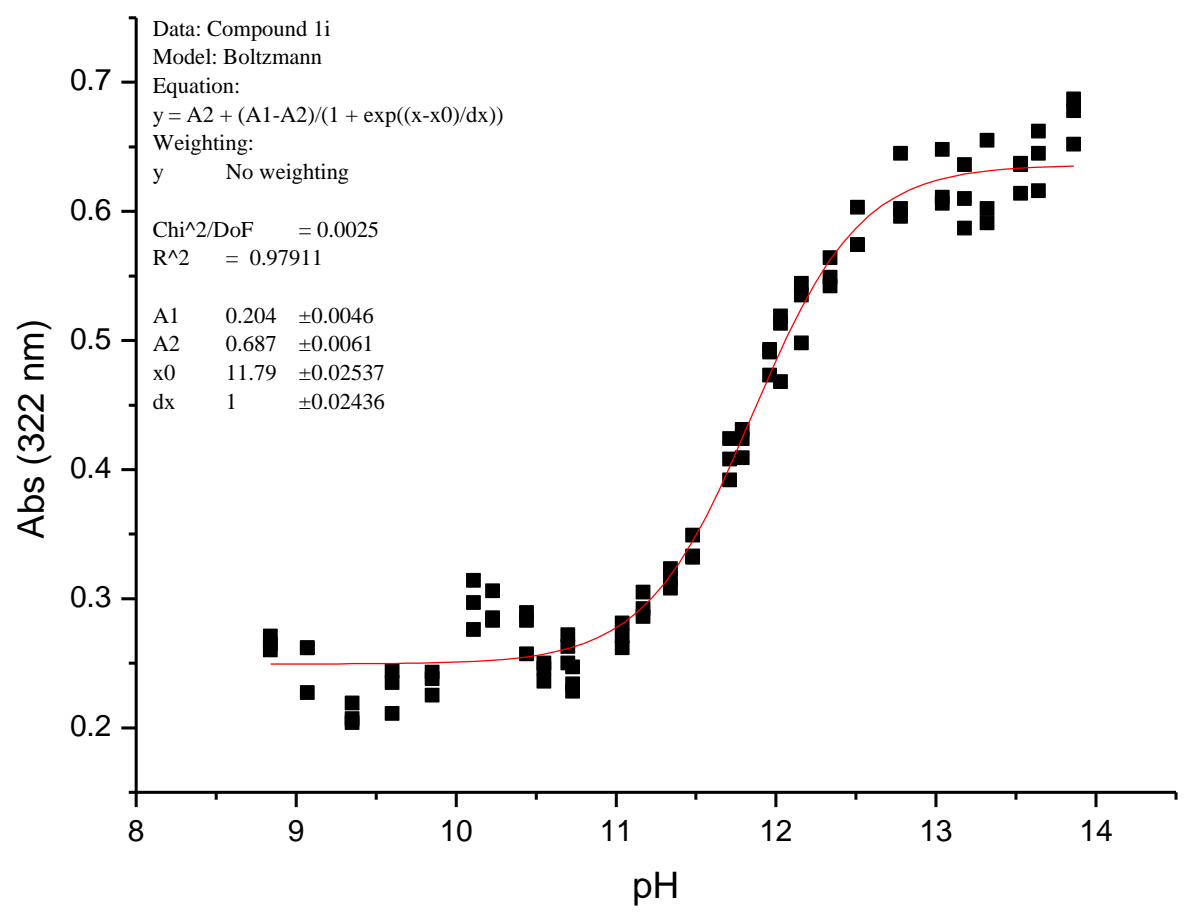

pH vs. absorbance plot for $1 \mathbf{j} / 2 \mathbf{j}$

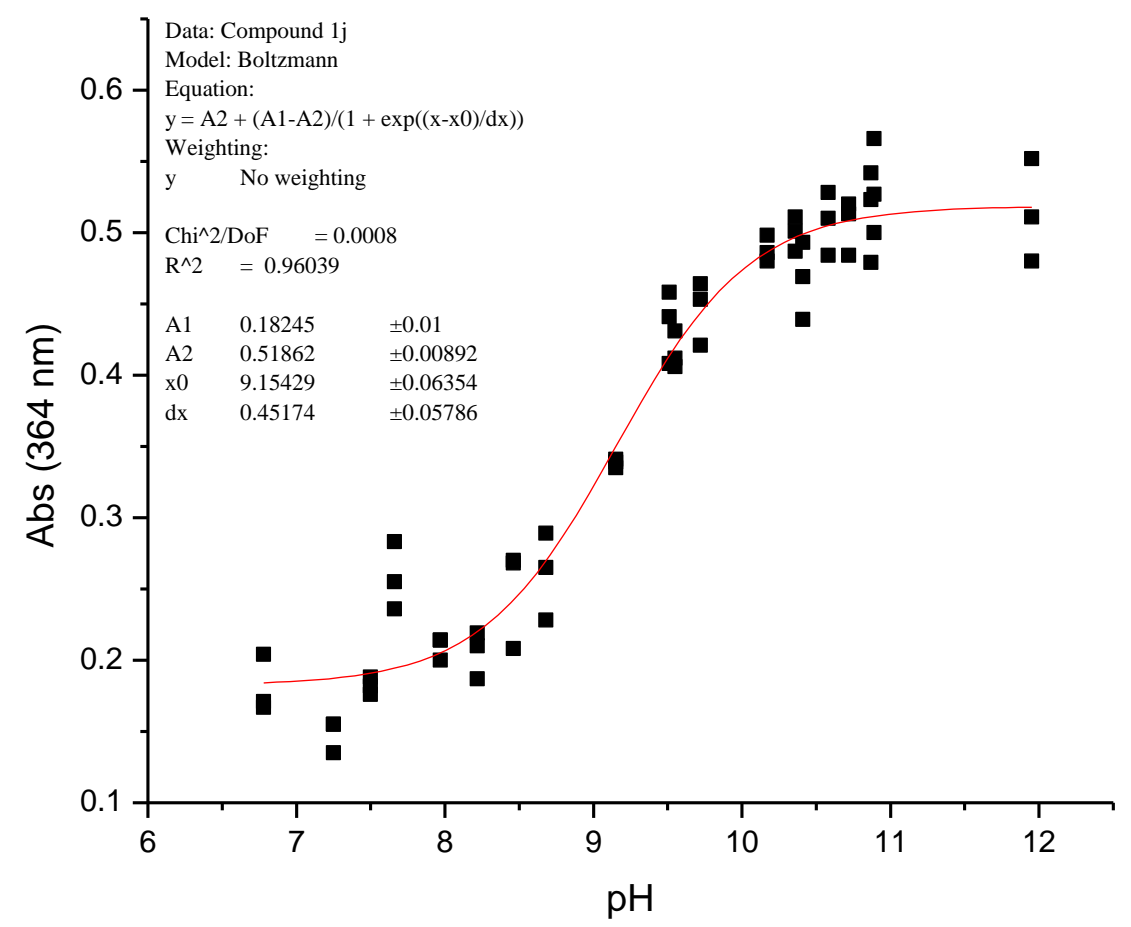


pH vs. absorbance plot for $1 \mathrm{k} / 2 \mathrm{k}$

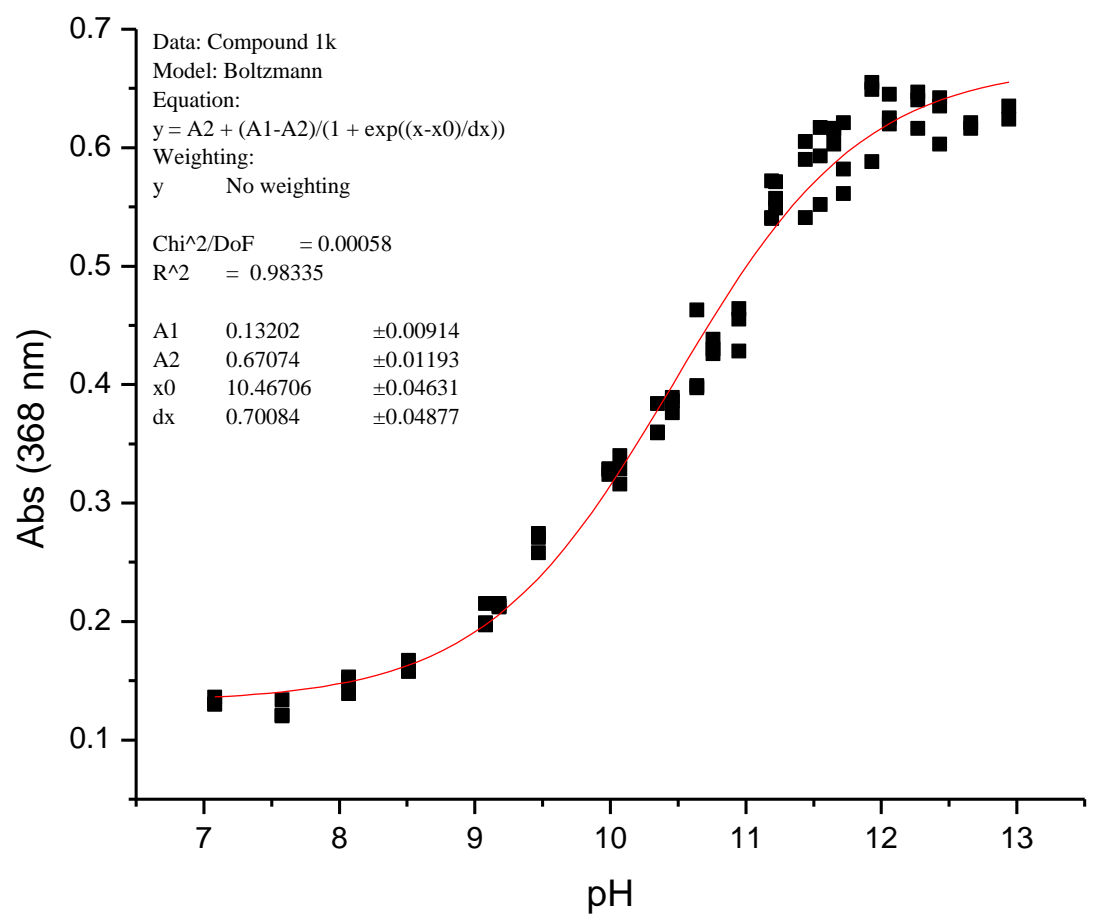

pH vs. absorbance plot for 11/2I

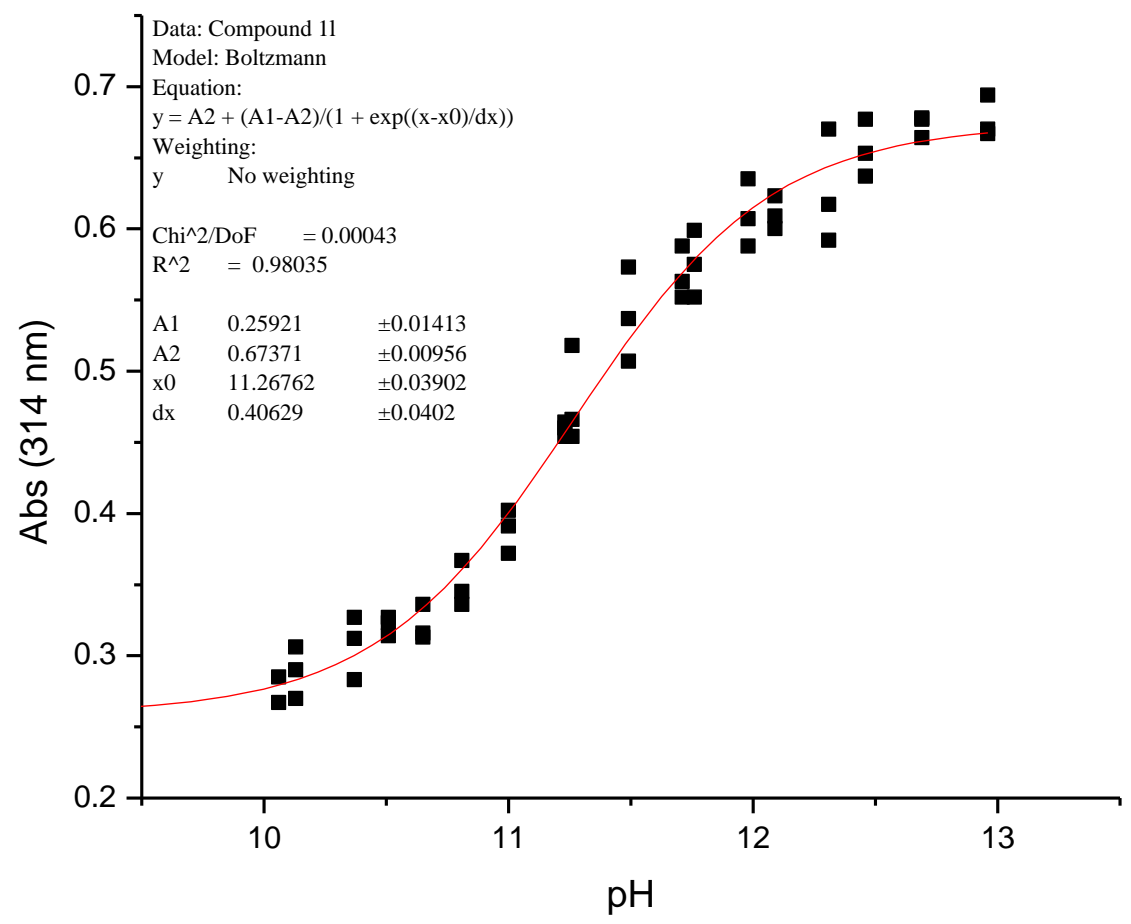




\section{pH vs. absorbance plot for $1 \mathrm{~m} / 2 \mathrm{~m}$}

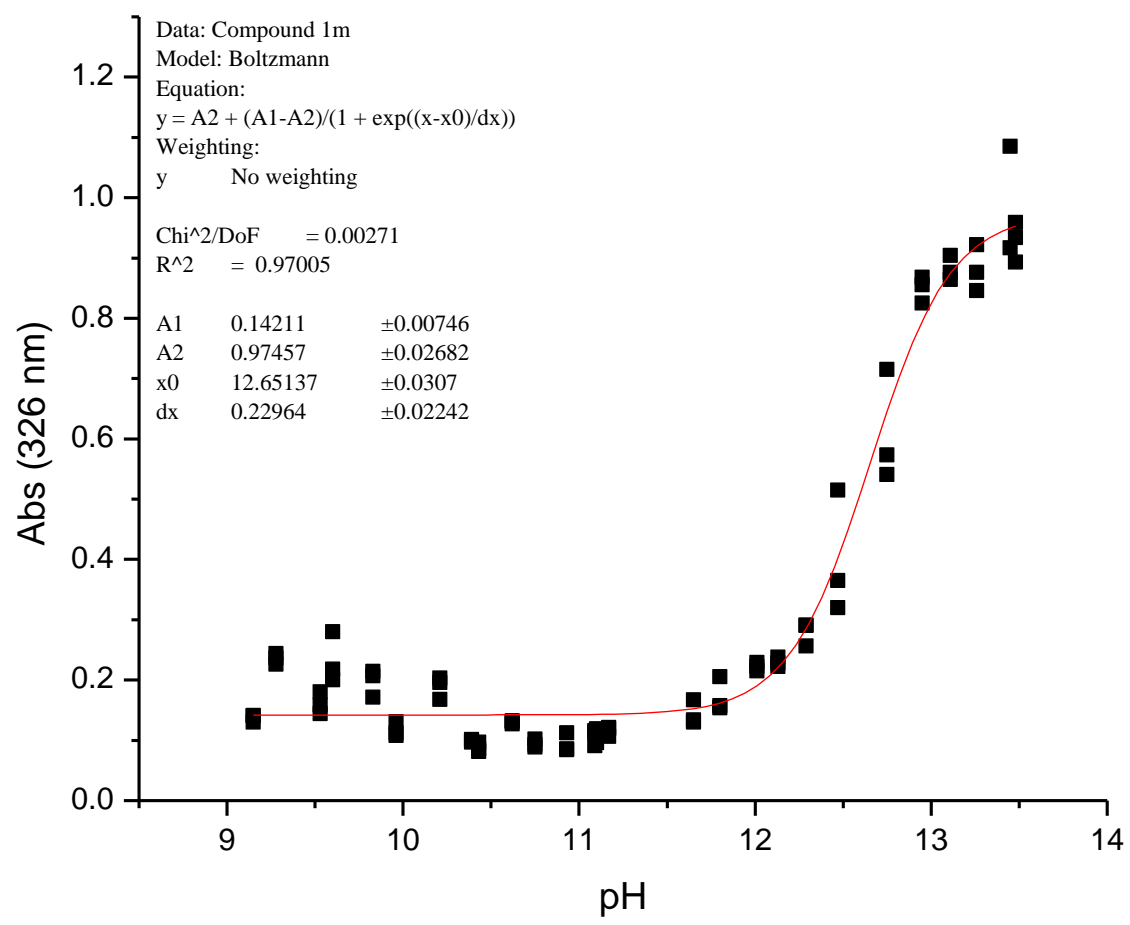

pH vs. absorbance plot for 1 n/2n

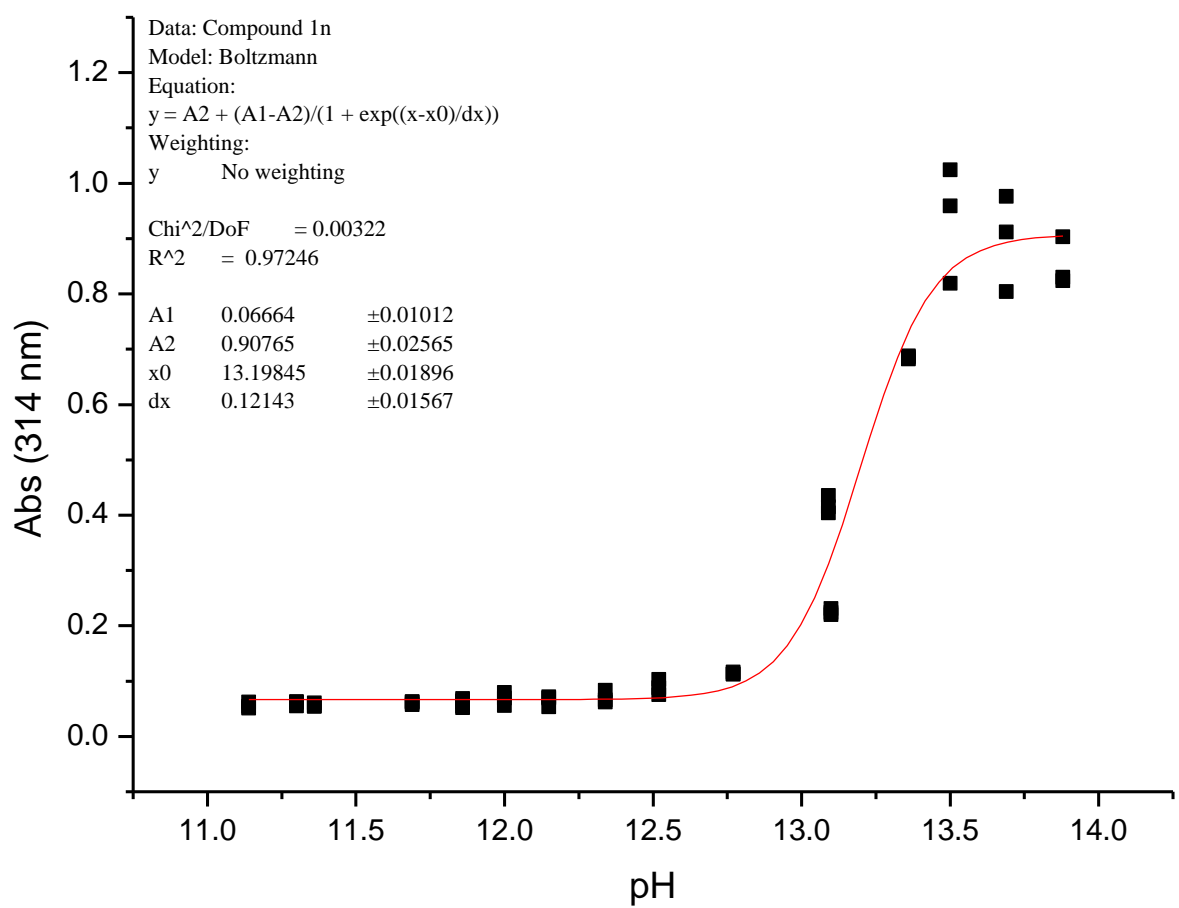

